\title{
1 New species of mammaliaform and the cranium of Borealestes (Mammaliformes: \\ 2 Docodonta) from the Middle Jurassic of the British Isles
}

3

ELSA PANCIROLI ${ }^{1,2 *}$, ROGER B.J. BENSON ${ }^{3}{ }^{\text {VINCENT FERNANDEZ }}{ }^{4,5}$, RICHARD J.

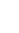
BUTLER ${ }^{6}$, NICHOLAS C. FRASER ${ }^{1,2}$, ZHE-XI LUO $^{7}$ and STIG WALSH ${ }^{1,2}$

${ }^{1}$ Natural Science Department, National Museums Scotland, Edinburgh, Scotland, EH1 1JF, UK. *elsa.panciroli@ed.ac.uk; nick.fraser@nms.ac.uk; s.walsh@nms.ac.uk;

8

2 School of Geosciences, Grant Institute, University of Edinburgh, Scotland, EH9 3JW, UK.

${ }^{3}$ Department of Earth Sciences, University of Oxford, Oxford, England, OX1 3AN, UK. roger.benson@earth.ox.ac.uk;

${ }^{4}$ European Synchrotron Radiation Facility (ESRF), Beamline ID19, Grenoble, France.

${ }^{6}$ School of Geography, Earth \& Environmental Sciences, University of Birmingham, Edgbaston, Birmingham, B15 2TT, UK. r.butler.1@bham.ac.uk

\section{${ }^{5}$ Natural History Museum, Cromwell Road, London, UK.}

17 Running title: New mammaliaform and the cranium of Borealestes

\section{8}

21 Docodonta are one of the earliest diverging groups of mammaliaforms, and their morphology

22 provides key information on the transition between non-mammalian cynodonts and Mammalia.

23 We describe the partial skulls of two docodontans Borealestes serendipitus and Borealestes 
24 cuillinensis sp. nov. from the Kilmaluag Formation (Middle Jurassic: Bathonian), Isle of Skye, 25 Scotland. We visualize their cranial anatomy using laboratory and synchrotron X-ray micro-CT. 26 The skulls belong to two partial skeletons, currently comprising the most complete Mesozoic 27 mammal fossils reported from the British Isles. The associated upper and lower dentitions show 28 that the lower dentition of Borealestes is not diagnostic to species level. We establish, $B$. 29 cuillinensis, based on upper molar characters, and re-identify upper molars previously assigned 30 to 'Borealestes' mussettae as belonging to B. cuillinensis. 'Borealestes' mussettae, based on 31 distinctive lower molars, is found to be morphologically and phylogenetically distinct from 32 Borealestes, necessitating assignment to a new genus, Dobunnodon gen. nov. The skulls of Borealestes retain many plesiomorphic features seen in Morganucodon but absent in more crownward mammaliaforms. Our study highlights that generic and species taxonomy of docodontans are more reliable when based on both upper and lower teeth, while lower molar morphology may underrepresent the true diversity of Mesozoic mammaliaforms.

Additional key words: Bathonian -Isle of Skye -Jurassic - mammals - Mesozoic - Scotland

\section{INTRODUCTION}

43 The early diverging mammaliaform group, Docodonta, is an extinct clade that falls outside the 44 mammalian crown-group (Mammalia). As an outgroup to Mammalia, Docodonta can provide 45 key information for understanding the morphological evolution of mammals as a whole 46 (Simpson, 1929; Lillegraven \& Krusat, 1991; Kielan-Jaworowska et al., 2004; Martin, 2018).

47 Recent discoveries of relatively complete cranial and skeletal materials and their analyses have 48 led to the consensus that Docodonta are closer to crown-group mammals than Sinoconodon 
49 and Morganucodonta (Wible \& Hopson, 1993; Luo, 1994; Luo et al., 2002; Martin, 2005, 2018),

50 but probably less crownward than haramiyidans (e.g. Luo et al., 2015a; 2017; Zhou et al.,

51 2019). Docodonta are first known from the Middle Jurassic - when they were among the first

52 mammaliaform clades to emerge across Eurasia (Waldman \& Savage, 1972; Luo \& Martin,

53 2007) - and become particularly abundant through the transition from the late Middle Jurassic to

54 the Late Jurassic (Averianov \& Lopatin 2006; Hu et al., 2006; Ji et al., 2006; Averianov et al.,

55 2010; Martin et al., 2010; Meng et al., 2015; Rougier et al., 2015; Zhou et al., 2019). The

56 youngest docodontans currently known are Sibirotherium and Khorotherium, from the Lower

57 Cretaceous of Russia (Maschenko et al., 2002; Averianov et al., 2018). Docodonta are

58 hypothesized to be more closely related to the Late Triassic taxa Tikitherium (Datta, 2005) and

59 Woutersia (Sigogneau-Russell \& Hahn 1995), than to other Late Triassic mammaliaforms. If the

60 relationships of these putative outgroups can be corroborated, Docodonta would have a long

61 ghost lineage, extending from the Late Triassic into Middle Jurassic (Luo \& Martin, 2007),

62 although a Late Triassic split from other groups of early-diverging mammals is consistent with

63 their hypothesized phylogenetic position.

Docodontans are unique in possessing more complex molar occluding surfaces than other early-diverging mammaliaforms, and these molar morphologies are also disparate within Docodonta (Luo \& Martin, 2007). These morphologies are formed by a distinct arrangement of cusps and crests that produce crushing and shearing functions unknown in contemporary mammaliaforms, but somewhat functionally analogous to therian and australosphenidan mammals (Jenkins, 1969; Gingerich, 1973; Schultz et al., 2017). Docodontans also possessed some derived modern mammal-like features, such as saddle-shaped hyoids (Zhou et al., 2019), and some of the intricate vascular vessels in the pars cochlearis around the inner ear (Panciroli et al., 2018; Harper \& Rougier 2019). However, they also retained many plesiomorphic stem mammaliaform characteristics, such as postdentary elements attached to the dentary (Lillegraven \& Krusat, 1991; Ji et al., 2006; Meng et al., 2015). The discovery of more complete 
skeletal material, particularly from China, has shown this group to possess an unusually wide range of locomotor specializations associated with divergent ecologies, including fossorial, semi-aquatic and arboreal specializations (Ji et al., 2006; Martin 2006; Luo et al., 2015b; Meng et al., 2015; Zhou et al., 2019). This makes the group of key interest to our understanding of early mammal evolution.

The first docodont discovered in the British Isles was Borealestes serendipitus, from the Bathonian rocks of the Kilmaluag Formation near Elgol on the Isle of Skye, Scotland (Waldman \& Savage, 1972) (Fig. 1). Since that time, additional teeth of $B$. serendipitus and other proposed species of Borealestes have been found from multiple localities of the Forest Marble Formation in England (Sigogneau-Russell, 2003; Evans, 1992). The holotype of B. serendipitus (BRSUG 20570) comprises part of a dentary with nine teeth (p3 to m6; Waldman \& Savage, 1972; Panciroli et al., 2019). Much more complete fossil materials, primarily tooth-bearing mandibles, but also a partial postcranial skeleton including cranial elements (NMS G.1992.141.1 and associated material) were collected in 1973, and are now referred to $B$. serendipitus (Panciroli et al., 2019). A second species, 'Borealestes' mussettae, was erected based on isolated molar teeth from penecontemporaneous sediments at Kirtlington Cement Quarry (Forest Marble Formation; Bathonian, Middle Jurassic) in Oxfordshire (Sigogneau-Russell, 2003). The taxonomic issues of Borealestes species were most recently examined by Panciroli et al. (2019).

4

A second partial skeleton (NMS G.2020.4.1.1) was collected from Skye in 2018, but this new find was not scanned and visualized in time for inclusion in the study of Panciroli et al. (2019). The new specimen reveals new diagnostic features of the upper molars that distinguish species of Borealestes. Specimens NMS G.1992.141.1 and NMS G.2020.4.1.1 both include associated upper and lower dentitions, including indistinguishable lower molars, but distinctly different upper molars. This observation was unexpected as it is generally assumed in studies of Mesozoic mammals that differences in upper dentitions should be reflected by differences in 
101 lower dentitions. The upper molars of NMS G.2020.4.1.1 skeleton match those of an isolated 102 upper molar (NHMUK PV M46871) previously referred to 'B.' mussettae (species taxonomy 103 sensu Sigogneau-Russell, 2003, interpretation by Panciroli et al., 2019: fig 7). The upper 104 dentition of NMS G.2020.4.1.1, and further re-examination of taxonomic characters of the 105 mandible allow us to establish a new species to which NHMUK PV M46871 is also referred. The 106 holotype of ' $B$ '. mussettae, a lower molar with distinctively different features from the lower 107 molars of Borealestes species (Panciroli et al., 2019; and herein), is hereby assigned to a new 108 genus.

109

MATERIAL AND METHODS

111

Institutional abbreviations: BRSUG (formerly UBGM), Geology Museum, University of Bristol,

113 Bristol, UK; NMS (formerly RSM), National Museums Scotland, Chambers Street, Edinburgh, 114 UK; NHMUK (formerly BMNH), Natural History Museum, London, UK; OUMNH, Oxford 115 University Museum of Natural History, Oxford, UK.

117 Specimens

118 We describe the crania of NMS G.1992.47.121.1, the partial skeleton of Borealestes 119 serendipitus (Fig. 2) and NMS G.2020.4.1.1, the partial skeleton of the new species Borealestes 120 cuillinensis (Fig. 3). Both specimens are held in the National Museums Scotland (NMS) 121 collections. Only the crania are described herein, the postcrania are currently under study.

123 Waldman. A block of rock containing it was removed using a Pjonjar drill, and mechanically

124 prepared by S. Finney at the University of Cambridge between 1994-1996 using a sodium 125 bicarbonate airbrasive. It was then consolidated with $2 \%$ Paraloid B72. Some portions of the 126 skeleton became detached from the limestone block (it is unclear when this occurred) and are 
127 stored separately. These separate elements are: NMS G.1992.47.121.2, the left petrosal

128 (Panciroli et al., 2018a); NMS G.1992.47.121.3, the right dentary (Panciroli et al., 2019); NMS

129 G.1992.47.121.4, the premaxilla and nasal fragment; NMS G.1992.47.121.5 a metatarsal; NMS

130 G.1992.47.121.6, right clavicle; NMS G.1992.47.121.7, a carpal/tarsal element; NMS

131 G.1992.47.121.8, a chevron; NMS G.1992.47.121.9, ?cranial fragment; NMS G.1992.47.121.10,

132 carpal/tarsal element; NMS G.1992.47.121.11, fragment of ischium; and NMS

133 G.1992.47.121.12, fragment of rib. Only skull elements are described here.

134 The block containing NMS G.1992.47.121.1 was substantially larger when collected

135 ( $\sim 240 \mathrm{~mm}$ in length, $\sim 170 \mathrm{~mm}$ in width and $\sim 50 \mathrm{~mm}$ in depth) and was reduced in size by a

136 preparator at NMS in 2015 when it became clear it required reduction to perform successful X-

137 ray micro-computed tomography scans. All offcuts were retained. Only the section containing 138 the skull is included herein (Fig. 2).

NMS G.2020.4.1.1 was discovered in 2018 by RJB during fieldwork by National

140 Museums Scotland, University of Oxford and University of Birmingham. It was removed in the

141 field using a rock saw and then reduced in size to permit $\mu \mathrm{CT}$. Using an iterative process of pilot

$142 \mu \mathrm{CT}$ acquisition, lossless block-splitting and removal of excess matrix using lab-based rock

143 cutting equipment (carried out by RBJB), optimal results could be obtained without loss of fossil

144 material. Only parts AA and BB containing the skull (Fig. 3) are included herein.

145

146

X-ray micro-computed tomography and data processing

147

NMS G.1992.47.121.1 was scanned at the European Synchrotron Radiation Facility

148 (ESRF, Grenoble, France) using propagation phase contrast X-ray micro-computed

149 tomography. The whole block was first imaged at the beamline ID17 at low resolution to locate

150 the position of bones. The area containing skull bones was then scanned at the beamline ID19

151 using filtered white beam with a total integrated energy of $201 \mathrm{keV}$ (wiggler 150b gap $26.5 \mathrm{~mm}$;

152 filters: Al $5.6 \mathrm{~mm}, \mathrm{Cu} 15.6 \mathrm{~mm}, \mathrm{~W} 0.5 \mathrm{~mm}$ ), a sample-detector propagation distance of $10 \mathrm{~m}$ 
153 and an indirect detector (200 $\mu$ m LuAG, 1× magnification from two Hasselblad lenses, 154 PCO.edge 5.5) generating data with an isotropic voxel size of $6.15 \mu \mathrm{m}$. Each acquisition 155 consisted of 6000 frames of 0.3 second exposure over a rotation of $360^{\circ}$. The centre of rotation 156 was shifted to increase the horizontal field of view by $\sim 85 \%$. Several scans were needed on the 157 vertical axis to image the full sample, keeping an overlap of $\sim 50 \%$ between consecutive scans. 158 Tomographic reconstruction was done using PyHST2 (Mirone et al., 2014) using the single 159 distance phase retrieval approach (Paganin et al., 2002). Post processing included: modification 160 of the bit depth from 32 bits to 16 bits, using the $0.001 \%$ minimum and maximum exclusion 161 values of the 3D histogram generated by PyHST2; vertical stitching of the series of acquisition, 162 using a weighted average based on the vertical intensity profile of the beam; ring correction 163 (Lyckegaard et al., 2011); cropping of the volume. Finally, we applied a binning $2 \times 2 \times 2$ to reduce 164 the data size while increasing the signal-to-noise ratio, making it easier to segment the data. 165 Other specimens were imaged using laboratory $\mathrm{X}$-ray $\mu \mathrm{CT}$ at various facilities 166 (parameters for each acquisition are listed in Table 1). NMS G.1992.47.121.2 and NMS 167 G.1992.47.121.4 were scanned at the University of Edinburgh by I. Butler and EP at the School 168 of Geosciences Experimental Geoscience Facility, using their in-house built $\mu C T$ system. The 169 system comprises a Feinfocus 10-160 kV dual transmission/reflection source (Feinfocus 170 Röntgen-Systeme GmbH, Garbsen, Germany), MICOS UPR-160-AIR ultra-high precision air171 bearing table (PI miCos GmbH, Eschbach, Germany), Perkin Elmer XRD0822 amorphous 172 silicon $x$-ray flat panel detector and terbium doped gadolinium oxy-sulfide scintillator 173 (PerkinEImer, Waltham, USA). Data acquisition software was written in-house, and tomographic 174 reconstruction were performed by I. Butler using Octopus 8.7 software (TESCAN Orsay Holding 175 a.s., Brno, Czech Republic). Data for NMS G.1992.47.121.2 have a voxel size of 8.9 $\mu \mathrm{m}$, and 176 for NMS G.1992.47.121.4 a voxel size of $6.43 \mu \mathrm{m}$.

177 X-ray micro-computed tomographic data for NMS G.1992.47.121.3 and all parts of NMS 178 G.2020.4.1.1 were obtained by RBJB and T. Davies, and were imaged at the University of 
179 Bristol using a Nikon XTH 225 ST (Nikon Metrology, Leuven, Belgium) with a 225 kV rotating 180 target. The scan resolution for NMS G.1992.47.121.3 was 12.77 $\mu \mathrm{m}$ and for NMS G.2020.4.1.1 181 parts $A A$ and $B B$ the scan resolution was $22.14 \mu \mathrm{m}$ and $20.05 \mu \mathrm{m}$ respectively.

$182 \quad$ All tomographic data were segmented and digitally reconstructed by EP using Mimics 18319.0 (Materialise NV, Leuven, Belgium) at NMS and the University of Oxford. Where possible 184 (i.e. when they were not covered completely by matrix or sediment), specimens were also 185 observed using conventional microscopy at NMS. Measurements were taken using the 186 measurement tools in Mimics 19.0, and corroborated with manual measurements using fine 187 callipers or a microscope where possible. Tooth measurement methodology and cusp 188 nomenclature are as in Panciroli et al. (2019). CT data and resulting 3D models are available at 189 Morphosource (www.morphosource.org/Detail/ProjectDetail/Show/project_id/1092). 190 191 Phylogenetic analysis

192 We analysed the character matrix of Panciroli et al. (2019), modified from Meng et al. (2015), 193 with the addition of characters states for $B$. cuillinensis, and revising character states for ' $B$.' 194 mussettae. This data matrix has 25 taxa, scored for 48 characters of the dentary and dentition 195 only (characters of the crania and postcrania are currently being scored for a larger 196 phylogenetic analysis in progress). We analysed these data using PAUP*4.0 Version 4 197 (Swofford, 2003), conducting a branch-and-bound tree search using parsimony with characters 198 unordered and equally weighted. Six equally most parsimonious trees of 131 steps were 199 retained, and summarized as a strict consensus tree, scaled to time using data from Panciroli et 200 al. (2019). Full datasets and details of analysis can be found in Supplementary Material.

202 Geological background

203 Specimens described herein (except NHMUK PV M46495) were collected from the Kilmaluag 204 Formation (Harris \& Hudson, 1980) on the Strathaird Peninsula of the Isle of Skye (Fig. 1). The 
205 Kilmaluag Formation is part of the Great Estuarine Group (formerly Great Estuarine Series 206 [Judd 1878: 722]). This formation comprises a series of near-shore shallow marine, varied 207 salinity lagoon and freshwater lagoon sediments of Bathonian age (Harris \& Hudson, 1980; 208 Andrews, 1985; Barron et al., 2012). These Mesozoic sediments are overlain disconformably by 209 Cenozoic basalt (Harris \& Hudson, 1980).

210 The Kilmaluag Formation crops out on the islands of Eigg, Skye and Muck, in the Inner 211 Hebrides of Scotland. It is approximately $25 \mathrm{~m}$ in thickness at the most complete section on the 212 Strathaird Peninsula, where there are predominantly argillaceous (muddy) limestone facies 213 (Harris \& Hudson, 1980; Andrews, 1985; Morton \& Hudson, 1985). The Kilmaluag Formation 214 falls within the Retrocostatum Zone, of Late Bathonian age (Barron et al., 2012), just over 166.1 215 Mya (Cohen et al., 2019). It includes predominantly low-salinity and freshwater facies, especially 216 on the Strathaird Peninsula, as demonstrated by the presence of freshwater ostracods 217 Darwinula and Theriosynoecum (Wakefield, 1995), shallow freshwater to oligohaline 218 conchostracans such as Antronestheria and Pseudograpta (Chen \& Hudson, 1991) and 219 freshwater gastropods Viviparus (Andrews, 1985; Morton \& Hudson, 1995; Barron et al., 2012). 220 Vertebrate fossils are thought to predominantly come from the 'Vertebrate Beds', horizons 2219 and 10 of Andrews (1985). These beds alternate between muddy carbonates, hard blue-grey 222 limestones, micrites, wackestones and breccia conglomerates, and appear to be predominantly 223 freshwater in origin (Andrews, 1985). Vertebrate fossils from multiple groups have been found in 224 these beds (Evans et al., 2006; Panciroli et al., 2020), including fish (Rees \& Underwood, 2006), 225 amphibians (Evans \& Waldman, 1996), lepidosaurs (Waldman \& Evans, 1994; Evans \& 226 Waldman, 1996), testudines (Anquetin et al., 2009, 2010) mammaliamorphs and 227 mammaliaforms (Waldman \& Savage, 1972; Close et al., 2016; Panciroli et al., 2017a, b, 228 2018b), crocodylomorphs (Wills et al., 2014) and dinosaurs (Barrett 2006). NMS G.2020.4.1.1 229 was collected from the top of a 1 metre thick argillaceous limestone, bed 9C of Andrews (1985), 230 close to the base of the 'Vertebrate Beds'. Vertebrate fossils (including NMS G.1992.47.121.1) 
231 are also recovered from loose boulders on the foreshore. It is not certain which exact horizons

232 these boulders come from, but the lithology is congruent with the 'Vertebrate Beds'.

233

234

235

236

237

238

239

240

241

242

243

244

245

246

247

248

249

250

251

252

253

254

255

256

\section{RESULTS}

\section{Phylogenetic Analysis}

The results of our phylogenetic analysis support the sister-taxon relationship of

Borealestes serendipitus and Borealestes cuillinensis, and the placement of Dobunnodon

mussettae as the sister to a clade comprising Borealestes species, Docofossor, Docodon and

Haldanodon (Fig. 4). This phylogenetic result, and the morphological distinctiveness of the lower

molars of $D$. mussettae indicates the need for a separate genus to accommodate the type species of 'Borealestes' mussettae.

Relationships among the rest of Docodonta are the same as recovered in Panciroli et al. (2019), but there is less support for the clade Tegotheriidae (proposed by Averianov et al.

2010). A larger analysis incorporating cranial and postcranial characters scored from NMS

G.1992.47.121.1 (and associated material) and NMS G.2020.4.1.1 is currently underway, and may add further insight into the relationships within Docodonta.

\section{SYSTEMATIC PALAEONTOLOGY}

Mammaliaformes Rowe, 1988

Docodonta Kretzoi, 1946

Docodontidae Simpson, 1929

Borealestes Waldman \& Savage, 1972

Type species: Borealestes serendipitus Waldman \& Savage, 1972 


\section{Revised differential diagnosis}

258 Dental formula 4.1.?5.4/4.1.5.5(6). As in other docodontans: possesses an anterior

259 'pseudotalonid basin' formed by cusps a, b, and g; retains plesiomorphic mammaliaform trait of 260 attachment of postdentary elements to the dentary; has an eflected angular process (sensu

261 Simpson, 1929; also see Schultz et al., 2017: figs. 2 and 3); enlarged medial ridge protuberance 262 (sensu Schultz et al., 2017); enlarged and pointed upper and lower canines that are twin-rooted.

263 The lower molars of Borealestes are: elongated anteroposteriorly, with labial row of higher 264 cusps arranged in anteroposterior alignment with largest cusp a, and lingual row of smaller 265 cusps with distinctive anterior cusp g and larger posterior cusp c; lower molars have cusps b-a266 c in a triangular arrangement. The a-g crest on cusp a is absent (present to variable extent on 267 cusp g) and the a-d crest on cusp a is also absent (but a labially oriented a-d crest is present 268 on cusp d). Borealestes has a distinctive a-c crest. Upper molars of Borealestes: buccolingually 269 wide and anteroposteriorly short; 'figure 8' shape, with anteroposteriorly constricted waist; two 270 main buccal cusps, A and C, plus a small cusp B in the buccomesial corner; lingual half of the 271 upper molar has main anterior lingual cusp X; cusp X larger and more prominent than smaller 272 posterior lingual cusp Y; labial cusps connected by a ridge/ridges anteroposteriorly; transverse 273 ridge extends between the main anterior labial cusp A and the main lingual cusp X. In the lower 274 molars Borealestes most closely resembles docodontans Krusatodon, Castorocauda, and 275 Haldanodon in sharing a larger cusp c than cusp g. It resembles Castorocauda and possibly 276 also Itatodon in having a slightly recurved cusp c. Borealestes is similar to Castorocauda and 277 Docodon in possessing an anterior 'cingulid' incorporating cusp e, and cusp e is anteriorly 278 projecting and forms part of the $\mathrm{d}-\mathrm{df}-\mathrm{e}$ interlock with the neighbouring molar, as in Krusatodon 279 and Simpsonodon. Borealestes has a distinct lingual cingulid in the premolars, and a posterior 280 labial cingulid, as seen in most other docodontans. Unlike Simpsonodon, Agilodocodon, and 281 Docodon, but like most other docodontans, Borealestes does not have dense creases and pits 282 or other ornamentation on molar enamel surfaces. Borealestes differs from Dobunnodon 
283 mussettae in having more elevated b-g crest and c-d crest, and the more lingually positioned 284 cusp e. Borealestes differs from all other docodontans except Docodon in having an anterior 285 fovea (sensu Panciroli et al., 2019: fig 1B3) on the upper molars: a concave area anterior to the 286 anterolingual crest. Borealestes differs from Docodon in having the anterior fovea positioned at 287 the anteroposteriorly constricted waist of the upper molars. Borealestes differs from Krusatodon, 288 Agilodocodon, Simpsonodon, Docodon, and Haldanodon in having transversely expanded and 289 anteroposteriorly slightly compressed lingual wing of the upper molar, similar to Docofossor and 290 Dsungarodon. Borealestes resembles Docofossor and Dsungarodon in having more reduced 291 cusps $Y$ and $Z$ on the upper molars, and a larger cusp $X$. 292 293 Referred specimens

294 Specimens referred to Borealestes sp. but not to species level-from the Kilmaluag Formation, 295 Isle of Skye: BRSUG 29007, fragment of right dentary; BRSUG 29008, three fragmentary 296 molars in matrix.

Differential diagnosis

302 Dental formula 4.1.?5.4/?4.1.5.5(6). Borealestes serendipitus differs from Borealestes 303 cuillinensis, the only other species in the genus, in having distinct anterolabial and anterolingual 304 crests between cusps $A$ and $X$ in the upper molars, and in that cusp $Z$ is reduced (Figs 5 and 6).

305 The anterior fovea is more distinct than in B. cuillinensis. The lower molar cusps are slightly less 306 dorsoventrally tall in B. serendipitus than in B. cuillinensis. The lappets of the dentary enclose 307 the cartilage of the Meckel's sulcus of $B$. serendipitus from the point ventral to the m3-m4 in 308 adult specimens, leaving a faint line running anteriorly, unlike in $B$. cuillinensis where it remains 
309 an open sulcus in adult (Fig. 7). The mandibular symphysis of $B$. serendipitus remains distinct 310 until ventral to the p3-p4, whereas it is much less distinct in B. cuillinensis.

312 Etymology: Species name from noun serendipity, defined as the faculty of making happy and 313 unexpected discoveries by accident.

315 Holotype

316 Partial left dentary, BRSUG 20570.

317

318 Description

319 The holotype BRSUG 20570 is a partial left dentary, removed from matrix, with nine teeth in 320 their alveoli (one only comprising roots). It measures $11 \mathrm{~mm}$ in length. 321

322 Stratigraphic provenance

323 Kilmaluag Formation, Late Bathonian, Middle Jurassic (Retrocostatum Zone: Barron et al., 324 2012)

326 Type locality

327 Just south of Cladach a' Ghlinne, Strathaird Peninsula, Isle of Skye, Scotland UK (Fig. 1).

329 Referred material

330 From the Kilmaluag Formation, Isle of Skye: NMS G.1992.47.121.1, partial skeleton.

BOREALESTES CUILLENSIS SP. NOV.

333 Zoobank registration: LSID urn:Isid:zoobank.org:act:E2EDCA4C-B0F7-46F1-AB7A334 118C3575BE69 


\section{Differential diagnosis}

337 Borealestes cuillinensis resembles Borealestes serendipitus in most features of upper molars, 338 but differs in having a more rounded cusp A, so that there is no anterior crest and no 339 anterolabial crest on cusp A (Figs 5 and 6). B. cuillinensis has a shorter anterolingual crest on 340 cusp $X$ than $B$. serendipitus, with a cuspule on the crest. Cusp $Z$ is reduced compared to $B$. 341 serendipitus. The anterior fovea is less distinct than in $B$. serendipitus. In the lower dentition, $B$. 342 cuillinensis is almost indistinguishable from that of $B$. serendipitus, except for having slightly 343 more pointed molar cusps. The lappets of the dentary do not enclose the cartilage of the 344 Meckel's sulcus of $B$. cuillinensis, unlike in $B$. serendipitus, and the mandibular symphysis is 345 less distinct in B. cuillinensis than in B. serendipitus (Fig. 7).

347 Etymology

348 Species named for the Cuillin, a mountain range on the Isle of Skye, Scotland, which overlooks 349 the holotype locality; the skyline of the mountain range resembles the cusps and ridges of the 350 teeth.

352 Holotype

353 NMS G.2020.4.1.1, a partial skull and postcranial remains (Fig. 3).

355 Description

356 The holotype NMS G.2020.4.1.1 is a partial skeleton that, following preparation for high-

357 resolution CT scanning, is contained within a series of small blocks of blue-grey micritic

358 limestone between $\sim 2-5 \mathrm{~cm}$ length. The dentaries and some skull elements are partially visible 359 on the surface, and within the rocks are the skull, vertebrae, scapulacoracoid, humerus, radii, 360 ribs and pes and manus elements. We infer that NMS G.2020.4.1.1 is an adult individual, as the 
361 last (ultimate) lower molar is positioned directly in front the coronoid process, as in adult 362 specimens of Docodon victor (Schultz et al., 2017).

363

364 Stratigraphic provenance

365 Kilmaluag Formation, Late Bathonian, Middle Jurassic (Retrocostatum Zone: Barron et al., 366 2012).

367

368 Type locality

369 Cladach a' Ghlinne, Strathaird Peninsula, Isle of Skye, Scotland UK (Fig. 1).

370

371 Referred material

372 From the Kilmaluag Formation, Isle of Skye: Partial left dentary BRSUG 20571; NMS

373 G.2018.27.1, fragment of right dentary in matrix. From the Forest Marble Formation of

374 Kirtlington, Oxfordshire: NHMUK PV M46394, NHMUK PV M46448, NHMUK PV M46580, and

375 NHMUK PV M46871, all upper molars. NHMUK PV M46316, NHMUK PV M46396, and possibly

376 NHMUK PV M46607 (uncertain), all upper molars.

377

378

379

380

381

382

383

384

385 Borealestes mussetti Sigogneau-Russell, 2003

386 Borealestes mussettae Averianov, 2004 (emended gender). 
Differential diagnosis

Dobunnodon mussettae resembles other docodontans in that it possesses an anterior

'pseudotalonid basin' on the lower molars, formed by cusps a, b, and g, has cusps b-a-c in a triangular arrangement, the lower molars are elongated anteroposteriorly, with labial row of higher cusps arranged in anteroposterior alignment with largest cusp a, and it has a lingual row 393 of smaller cusps with distinctive anterior cusp g and larger posterior cusp c. The lower molar of 394 Dobunnodon is unlike most docodontans, but is similar to Tashkumyrodon, in being 395 mediolaterally compressed. It resembles most docodontans, but differs from Borealestes, in that 396 the a-g crest is present on both cusp g and cusp a, and in having a strong a-d crest on cusp a 397 (Fig. 5). Cusp g is slightly more developed, and cusps $\mathrm{c}$ and $\mathrm{g}$ are placed further apart 398 anteroposteriorly, than in Borealestes. Unlike Simpsonodon, Agilodocodon, and Docodon, but 399 like most other docodontans, Dobunnodon lacks creases and pits, 'ornamentation' on the teeth. 400 Dobunnodon has an anterior lingual cingulid that passes below cusp $\mathrm{g}$ to midway along the 401 molar anteroposteriorly. The df cusp is more developed in Dobunnodon than in Borealestes and 402 is distinct from the $d$ cusp. Cusp e is positioned in alignment with the anteroposterior axis of the 403 molar, whereas cusp e is lingual of the anteroposterior axis on molars of Borealestes. The upper 404 molars are not yet known for this taxon.

405

406 Etymology: The genus name was given for one of the Iron Age Celtic tribes, the Dobunni, that 407 occupied the region around Kirtlington where the holotype was discovered. The species name 408 was given in honour of Dr Frances Mussett for her 'major participation in the accumulation of the 409 Kirtlington fauna' (Sigogneau-Russell, 2003).

\section{Holotype}

412 NHMUK PV M46495, a right lower molar (Fig. 5C) 
414 Description

415 The holotype NHMUK PV M46495, is a single right lower molar, lacking a root, and broken at 416 the base of cusp a (reconstructed for Fig. 5C), previously described by Sigogneau-Russell 417 (2003) and Panciroli et al. (2019).

419 Stratigraphic provenance

420 Forest Marble Formation, Late Bathonian, Middle Jurassic (Retrocostatum Zone: Barron et al., 421 2012).

422

423 Type locality

424 Kirtlington Cement Quarry, Oxfordshire, UK. 425 426

Referred material

427 From the Forest Marble Formation of Kirtlington, Oxfordshire: NHMUK PV M46224, NHMUK PV 428 M46239, NHMUK PV M46001, NHMUK PV M46066, NHMUK PV M46836, NHMUK PV 429 M46319, NHMUK PV M46809, and NHMUK PV M46835, all lower molars. From the Forest 430 Marble Formation of Watton Cliff, Dorset: NHMUK PV M46001, lower molar.

$434 \quad$ The fossil record for Mesozoic mammaliaforms comprises a disproportionate amount of 435 individual teeth and dentary fragments. It is common practice to use this sparse material as the 436 basis for erecting new species and taxonomic groups, thanks to the complexity of 437 mammaliaform teeth making them a reliable basis for systematic diagnoses. However, it has 438 been recognised that this practice may result in 'over-splitting' (erecting new groups based on 
439 over-interpretation of small differences in molar morphology). For example, the near complete

440 tooth row of Palaeoxonodon recovered recently on Skye was found to encompass the

441 diagnostic characters identified as the basis for previously erecting three different species in two 442 genera (Close et al., 2016). On the other hand, a lack of variation at certain loci on the lower 443 tooth row between species can result in failing to recognise taxonomically distinct 444 morphospecies, as shown here.

445 The lack of distinguishing features between the molars in the two Borealestes species, 446 B. serendipitus and $B$. cuillinensis, means that these two taxa cannot be identified from 447 individual lower molars alone. Nevertheless, we present features of upper molars (Fig. 5A and $448 \quad$ B) and dentary (Fig. 7, see below) that we consider distinct and indicative of the presence of 449 distinct morphospecies. Many isolated lower molars and dentary fragments previously assigned 450 to B. serendipitus (e.g. Sigogneau-Russell, 2003; Panciroli et al., 2019) therefore lack diagnostic 451 features at the level of species and must be considered as Borealestes. sp. This observation 452 has implications for our understanding of the taxonomic diversity of docodontans, and Mesozoic 453 mammals more generally, suggesting the potential for 'hidden' species that are not recognisable 454 from isolated lower molars.

455 The holotype of Dobunnodon mussettae (='Borealestes' mussettae in previous 456 taxonomic designation) is a lower molar, and the upper molars previously assigned to 457 'Borealestes' mussettae (Sigogneau-Russell 2003: fig. 4 and Panciroli et al., 2019) match the 458 morphology of the uppers of NMS G.2020.4.1.1, which are found in unequivocal association 459 with the lower molars and partial skeleton. We propose here that these upper molars (NHMUK 460 PV M404, PV M46394, NHMUK PV M46448, NHMUK PV M46580, and NHMUK PV M46871) 461 should be therefore reassigned to the new taxon, $B$. cuillinensis. The features of the lower 462 molars of NMS G.2020.4.1.1 - the a-g crest being absent, and a poorly developed df cusp - are 463 diagnostic for Borealestes and distinguish it from Dobunnodon. 
Only the first lower molar of Borealestes share two features with those of the holotype of Dobunnodon: a low width-to-length ratio, and wider gap between cusps c and g (Table 2).

466 Nevertheless, this is not present in the rest of the tooth row in Borealestes. Low width-to-length 467 ratio, and wider gap between cusps $\mathrm{c}$ and $\mathrm{g}$ are also seen in other docodontans in which the $\mathrm{m} 1$ 468 is known, which suggests that these may be problematic features upon which to erect new 469 docodontan taxa.

\section{DESCRIPTION}

472 Morphology of Borealestes serendipitus and Borealestes cuillinensis

473 NMS G.1992.47.121.1 comprises a partial skeleton of Borealestes serendipitus on a block of 474 blue-grey limestone. The block measures approximately $183 \mathrm{~mm}$ in length, $105 \mathrm{~mm}$ in width, 475 and between $148 \mathrm{~mm}$ and $340 \mathrm{~mm}$ in thickness. The surface of NMS G.1992.47.121.1 is 476 undulating, with several hairline cracks visible in the prepared upper surface, also visible in 477 synchrotron CT data. Skeletal elements are scattered on the surface of the block, including the 478 palate and elements of the skull (Figs 2 and 8). Synchrotron CT data revealed vertebrae, ribs, 479 radius, partial humerus, ilium, femur and manus and pes elements within the block (unpubl. data 480 EP). The surface bones sit on 'platforms' of rock, the result of acid and mechanical preparation, 481 whereby the surrounding rock was removed. At least seven such platforms no longer contain 482 fossil material, and likely indicate the original positions of bones that have been removed or 483 detached during handling, such as the petrosal NMS G.1992.47.121.2 (Panciroli et al., 2018a) 484 and the dentary (NMS G.1992.47.121.3 (Panciroli et al., 2019).

$485 \quad$ NMS G.2020.4.1.1 comprises a partial skeleton of Borealestes cuillinensis contained 486 within a series of small blocks of blue-grey limestone between $\sim 2-5 \mathrm{~cm}$ length (Fig. 3). The skull 487 is present between two of these blocks, which were broken apart across a natural crack in the 488 limestone. The left dentary is visible on the surface along with the right squamosal and part of 
489 the occipital condyles. The rest of the skull is contained within the rock and visible through X-ray

$490 \mu \mathrm{CT}$ (Figs 3 and 9).

491

492

493 Skull

494 Dentary

495 The right dentary Borealestes serendipitus, NMS G.1992.47.121.3 (Fig. 7, Table 3), is

496 nearly complete and was detached from NMS G.1992.47.121.1 during preparation. The

497 posteriormost portion of the left dentary remains on the surface of NMS G.1992.47.121.1 (Figs 2

498 and 7). The incisors are missing from NMS G.1992.47.121.3, but a single incisor and ventral tip

499 of an incisor root are present in NMS G.1992.47.121.1, located in the matrix underneath the

500 nasals. The damaged remnants of a premolar or molar are located within the matrix near a

501 posterior portion of the left dentary. The tip of the main cusp of this tooth is missing and it is

502 damaged lingually and buccally. The remains of the posterior root are present, but fragmented.

503 It is not possible to give a more exact identification due to the poor preservation.

$504 \quad$ The left dentary of Borealestes cuillinensis, NMS G.2020.4.1.1 is preserved on the 505 surface of the limestone block (Fig. 3, Table 3). It comprises p4 to m5 within an incomplete 506 dentary. The m5 can be reliably identified as the ultimate molar because it has a reduced size 507 and two roots appressed to each other (Fig 6D and 9), which are typical of the most posterior 508 lower molar of a molar series in docodontans (Schultz et al., 2017; Panciroli et al., 2019). The 509 ultimate lower molar is in alignment with and anterior to the coronoid process on the dentary 510 (Fig. 10A). The dentary has a preserved dentary condyle, most of the coronoid process, and a 511 medial ridge with its protuberance and posterior notch (Fig. 10A and C). The tip of the angular 512 process is preserved, but was broken from the dentary during preparation for scanning. A small 513 section was lost, but the position of the remaining fragment was preserved in the limestone 514 surface, and has been repositioned digitally (Fig. 10B and C). An anterior portion of the right 
515 dentary is present in NMS G.2020.4.1.1, including the tooth row from the canine to m2 (Fig. 516 11A). An isolated incisor and isolated premolar are also present, separated from the tooth row 517 (Fig. 3B).

518 The morphology of the lower teeth of both species of Borealestes conforms to that 519 previously described for $B$. serendipitus in Panciroli et al. (2019). The incisors have a large 520 buccal bulge and slightly recurved cusp. A ridge runs from the tip of the cusp to the base of the 521 crown, where there is a small cuspule along the rim of the base of the crown. The single root is 522 wide, tapering ventrally. The alveoli on the preserved right dentary of $B$. serendipitus indicate 523 that the anterior incisors were strongly procumbent, especially i1. This is also seen in other 524 docodontans such as Agilodocodon (Meng et al., 2015). The slightly extended lingual cingulum 525 in the m4 of NMS G.2020.4.1.1 is not considered diagnostic. This feature appears more distinct 526 in the m4 of the holotype of B. serendipitus, BRSUG 20570 than it is in NMS G.1992.47.121.3, 527 and the lingual cingulum of the m5 in NMS G.1992.47.121.3 appears extended compared to 528 either BRSUG 20570 or NMS G.1992.47.121.3. This suggests it is not a reliable diagnostic 529 feature, but is variable among Borealestes species.

530 The dentary appears slightly more curved dorsoventrally in B. cuillinensis than in $B$. 531 serendipitus, particularly the anterior portion of the dentary (Fig. 7). The position of the 532 posteriormost foramen is ventral to $\mathrm{p} 1$ in both species (Fig. 11A1, Panciroli et al., 2019). In $B$. 533 cuillinensis the mandibular symphysis is indistinct posterior to the canine (Figs 7B and 10A2). 534 The coronoid process is almost complete in B. cuillinensis, and appears tall, with the anterior 535 edge steeply ascending from posterior to the m5 (Fig. 10). The posterior edge of the coronoid 536 process dorsal to the dentary condyle appears to curve posteriorly, but the dorsal-most portion 537 is missing.

538

539 Premaxilla 
541 nearly complete, but have been dislodged from the main block surface and are slightly crushed.

542 The left premaxilla is displaced anteriorly in relation to the right premaxilla. The left premaxilla is 543 also more complete, and holds alveoli for I2 and I3 (Fig. 12A). Identification of incisors is 544 possible due to the presence of the intranarial process on the right premaxilla (Fig. 12A3, A4, 545 and A6), and the position of the anterior premaxillary foramen in relation to I1 and I2 (Fig. 546 12A6). Incisors $I 3$ and 14 are intact and approximately in life-position, and the root of $I 2$ is in 547 place, but its crown is broken off at the alveolar margin and missing. In the right premaxilla, the 548 alveoli for I1-3 are present, although the lateral margin of the premaxilla is more fragmented. 549 The 13 alveolus is crushed, and 13 is not present, but I1-2 are both present and approximately in 550 position, with some displacement. Only a fragment of the right premaxilla is preserved in 551 Borealestes cuillinensis NMS G.2020.4.1.1 (Fig. 11B). This fragment is incomplete medially, but 552 contains the alveoli with the I2 and I3 in situ and undamaged, and the I 1 is sitting next to the I1 553 alveolus.

In both species of Borealestes the incisor morphology is approximately the same. The 556 upper incisors are slightly recurved with a single-rooted I1 and double-rooted I2-I3. Little of the 557 premaxillary morphology remains in NMS G.2020.4.1.1, but based on this fragment and the 558 preserved maxilla (below), the premaxilla contains only I1-I3, and is shallow dorsoventrally. The 559 I2 and I3 are less caniniform than in B. serendipitus NMS G.1992.47.121.4, and proportionally 560 smaller dorsoventrally. For more detailed description of upper incisor morphology in $B$. 561 serendipitus see Panciroli et al. (2019).

562 The margins of the incisive foramen are intact in B. serendipitus NMS G.1992.47.121.1.

563 The anterior edges of the foramen lie mediolaterally parallel to the posterior margin of the 12 564 alveoli. There is a small projection of the premaxilla, jutting posteriorly into the incisive foramen 565 where the premaxillae contact each other anteriorly, creating a heart-shaped anterior margin to 
566 the foramen Fig. 12A6). Anterior to the incisive foramen are the ventral premaxillary foramen, 567 adjacent to I2. There are also two much smaller foramina medial to the I3 alveoli (Fig. 12A5). On the ventral palatal plate of the premaxillae there are depressions between the alveoli 569 and medial to the toothrow, which are for the receipt of the lower incisor tips when the mouth is 570 closed (Fig. 12A5). The posterior margin of the premaxillae which contacts with the maxilla is 571 not preserved. The anteriormost tips of the premaxillae are preserved, although in poor 572 condition. There is a stump or base of the internarial process on the right premaxilla-this 573 makes identification of the right I1 certain. In the interior of the premaxilla there is a canal 574 connecting from the anterior premaxillary foramen to the ventral premaxillary foramen (Fig. 575 12A6). The anterior opening of this canal is exposed on the broken anterior surface of the left 576 premaxilla (Fig. 12A4). Posteriorly this canal is traced to the ventral premaxillary foramen, to 577 which the canal is connected from inside the premaxilla. This canal splits into branches in the 578 interior of the right premaxilla. These canals cannot be traced as extensively in the right 579 premaxilla due to poor preservation, but part of this incomplete canal is present in the right 580 premaxilla, and connects the ventral premaxillary foramen laterally toward the interdental gap 581 between I1 and $\mathrm{I}$.

582 The lateral surfaces of the premaxillae are more or less vertical from the alveolar 583 margins. The dorso-ventral depth of the premaxilla increases posteriorly, from $\sim 0.5 \mathrm{~mm}$ anterior 584 to $\mathrm{I} 2$, to $\sim 2.4 \mathrm{~mm}$ at the alveolus of $\mathrm{I} 3$, and the alveolus of $\mathrm{I} 4$ is in the anteriormost portion of the 585 maxilla (see below). The posterior margin of the 14 alveolus is missing. On the endocranial 586 surface of the premaxillae, a groove runs from the endocranial openings of each of the ventral 587 premaxillary foramen, meeting in the midline across the sutures. This creates a canal between 588 the endocranial openings of the ventral premaxillary foramen.

590 Maxilla and palatine 
592 posteriorly to the broken maxillary base of the zygomatic arch (Figs 13 and 14, Table 3). Teeth

593 are preserved from P4-M4, but are damaged. The facial part of the anterior maxilla is not

594 complete, and the premolar-bearing margin of the maxilla is missing, so the exact count of the

595 premolars is not known. But five upper premolars can be reconstructed based on the lower

596 premolar number on the complete mandible of the specimen (right dentary, NMS

597 G.1992.47.121.3, Fig. 7). The palatal processes of both maxillae are fragmented; the right

598 maxilla is more complete. Both maxillae have preserved the cheek teeth in life-position-the

599 right P4 to M4, and left P5 to M4. The crowns of these teeth, especially the premolars, have

600 been abraded. This ventral surface of the palatal plate of the maxillae, which contain the teeth,

601 was uppermost on the matrix when the fossil was found (Fig. 2). The worn surfaces of the teeth

602 are not due to dental occlusion, but due to taphonomic abrasion. Upper premolar and molar

603 morphology for B. serendipitus NMS G.1992.47.121.1 was presented in Panciroli et al. (2019).

604

The left maxilla of Borealestes cuillinensis NMS G.2020.4.1.1 is almost complete, with

605 only the section between P1 and P4 mostly missing, except for a fragment of the lateral surface

606 dorsal to the position of P1-P3 (Fig. 15, Table 3). Teeth are well preserved from 14-P1, and P4-

607 M4. The 14 alveolus is enclosed by the maxilla (Fig. 15A1-2), unlike in B. serendipitus, in which

608 the 14 alveolus is enclosed by the premaxilla (Fig. 12A). The 14 (which is displaced but complete

609 in NMS G.2020.4.1.1, Fig. 15A1-2) is not caniniform, unlike in B. serendipitus. There is a

610 depression for the lower canine tooth tip to rest in when the mouth is closed, positioned

611 between the 14 and C (Fig. 15A2). The P1 is small, but has a recurved main cusp and small

612 posterior cuspule. A distinct diastema separates the P1 from the P2 alveolus in NMS

613 G.2020.4.1.1 (Fig. 15A1-2). The P2 is not present and the anterior of the maxilla is

614 dorsoventrally tall, bulging laterally at the level of the canine, and constricting medially at the

615 diastema (Fig. 15A2-3). There is a foramen dorsal to the space between the 14 and canine 
616 alveoli. A larger infraorbital foramen is dorsal to the P5, and there is a possible foramen dorsal 617 to M1.

618 Although the right maxilla of B. cuillinensis NMS G.2020.4.1.1 is damaged, it includes 619 the tooth row from P3-M4 and a large portion of the maxilla itself, although broken into three 620 pieces (Fig. 16A). The P3 to M1 are damaged. In the left and right maxilla the maxillary base of 621 the zygomatic arch is preserved, and it appears in the left maxilla to project posteriorly beyond 622 the maxilla-palatine suture posterior to the ultimate molar. In the left maxilla the palatal process 623 is present, but displaced ventrally (Fig. 15A2). The medial edge of the palatal process of the 624 maxilla is dorsoventrally deep. As in B. serendipitus, the posterior part of the maxilla holds the 625 ultimate molar and its roots. The contact between the maxilla and palatal process of the palatine 626 appears to have been close to the lingual edge of the molar row as in $B$. serendipitus, but the 627 maxilla is broken here and so this interpretation is uncertain. We interpret a separate bone 628 fragment preserved in NMS G.2020.4.1.1 as the palatal process of the right maxilla of $B$. 629 cuillinensis (Fig. 16B). It includes the posterior rim of the process (which is missing the more 630 complete left maxilla), and indicates that it projected posteriorly into the palatal process of the 631 palatine.

632 The palatal process of the maxilla in B. serendipitus NMS G.1992.47.121.1 continues 634 posteriorly until approximately the level of the M2/3 (Fig. 13A1). Crushing and displacement of 635 the medial portion of the palatal process of the maxillae makes this area difficult to interpret. The 636 greater palatine foramen is preserved medial to $M 2$, and the palatal process of the maxillary 637 bone appears to project posteriorly into the palatal process of the palatine bone along the 638 midline suture. This projection has a low ventral anteroposterior ridge. An alternative 639 interpretation is that the palatal process of a maxilla ends at M2/3, and the "projection" 640 aforementioned may be the palatal process of the palatine. The posteriormost portion of the 641 palatal process of the maxillary bone is not preserved in the left maxilla. 
The posterior part of the maxilla holds the ultimate molar and its roots. The contact of the

643 maxilla with the palatine appears smooth. The contact between the maxilla and palatal process

644 of the palatine appears to have been close to the lingual edge of the molar row, but as the

645 maxilla is broken here, this interpretation has some uncertainty. A fragment of the right palatine

646 indicates that the suture may have been as little as $0.4 \mathrm{~mm}$ from the lingual margin of the

647 alveolus of the ultimate molar. The maxillary base of the zygomatic arch is better preserved in

648 the right maxilla, and does not appear to posteriorly project beyond the maxilla-palatine suture

649 posterior to the ultimate molar (Fig. 13).

650 The suture of the maxilla-lacrimal slopes posteroventrally from a point dorsal to M2, to

651 P4, overlapping the ventralmost portion of the lacrimal (Fig. 13A2 and 14B). Although the lateral

652 wall of the maxilla is somewhat compressed (a post-mortem distortion) it is clearly laterally

653 convex. The lateral portion of the left maxilla is not preserved.

654 The lateral surface of the maxilla shows three anterior foramina of the infraorbital canal.

655 These foramina are dorsal to the roots of the P5/M1 junction, P4/P5 junction, and P3/P4

656 junction of the right maxilla (Fig. 13A).

657 Crushing makes it impossible to reconstruct most of the endocranial surface and internal

658 structure of the maxilla (Fig. 14A). However the groove on the posterior endocranial surface of

659 the maxilla for the lacrimal is well preserved on both maxillae. Compression has also distorted

660 the shape of the palatal surface of the maxilla, tilting the tooth row mediodorsally.

661

662 Nasals

663 Three fragments of the nasal bone are preserved in Borealestes serendipitus: the right 664 and left from just anterior to the anteriormost projection of the lacrimal, to just anterior to the 665 suture with the frontal (the latter suture line is not preserved) (Figs 13 and 14). There is also an 666 anterior fragment of the left nasal (Fig. 12B). The anterior fragment of the left nasal is separated 667 from the rest of the skeleton and is attached to the premaxillae by a small portion of matrix and 
668 Paraloid, as part of NMS G.1992.47.121.4. It includes an anterior foramen on the exterior dorsal 669 surface (Fig. 12B3-4). There is a dorsoventrally deep midline suture where it would have met 670 the right anterior frontal (Fig. 12B2). The nasal in Borealestes cuillinensis NMS G.2020.4.1.1 is 671 badly broken, but preserves what appears to be the edge of the anterior nasal foramen, which 672 appears to be large, and the ridge of the nasal-maxilla suture along its length (Fig. 17A3).

673 The rim of the anterior nasal notch in B. serendipitus indicates the notch was wide and 674 terminated $1.6 \mathrm{~mm}$ anterior to the anterior nasal foramen. The nasal is narrow anteriorly, 675 widening and extending under the maxilla posterolaterally. A ridge is present on the lateral side 676 of the nasal, where it sat under the anterior edge of the maxilla (Fig. 12B3-4), and presumably 677 under the septomaxilla, although neither those bones nor their facets are preserved. On the endocranial surface of the nasals of $B$. serendipitus, strong ridges run 679 anteroposteriorly along the length of this section of the nasal (Fig. 12B). These ridges are not 680 visible in the larger posterior portions of nasal. the portion of the right nasal is preserved in $B$. 681 cuillinensis NMS G.2020.4.1.1, is identified by similar endocranial ridges running 682 anteroposteriorly along the endocranial surface (Fig. 17A1). We tentatively interpret these 683 ridges as the remnants, or incompletely preserved base of, the naso-turbinates (Fig. 12B1-B2). 684 They are not well enough preserved in either Borealestes specimen to further interpret their 685 structure.

686 In B. serendipitus posterior nasal portions are much wider than the anterior portion, and 687 their midline suture is dorsoventrally deep and forms a projecting ridge endocranially where they 688 join (Fig. 14A-B). Crushing has distorted the original shape of the nasals, making them appear 689 flatter than they may have been in life. The posteriormost nasal foramen is positioned 690 mediolaterally halfway across each nasal on the anterior portion of the preserved bone (Fig. 691 14B). These foramina open directly into the nasal cavity. Crushing has made it difficult for us to 692 identify or fully reconstruct endocranial structures of the nasals, but nevertheless the broken 693 fragments visible in the CT cross sections (Fig. 14A) sitting between the nasals and the maxillae 
694 are likely the crushed and incomplete remnants of the naso-turbinates, the incomplete parts of 695 which are also preserved on the underside of the nasal as mentioned above. We tentatively 696 interpret that remnants of the maxillary turbinates are preserved on the inner surface of the 697 maxillary, but the maxillary turbinates themselves are not well preserved enough to be 698 reconstructed.

$700 \quad$ Lacrimals

$701 \quad$ Both lacrimals are preserved in Borealestes serendipitus NMS G.1992.47.121.1: the 702 right lacrimal is in natural articulation with the maxilla (Figs 13 and 14), and the left lacrimal is 703 located on the surface of the block, posterior to the maxillae (Fig. 14C). The right lacrimal is 704 more complete than the left. Only the right lacrimal is preserved in Borealestes cuillinensis NMS 705 G.2020.4.1.1, including the zygomatic process of the lacrimal, and the lacrimal foramen (Fig. 706 18). The orbital flange is broken and not present in this specimen.

707 The morphology of the lacrimal is similar in both species of Borealestes, but the lacrimal 708 is less convex laterally in B. cuillinensis than in B. serendipitus. The zygomatic process of the 709 lacrimal is long and slender and extends to the line of the posterior edge of the ultimate molar in 710 B. serendipitus, and sits in a dorsal groove of the maxilla, where they form the anterior base of 711 the zygomatic arch (Figs 13A2, 14B and 18). It has a distinct lateral groove to receive the jugal. 712 In B. serendipitus the orbital flange of the lacrimal extends posteriorly at least as far as the end 713 of the zygomatic process, but in neither specimen of Borealestes is the suture with the frontal 714 preserved.

$715 \quad$ The dorsal and ventral lacrimal foramina are large (Figs 13A2 and B, 14B-C and 18).

716 The lacrimal is laterally convex, and endocranially the surface is domed, with two dorsoventral

717 ridges: one on the orbital flange of the lacrimal, posterior to the lacrimal foramen; the second 718 anteriorly, on the facial extension of the lacrimal (Figs 13B3, 14C4 and 18A2). On the lateral 719 exterior surface of the lacrimal, the ridge that receives the jugal posteriorly runs along the length 
720 of the lacrimal anteriorly, where it marks the edge of the maxilla (Figs 13A2 and B4, 14C2 and 721 18A1). Ventral to this groove, the lacrimal sits underneath the lateral surface of the maxilla (Figs $72213 \mathrm{~A} 2$ and $14 \mathrm{~B}$ and $\mathrm{C} 2$ ). The anteriormost portion of the facial extension of the lacrimal is not 723 preserved on either species of Borealestes, and it is unclear how far it extends, or how it meets 724 the nasal and maxilla anteriorly.

726 Frontals

727 A fragment of the dorsomedial portion of the left frontal of Borealestes serendipitus is 728 located beside the postparietal on the surface of the block of limestone NMS G.1992.47.121.1

729 (Fig. 2). The interfrontal suture is partly preserved (Fig. 19A). Although somewhat damaged 730 along its edge, it is clearly vascularised internally (Fig. 19A1), and thickens anteriorly. This 731 thickening is due to a transverse ridge on the endocranial surface, which we interpret as the 732 ridge on the frontal that corresponds to the circular or annular fissure separating the posterior 733 margin of the fossa for the olfactory bulb from the anterior margin of the fossa for the cerebral 734 hemisphere, if the brain endocast were intact and fully preserved (Fig. 19A2). A similar ridge is 735 seen on the brain endocast of the mammaliaform Morganucodon (Kermack et al. 1981; Rowe et 736 al. 2011) and later mammaliaforms.

737 The posterior of the frontal bone, where it meets the interparietal, is not preserved, nor is 738 the lateral wall. The remnants of an anteroposterior indentation and ridge on the external 739 surface of the frontal, sloping posteroventrally, is interpreted as either an orbital ridge, or as 740 marking the extent of the anterior overlap of the parietal bone (see below) (Fig. 19A3 and A5). 741 As the anteriormost portion of the parietal is not preserved, it is not possible to confirm this. 742 Anteriorly, a possible foramen could correspond to the infraorbital foramen of 743 Haldanodon (Lillegraven \& Krusat, 1991) (Fig. 19A3). However, this area is damaged and the 744 anterior portion missing so this identification is not certain. 
746

747

748

749

750

751

752

753

754

755

756

757

758

759

760

761

762

763

764

765

766

767

768

769

770

771

Parietals

The left parietal is the largest preserved portion of the cranium of Borealestes

serendipitus NMS G.1992.47.121.1, with most of it present including the medial interparietal suture, the parietal-postparietal suture, and multiple lateral fragments (Fig. 20). The posterior of the cranium formed by the parietal is transversely wide, with a small sagittal crest at the dorsoventrally deep suture between the left and right parietals. Where the interparietal suture meets the postparietal suture, the parietal contributes to a dorsal projection of the sagittal crest. The parietal is overlapped by the postparietal along the posterior margin, forming a slight nuchal crest running posterolaterally (Fig. 20B and D).

The walls of the parietal are thin, except along the interparietal suture where the parietals are thicker and contribute to the sagittal crest. The lateral part of the parietal in the temporal area is also thickened. This corresponds to a bulge on the endocranial surface, which we interpret as marking the rim of the indentation of the meninges of the left side of the cerebellum and left cerebral hemisphere. This ridge is concurrent with the low ridge associated with the transverse sinus sulcus, as seen on the endocranial surface of the parietal in the skull roof of Morganucodon (Kermack et al. 1981: fig 31) (Fig. 20A and C). On the exterior posterolateral wall of the parietal, a ridge running parallel to the nuchal crest probably marks the overlapped edge of the dorsal flange of the squamosal (Fig. 20B and D).

The identity of an indentation on the anterior dorsolateral surface of the parietal (Fig. $20 \mathrm{~B}$ ) is uncertain. Crushing and flattening of the bone here makes interpretation difficult and hinders reconstruction, but there are three possibilities: 1) it represents post depositional damage; 2) it marks the posterodorsal overlap of the bones of the temporal region; or 3) it resulted from the bite of a predator or scavenger. We consider the third possibility to be the least likely, and favour the second interpretation, which would suggest that the bone located anteroventrally below this indentation could be a fragment of the temporal region. 
772 Postparietal

773 The postparietal of Borealestes serendipitus is approximately triangular in shape along 774 the dorsal edge where it meets the parietals (Fig. 19D). It slopes posteroventrally towards the 775 supraoccipital (not preserved). The posteroventral edge of the postparietal is not preserved. A 776 small projection of the postparietal inserts between the parietals posterior to the interparietal 777 suture, and this forms the dorsalmost projection of the sagittal crest. Laterally in both directions, 778 the postparietal overlaps the posterior edge of the parietals, contributing to a nuchal crest.

779 There is a gentle bulge along the midline of the postparietal, forming a midline ridge (Fig. 780 19D1). There are a series of foramina along the exterior dorsal side of the postparietal. The 781 postparietal is well vascularised, including along the length of the medial ridge (Fig. 19D3). The 782 endocranial surface of the postparietal is unclear-the limited contrast in the synchrotron CT 783 data between this section of the fragment and the matrix it sits upon make digital segmentation 784 problematic. However, there is an endocranial swelling that mirrors the exterior medial ridge of 785 the postparietal. Posteroventrally the postparietal thins, but the suture with the posteriormost 786 portion of the cranium is missing.

787

788

Petrosals

The petrosals of $B$. serendipitus, NMS G.1992.47.121.1 and NMS G.1992.47.121.2, 790 have previously been described (Panciroli et al., 2018a). Both petrosals are preserved: the right 791 petrosal is more complete, and still attached to the matrix as part of NMS G.1992.47.121.1. The 792 left petrosal NMS G.1992.47.121.2 is less complete, and is separate from the rest of the 793 skeleton.

795 Squamosal

796 The right squamosal of Borealestes serendipitus is preserved in NMS G.1992.47.121.1, 797 located beside the occipital condyles, separated from the rest of the skull, and below the surface 
798 of the block (Figs 2 and 19B). The right squamosal of Borealestes cuillinensis is well preserved 799 in NMS G.2020.4.1.1 (Fig. 21A), along with the anterior tip of the zygomatic process of the left 800 squamosal (Fig. 21B).

801 The squamosal of B. serendipitus shows a long and slender zygomatic process (Fig.19) .

802 In B. cuillinensis the zygomatic process narrows anteriorly and has a distinct ridge along its length 803 on the dorsal margin (Fig. 21A2), giving it a comparatively more robust appearance, more similar 804 to the squamosal glenoid and zygoma of Haldanodon (Lillegraven \& Krusat, 1991; Ruf et al., 805 2013).

806 In both Borealestes species there is a wide glenoid fossa for articulation with the dentary 807 condyle, although it is slightly wider in B. cuillinensis (Fig. 21A1 and A3). In both species the 808 squamosal glenoid is a shallow and concave structure with a slightly raised postglenoid ridge, 809 and the glenoid appears to have an oval outline in ventral view narrowing anteriorly in a 810 teardrop shape (Figs 19B and $21 \mathrm{~A}$ ). The beginning of a distinct postglenoid ridge is preserved in 811 B. cuillinensis NMS G.2020.4.1.1, but part of it is missing laterally. The more complete 812 squamosal of this specimen suggests the squamosal projected less laterally than in $B$. 813 serendipitus, but that the skull would have a similar elongate triangular shape (Figs 8 and 9).

814 As for all docodontans there is a constriction in the neck of the glenoid in both species of 815 Borealestes, visible medial to the glenoid (Fig. 19A2 A3, and 21A), for example as seen in 816 Haldanodon (Luo 1994; Ruf et al. 2013). Although the lateral extent of the constriction cannot be 817 determined in B. serendipitus NMS G.1992.47.121.1 because this lateral margin of the glenoid is 818 damaged, the constriction appears to be less pronounced in Borealestes species than 819 Haldanodon.

820 There is a large, broadly concave surface on the medial aspect of the squamosal cranial 821 moiety in B. serendipitus NMS G.1992.47.121.1, which we tentatively identify as the contact of 822 the squamosal to the lateral side of the paroccipital process of the petrosal, but this area is not 823 well preserved. The part of the squamosal that would contact the paroccipital process of the 
824 petrosal extends from just posterior to the glenoid fossa medially to a depression called the 825 entoglenoid recess (sensu Ruf et al., 2013: fig. 2-this is the same as the ventromedial squamosal 826 recess of Lillegraven \& Krusat, 1991). The right petrosal of $B$. serendipitus is preserved but is 827 separated from the squamosal (see Panciroli et al. 2018). Unfortunately the junction between the 828 right petrosal and the right squamosal is not preserved well enough to interpret the other features 829 expected to be located in this area, such as the crista parotica and the fossa incudis, both of which 830 are missing.

831 In B. cuillinensis part of the cranial moiety of the squamosal is preserved, and has a 832 strong dorsal ridge that curves anterodorsally (Fig. 21A2 and A4-5). The entoglenoid recess (= 833 the ventromedial squamosal recess of Lillegraven \& Krusat, 1991) and external auditory meatus 834 are preserved (Fig. 21A1 and A3). The entoglenoid recess is shallow concave structures medial 835 to the glenoid fossa, and it bears resemblance that of $B$. serendipitus. However, the crista 836 parotica and the fossa incudis in the adjacent region of the petrosal are not preserved, and it is 837 not feasible to interpret these and other structures in the junction regions of the squamosal and 838 the petrosal.

840 Occipital condyle and exoccipital

841 In Borealestes serendipitus NMS G.2020.4.1.1 the exoccipital and occipital condyles are 842 separated from the skull, and are preserved within the matrix beside the right squamosal (Fig. 843 2). The occipital condyles of Borealestes cuillinensis NMS G.2020.4.1.1 are located on the 844 surface of the limestone, resting against the left dentary (Fig. 3). Fragments of the exoccipital 845 are attached to the left occipital condyle (Fig. 21C), but they are poorly preserved.

846 The occipital condyles appear indistinguishable between the species of Borealestes. We 847 tentatively identify the odontoid notch in the occipitals. However it is uncertain whether the 848 exoccipitals contacted at the midline dorsomedially, ventral to the postparietal. Due to a lack of 849 preservation, there may have been a slight gap in the contact with the supraoccipital (Figs 19C 
850 and 21C). On the preserved part of exoccipital of Borealestes serendipitus, the interior of the 851 bone appears to be hollow and trabeculated. The pars cochlearis of the petrosal shows multiple

852 vascular channels including circumpromontorial plexus through the bone in $B$. serendipitus

853 (Panciroli et al., 2018). The paroccipital region of the petrosal exhibits pneumaticity (e.g.,

854 paroccipital pneumatic recess) as in Haldanodon (Ruf et al. 2013), and the pneumatic space in

855 the middle ear appears to be connected to the well developed vascular plexus structure inside

856 the paroccipital region and in the adjacent exoccipital. The trabeculated and hollowed interior

857 spaces of the petrosal and exoccipital would have been filled with vasculature and/or bone

858 marrow (Ruf et al. 2013: fig. 4). Even the occipital condyles are hollow and trabeculated (Ruf et

859 al., 2013: fig. 3D and 4: 'condylar plexus'). The hollowed interior of the exoccipital, especially the

860 occipital condyle of Borealestes, appears to be similar. Based on this, it is interpreted here that

861 the exoccipital bone has similar interior vascularised and trabeculated interior structure in

862 Borealestes, as interpreted for docodontans as a whole. The occipital condyles project from the

863 base of the skull and are oval in shape. The jugular process of the right exoccipital is preserved

864 on the ventral side, although there is damage to the ventral aspect of the exoccipitals. The

865 basioccipital is not preserved.

866

867 DISCUSSION

868 Phylogenetic Analysis and Position of Dobunnodon mussettae

869 The phylogenetic analysis support the erection of a new species of Borealestes, and the

870 placement of ' $B$.' mussettae into a new genus. The species 'Borealestes' mussettae was

871 erected based on the holotype lower molar and associated upper molars (Sigogneau-Russell

872 2003). However, the new material assigned to B. cuillinensis (NMS G.2020.4.1.1) herein

873 includes upper molars that match those assigned to 'B.' mussettae by Sigogneau-Russell

874 (2003) and Panciroli et al. (2019), confirming that all upper molar material previously assigned

875 to 'B.' mussettae belongs instead to $B$. cuillinensis. Therefore, the hypodigm of ' $B$.' mussettae 
876 now includes only lower molars, which can be compared to the type specimen (see Systematic 877 Palaeontology). Previous phylogenetic analysis that recovered 'B.' mussettae and $B$.

878 serendipitus as sister taxa was based on both the upper and lower molar characters (Panciroli 879 et al. 2019). These species were previously united particularly by the character of the presence 880 of an anterior fovea (sensu Panciroli et al. 2019) at the buccolingual midpoint of the upper 881 molar, a feature that can no longer be said to be present in ' $B$.' mussettae.

882 The remaining 'B.' mussettae lower molars differ significantly from those of Borealestes, 883 therefore it is justified to place it in the new genus, Dobunnodon. In Dobunnodon the a-g crest 884 is present on cusp $\mathrm{g}$ and cusp a, and there is a strong a-d crest on cusp a - both of these 885 features are absent in lower molars in Borealestes species (Fig. 6). Cusp g is slightly more 886 developed in Dobunnodon, and cusps $\mathrm{c}$ and $\mathrm{g}$ are placed further apart anteroposteriorly than in 887 Borealestes. The more developed cusp df - distinct from the $\mathrm{d}$ cusp - and the more central 888 position of the cusp e (mediolaterally) all differentiate this taxon from Borealestes. Based on 889 these differences and without the upper molar characters that had united these taxa in Panciroli 890 et al. (2019), we consider there to be sufficient grounds to separate these taxa at genus level. $B$. 891 serendipitus was named first, so we place 'B.' mussettae in the newly erected genus, 892 Dobunnodon, retaining the original species name (Sigogneau-Russell, 2003).

894 Crania

895 Anterior cranial elements

896 Borealestes serendipitus and Borealestes cuillinensis have similar elongate and slender 897 dentary morphology. Nevertheless, specimens available so far suggest they can be interpreted 898 as being distinguished by the morphology of the Meckel's sulcus, which is closed anterior to the 899 position of $\mathrm{m} 3$ in $B$. serendipitus but open in B. cuillinensis, and the mandibular symphysis, 900 which is more distinct in B. serendipitus than in B. cuillinensis. However, we accept that with 901 limited material in which the Meckel's sulcus is preserved, this character may be unreliable and 
902 show intraspecific variation. For example, the degree of development of anterior part of the

903 Meckel's sulcus may be age-dependent, as evidenced by growth series of mandibular

904 specimens of Docodon victor (Schultz et al. 2017). The degree to which the sulcus is open or

905 closed appears to be somewhat variable in specimens of Morganucodon watsoni (P. Gill pers.

906 comm.) and variable depending on developmental stage of the mandible in monotremes.

907 The holotype of B. cuillinensis (NMS G.2020.4.1.1) is overall smaller than B. serendipitus

908 NMS G. 1992.47.121.1 (and associated material) (Table 2). Size can be unreliable in

909 distinguishing between species, as differences in size may represent differences of growth

910 stage or intraspecific variation. However, patterns of dental eruption suggest that NMS

911 G.2020.4.1.1 is a fully grown adult, in spite of its smaller size. The ultimate lower molar of $B$.

912 cuillinensis (NMS G.2020.4.1.1) is in alignment with and anterior to the coronoid process on the

913 dentary (Fig. 10). In other docodontans with a growth series of younger to older individuals (e.g.,

914 Docodon victor, Schultz et al., 2019), the ultimate molar ends up in front of the coronoid process

915 in the older and fully adult individual as the jaw grows longer.

916 Most features of the anterior bones of the skulls of Borealestes are similar to those seen

917 in other docodontans, but particularly the long, gracile rostrum of Agilodocodon (Meng et al.,

918 2015). By comparison to the more complete basicranium with intact squamosal and petrosal of

919 Haldanodon (Lillegraven \& Krusat, 1991), for which there is a more recent reconstruction (Ruf et

920 al., 2013), we interpret that the squamosal projects far laterally, making the skull widest at this

921 point and giving the skull an overall triangular outline in the dorsal or the ventral views (Figs 8,

9229,19 and 21).

$923 \quad$ The anterior lower incisors of $B$. serendipitus are strongly procumbent, especially $\mathrm{i} 1$, as

924 seen in Agilodocodon. This characteristic was argued in Agilodocodon to suggest a possible

925 adaptation for exudativory, with this procumbent morphology resembling that seen in old world

926 monkeys that gnaw on bark to eat sap (Meng et al., 2015: 765). This would have been a

927 plausible feeding mode for an arboreal docodontan, but close comparison between extant 
928 exudativores and Agilodocodon does not support this idea, as these docodontans do not have 929 features such as restricted labial enamel, broad lower incisor girth, toothcombs and 'short930 tusked' canines (Wible \& Burrows, 2016). The morphology of the docodontan procumbent 931 incisors more closely resembles extant insectivorous mammals, such as macroscelideans, and 932 this is also supported by the molar morphology.

933 In the specimen of $B$. serendipitus, NMS G.1992.47.121.4, it is not entirely clear if the 934 premaxilla formed the posterior margin of 14 as in Haldanodon, or whether it was formed by the 935 maxilla. In B. cuillinensis NMS G.2020.4.1.1, the 14 alveolus is entirely within the maxilla, and 936 the 13 alveolus is formed by the premaxilla. In Morganucodon the premaxilla-maxillary suture is 937 located between I3 and I4, with I3 in the premaxilla and I4 in the maxilla (Kermack et al., 1981: 938 fig 80), whereas in Docodon apoxys this suture runs through the alveolus of 15 , and the 15 is 939 completely within the premaxilla (Rougier et al. 2015: fig 6). At the anterior end of the right 940 premaxilla in NMS G.1992.47.121.4 the probable stump of the internarial process, or the 941 median process of the premaxillary bone, can be identified, as in Haldanodon (Lillegraven \& 942 Krusat, 1991:59). This is a plesiomorphic feature retained in mammaliaforms, seen in all 943 docodontans (e.g., Luo et al. 2015b: fig. 1) and so although not preserved in NMS G.2020.4.1.1, 944 it was most likely present.

945 The vascular canals connecting the anterior premaxillary foramen anteriorly and laterally 946 are likely to be for the greater palatine nerve and artery, and similar vascular channels have 947 been traced in pre-mammalian cynodonts (Benoit et al., 2016). Some features observed in other 948 docodontans such as Haldanodon, that are not preserved in this specimen of $B$. serendipitus 949 include a bulging canine root in the maxilla, the position of the infraorbital foramen just posterior 950 to the canine, presence and position of the septomaxilla, and the "posterior salient" of the 951 premaxillary bone (Lillegraven \& Krusat, 1991: 46). The bulging canine root is present in this 952 specimen of $B$. cuillinensis, and the infraorbital foramen is located poster to the canine dorsal to 953 P5 (and smaller foramina are located anterior to the canine, and dorsal to M1). We have 
954 therefore reconstructed the missing portions of the skull of these species of Borealestes based

955 on the morphology of these features as present in B. cuillinensis, and as seen in other

956 docodontans, notably Agilodocodon (Figs 8 and 9).

957 The greater palatine foramen marks the edge of the palatal process of the maxilla in

958 NMS G.1992.47.121.1, medial to M2, and the palatal process of the maxillary bone may project

959 posteriorly into the palatal process of the palatine bone along the midline suture in NMS

960 G.1992.47.121.1 but it is unclear due to damage to the specimen (Fig. 13A). In B. cuillinensis

961 we interpret one fragment of bone as the palatal process of the maxilla, which has a projection

962 that would intrude posteriorly into the palatal process of the palatine bone. Such a projection is

963 not seen in Morganucodon nor Haldanodon. The position of the greater palatine foramen in $B$.

964 serendipitus differs from Haldanodon. In both taxa it is positioned medial and slightly anterior to

$965 \mathrm{M}$, and there is no greater palatine groove (unlike in Morganucodon). But in Haldanodon the

966 foramen is oblong, positioned closer to the midline suture, and on the edge of the palatine

967 process of the maxilla. It is not clear whether the posterior rim of the grater palatine foramen in

968 either species of Borealestes is formed by the palatine process of the palatine (as in

969 Haldanodon), but the foramen is more rounded in NMS G.1992.47.121.1, and positioned closer

970 to the toothrow (Fig. 13A).

971 Because the external aspect of the maxilla is dorsoventrally compressed in $B$.

972 serendipitus (NMS G.1992.47.121.1, Figs 13 and 14), the two posterior foramina appear

973 relatively small in comparison to the large infraorbital foramina in the maxilla in Docodon

974 (Schultz et al., 2017), Haldanodon (Lillegraven \& Krusat, 1991) and Docofossor (Luo et al.,

975 2015b). In B. cuillinensis (NMS G.2020.4.1.1) the foramen dorsal to P5 appears similar to the

976 large infraorbital foramina in these taxa (Fig. 15A1). Only the rounded posterior edge of the

977 anteriormost infraorbital foramen is preserved. In both Borealestes species these infraorbital

978 foramina are located more anteriorly in relation to the tooth row than in Docodon: in Docodon

979 two infraorbital foramina are located dorsal to the M1/M2 junction and roots of P4 on the lateral 
980 side of the maxilla (Schultz et al., 2017: fig. 9). In Haldanodon three foramina are located above 981 the roots of the penultimate and ultimate premolars, and the M1 (T. Martin, pers. com.).

982 The posteriorly mediolaterally broad nasals in B. serendipitus more closely resemble 983 Haldanodon in their width (Lillegraven \& Krusat, 1991:p46), than the slightly narrower skull of 984 Agilodocodon (Meng et al., 2015), or the greater extension of the maxillae and lacrimals dorsally 985 as seen in Morganucodon (Lillegraven \& Krusat, 1991). This accentuates the triangular dorsal 986 profile of the skull of $B$. serendipitus, exaggerated further by the wide zygomatic arches (see 987 below). The posterior nasal foramina in $B$. serendipitus are positioned approximately in line with 988 P4, which is more posteriorly positioned and fully enclosed by the nasal than in Haldanodon. As 989 in Haldanodon, but unlike Morganucodon, the nasals extend posteriorly to lie at least in line with 990 the base of the maxillary base of the zygomatic arch. Anteriorly the nasals of $B$. serendipitus 991 resemble Haldanodon, with a long projection of the nasal medial to the anterior nasal foramen. 992 The lacrimal, and what remains of the frontal, resemble other docodontans and basal 993 mammaliaforms such as Morganucodon.

Posterior cranial elements

The small sagittal crest along the unfused medial contact of the parietals of $B$.

997 serendipitus NMS G.1992.47.121.1 is similar to that seen in other docodontans, but is slightly 998 less prominent than in Haldanodon, or the geologically older basal mammaliaform 999 Morganucodon. The nuchal crest is also similar to other docodontans, notably Haldanodon. 1000 Both of these features are seen variably in other mammal groups, usually associated with 1001 muscular attachment and/or sexual dimorphism. However the interparietal described in 1002 Haldanodon is positioned posteriorly between the parietals and the dorsal edge of the 1003 postparietal (Lillegraven \& Krusat, 1991:77). In B. serendipitus, the postparietal sits against the 1004 parietal directly, and a small dorsal projection slots into the parietal suture to contribute to the 1005 small sagittal crest (Figs 8, 19D and 20). The bulge along the midline of the postparietal and the 
1006 foramina present on the dorsal lateral surface, indicate high vascularisation of this bone, and 1007 conform with the form of the postparietal in Haldanodon.

1008 The complete morphology of the petrosals of this specimen of $B$. serendipitus has been 1009 described previously (Panciroli et al., 2018a). The portion of squamosal preserved in NMS 1010 G.1992.47.121.1 includes the auditory meatus and the glenoid fossa, and suggests a gracile 1011 squamosal and jugal more like Agilodocodon (Meng et al., 2015) than the more robust 1012 squamosal and jugal of Haldanodon (Lillegraven \& Krusat, 1991). We interpret the squamosal to 1013 project far laterally, as in Haldanodon, giving the skull a triangular outline from above (Fig. 8).

1014 The squamosal of $B$. cuillinensis appears more robust than $B$. serendipitus, with a broader 1015 glenoid fossa and slightly deeper zygomatic process (Figs 9 and 21). It remains more gracile 1016 than that seen in Haldanodon. Most of the dorsal part of the squamosal cranial moiety is not 1017 preserved in either specimen of Borealestes, but the indentation on the posterolateral side of 1018 the parietal in NMS G.1992.47.121.1 suggests it was present and extended approximately a 1019 third of the way up the parietal dorsally (Fig. 20B and D), making it more similar to 1020 Morganucodon than Haldanodon. The squamosal glenoid and zygoma in Borealestes are 1021 similar to those of Haldanodon (Lillegraven \& Krusat, 1991; Ruf et al., 2013). The posteromedial 1022 portion of the squamosal (= the cranial moiety of the squamosal) posterior to the glenoid fossa 1023 is broken and displaced in B. serendipitus (NMS G.1992.47.121.1). However, on the cranial 1024 moiety there is the beginning of a strong dorsal ridge (Fig. 20B2)—possibly this ridge would join 1025 dorsally with the strong nuchal crest on the lateral aspect of the parietal (Fig. 20), which is the 1026 case in the preserved skull of Haldanodon (Lillegraven \& Krusat, 1991).

1027 The morphology of the occipital condyles in both Borealestes species resembles 1028 Haldanodon (Lillegraven \& Krusat, 1991; Ruf et al., 2013), and is little changed from other early 1029 mammaliaforms such as Sinoconodon, Morganucodon and Megazostrodon (Jenkins and 1030 Parrington, 1976; Kermack et al., 1981; Gow 1986; Crompton and Luo, 1993). 
1031 The crushing and flattening of the anterior dorsolateral surface of the parietal bone in 1032 NMS G.1992.47.121.1 B. serendipitus makes it unclear if the indentation there has resulted 1033 from pre- or post-depositional damage, or represents a ridge marking the posterodorsal overlap 1034 of the temporal bone. If it was the latter, this would suggest the bone located anteroventral to it 1035 was a fragment of the temporal region. However the indentation would suggest a strong finger1036 like projection of the temporal region, which is unlike that seen in other docodontans. 1037 1038 CONCLUSIONS

1039 The partial skeletons of Borealestes serendipitus and Borealestes cuillinensis comprise 1040 the most complete Mesozoic mammal skeletons reported from the British Isles to date. Their 1041 exceptional preservation - partially associated and with minimal compression - makes them 1042 globally significant. Being Bathonian in age, Borealestes is among the geologically oldest 1043 docodontans. It is of similar age to Castorocauda, Agilodocodon and Microdocodon of the 1044 Tiaojishan Formation directly dated to be about 165 Ma (Ji et al., 2006; Meng et al., 2015; Zhou 1045 et al., 2019), and to Itatodon, Hutegotherium and Simpsonodon from the Berezovsk site of the 1046 Middle Jurassic Itat Formation in West Siberia of Russia, which is also Bathonian (Averianov 1047 and Lopatin 2005; Averianov et al., 2010). These Borealestes species are of intermediate 1048 robustness compared to other docodontans, but share an elongate and slender dentary 1049 morphology more similar to Agilodocodon. Despite a consensus that Docodonta are closer to 1050 crown-group mammals than Sinoconodon and Morganucodonta, their skulls retain many 1051 plesiomorphic features seen in Sinoconodon, Morganucodon and Megazostrodon, such as the 1052 retention of postdentary bones, and internarial bar, and the morphology of the lacrimal, frontal, 1053 and occipital condyles. Most features of the anterior bones of the skulls of Borealestes are 1054 similar to those seen in other docodontans, but particularly the long, gracile rostrum of 1055 Agilodocodon. The structure of the petrosal, and complex cusp arrangement of the teeth, are 
1056 among the features that distinguish docodontans from other earlier diverging mammaliaforms 1057 clades.

1058 The surprising lack of distinguishing features between the lower molars of $B$.

1059 serendipitus and $B$. cuillinensis, means that these two taxa do not appear to be identifiable from 1060 individual lower molars alone. These species can be distinguished by their upper molars, and by 1061 the morphology of the Meckel's sulcus in the dentary (which is closed anterior to the position of $1062 \mathrm{~m} 3$ in B. serendipitus but open in B. cuillinensis) and the mandibular symphysis (which is more 1063 distinct in B. serendipitus than in in B. cuillinensis). This observation suggests potentially 1064 'hidden' species may be present in fossil assemblages that are not easily recognisable from 1065 isolated molars, and has implications for our picture of the taxonomic diversity of docodontans 1066 and Mesozoic mammals as a whole. 1067 1068 ACKNOWLEDGEMENTS

1069 EP was funded during part of this research by NERC grant number NE/L002558/1, with 1070 additional funding from the Palaeontographical Society and the Inverness Field Club. Many 1071 thanks to Scottish Natural Heritage and John Muir Trust for granting our permits for fieldwork 1072 each year on the Isle of Skye. We are grateful to all of the field work teams who have worked on 1073 Skye, including Michael Waldman (who has also provided many insights into the site), Andrzej 1074 Wolniewicz and Roger Close, who assisted with collection of specimens described herein. We 1075 acknowledge the European Synchrotron Radiation Facility for provision of synchrotron radiation 1076 facilities, and we would like to thank Paul Tafforeau for assistance in using beamline ID19. 1077 Thank you to Stephen Brusatte for his role as supervisor to EP, and along with lan Corfe and 1078 Florian Fusseis provided assistance in obtaining synchrotron beamtime. We would like to thank 1079 Tom Davies and lan Butler for their time and expertise acquiring CT scans. Tapadh leat to Sìne 1080 Ghilleasbuig, Dugald Ross, and Roddy Maclean for advice regarding the use of Scottish Gaelic 
1081 and local place names for naming. We thank Gemma Baker for insights into the stratigraphic 1082 position of NMS G.2020.4.1.1, based upon her undergraduate research project at the University 1083 of Birmingham. Many thanks for the detailed comments from our reviewers, Pamela Gill, 1084 Guillermo Rougier, and an anonymous reviewer, which helped improve this manuscript. 1085 1086 REFERENCES

1087 Andrews JE. 1985. The sedimentary facies of a late Bathonian regressive episode: the 1088 Kilmaluag and Skudiburgh Formations of the Great Estuarine Group, Inner Hebrides, Scotland. 1089 Journal of the Geological Society of London 142: 1119-1137. 1090

Anquetin J. 2009. A new stem turtle from the Middle Jurassic of Scotland: new insights into the 1092 evolution and palaeoecology of basal turtles. Proceedings of the Royal Society B 276: 879-886. 1093

Anquetin J. 2010. The anatomy of the basal turtle Eileanchelys waldmani from the Middle 1095 Jurassic of the Isle of Skye, Scotland. Earth and Environmental Science Transactions of the 1096 Royal Society of Edinburgh 101: 67-96.

1097

1098 Averianov AO. 2004. Interpretation of the Early Cretaceous mammal Peraiocynodon 1099 (Docodonta) and taxonomy of some British Mesozoic docodonts. Russian Journal of Theriology 1100 3: $1-4$.

Averianov AO, Lopatin AV. 2006. Itatodon tatarinovi (Tegotheriidae, Mammalia), a docodont 1103 from the Middle Jurassic of Western Siberia and phylogenetic analysis of Docodonta.

1104 Paleontological Journal 40: 668-677. 
1106 Averianov AO, Lopatin AV, Krasnolutskii SA, Ivantson SV. 2010. New docodontans from 1107 the Middle Jurassic of Siberia and reanalysis of Docodonta interrelationships. Proceedings of 1108 the Zoological Institute of Russian Academy of Sciences 314: 121-148.

Averianov AO, Martin T, Lopatin AV, Skutschas P, Schellhorn R, Kolosov P, Vitenko, D. 2018. A high-latitude fauna of mid-Mesozoic mammals from Yakutia, Russia. PLoS One 13: e0199983.

1113

Barrett PM. 2006. A sauropod dinosaur tooth from the Middle Jurassic of Skye, Scotland.

Transactions of the Royal Society of Edinburgh: Earth Sciences 97: 25-29.

Barron AJM, Lott GK, Riding JB. 2012. Stratigraphic Framework for the Middle Jurassic

Strata of Great Britain and the Adjoining Continental Shelf: Research Report RR/11/06. British

1119 Geological Survey, Keyworth. 177 pp.

Benoit J, Manger PR, Rubidge BS. 2016. Palaeoneurological clues to the evolution of defining 1122 mammalian soft tissue traits. Scientific reports 6: 25604.

Chen M, Luo Z-X, Wilson GP. 2017. The postcranial skeleton of Yanoconodon allini from the 1125 Early Cretaceous of Hebei, China, and its implications for locomotor adaptation in 1126 eutriconodontan mammals. Journal of Vertebrate Paleontology 37: e1315425.

1128 Chen PJ, Hudson JD. 1991. The conchostracan fauna of the Great Estuarine Group, Middle 1129 Jurassic, Scotland. Palaeontology 34: 515-545. 
1131 Close RA, Davis BM, Walsh S, Woloniewicz AS, Friedman M, Benson RBJ. 2016. A lower 1132 jaw of Palaeoxonodon from the Middle Jurassic of the Isle of Skye, Scotland, sheds new light on 1133 the diversity of British stem therians. Palaeontology 59: 155-169.

Crompton, AW, Luo Z-X. 1993. Relationships of the Liassic mammals Sinoconodon,

Morganucodon, and Dinnetherium. In: Szalay FS, Novacek MJ, and McKenna MC eds. Mammal

1137 Phylogeny: Mesozoic Differentiation, Multituberculates, Monotremes, Early Therians, and

1138 Marsupials. New York: Springer-Verlag, 30-44.

1139

1140 Datta PM. 2005. Earliest mammal with transversely expanded upper molar from the Late

1141 Triassic (Carnian) Tiki Formation, South Rewa Gondwana Basin, India. Journal of Vertebrate 1142 Paleontology 25: 200-207.

1143

1144 Evans SE. 1992. Small reptiles and amphibians from the Forest Marble (Middle Jurassic) of

1145 Dorset. Proceedings of the Dorset Natural History and Archaeological Society 113: 201-202. 1146

1147 Evans SE, Waldman M. 1996. Small reptiles and amphibians from the Middle Jurassic of Skye 1148 Scotland. In: Morales M. ed. The Continental Jurassic, Museum of Northern Arizona Bulletin 60: $1149219-226$.

1150

1151 Gambaryan PP, Kuznetsov AN, Panyutina AA, Gerasimov SV. 2015. Shoulder girdle and 1152 forelimb myology of extant Monotremata. Russian Journal of Theriology 14: 1-56.

1154 Gingerich PD. 1973. Molar occlusion and function in the Jurassic mammal Docodon. Journal of 1155 Mammalogy 254: 1008-1013. 
1157 Gow CE. 1986. A new skull of Megazostrodon (Mammalia: Triconodonta) from the Elliot

1158 Formation (Lower Jurassic) of southern Africa. Palaeontologia Africana 26: 13-23.

1159

1160 Harper T, Rougier GW. 2019. Petrosal morphology and cochlear function in Mesozoic stem 1161 therians. PLoS ONE 14: e0209457.

1162

1163 Harris JP, Hudson JD. 1980. Lithostratigraphy of the Great Estuarine Group (Middle Jurassic), 1164 Inner Hebrides. Scottish Journal of Geology 16: 231-250.

1165

1166 Hu YM, Meng J, Clark JM. 2007. A new Late Jurassic docodont (Mammalia) from northeastern 1167 Xinjiang, China. Vertebrata Palasiatica 45 :173-194.

1168

1169

Jenkins Jr FA. 1969. Occlusion in Docodon (Mammalia, Docodonta). Postilla 139: 1-24.

1170

1171 Jenkins Jr FA, Parrington FR. 1976. The postcranial skeletons of the Triassic mammals

1172 Eozostrodon, Megazostrodon and Erythrotherium. Philosophical Transactions of the Royal

1173 Society of London B Biological Sciences 273: 387-431

1174

1175 Ji Q, Luo Z-X, Yuan C-X, Tabrum AR. 2006. A swimming mammaliaform from the Middle

1176 Jurassic and ecomorphological diversification of early mammals. Science 311: 1123-1127. 1177

1178 Judd JW. 1878. The secondary rocks of Scotland. Third paper. The strata of the western coasts 1179 and islands. Quarterly Journal of the Geological Society of London 34: 660-743.

1181 Kermack KA, Mussett F, Rigney HW. 1981. The skull of Morganucodon. Zoological Journal of 1182 the Linnean Society 71: 1-158. 
1184 Kielan-Jaworowska Z, Cifelli RL, Luo Z-X. 2004. Mammals from the Age of Dinosaurs:

1185 Origins, Evolution, and Structure. New York: Columbia University Press.

1186

1187 Kretzoi M. 1946. On Docodonta, a new order of Jurassic Mammals. Anneles Historico1188 Naturales Musei Nationalis Hungarici 39: 108-111.

1189

1190

Kühne WG. 1956. The Liassic therapsid Oligokyphus. London: British Museum (Natural 1191 History).

1192

1193

Lillegraven JA, Krusat G. 1991. Cranio-mandibular anatomy of Haldanodon exspectatus 1194 (Docodonta; Mammalia) from the Late Jurassic of Portugal and its implications to the evolution 1195 of mammalian characters. Contributions to Geology, University of Wyoming 28: 39-138.

Luo Z-X. 1994. Sister taxon relationships of mammals and the transformation of the diagnostic 1198 mammalian characters. pp. 98-128. In Fraser NC, and Sues H-D, eds. The Shadow of 1199 Dinosaurs: Early Mesozoic Tetrapods. Cambridge: Cambridge University Press.

Luo Z-X, Kielan-Jaworowska Z, RL Cifelli. 2002. In quest for a phylogeny of Mesozoic 1202 mammals. Acta Palaeontological Polonica 47: 1-78.

Luo Z-X, Gatesay SM, Jenkins FA, Amaral AA, Shubin NH. 2015a. Mandibular and dental 1205 characteristics of Late Triassic mammaliaform Haramiyavia and their ramifications for basal 1206 mammal evolution. Proceedings of the National Academy of Sciences 112: E7101-E7109. 
1208 Luo Z-X, Meng Q-J, Ji Q, Liu D, Zhang Y-G, Neander Al. 2015b. Evolutionary development in 1209 basal mammaliaforms as revealed by a docodontan. Science 347: 760-764.

1210

1211 Luo Z-X, Meng Q-J, Grossnickle DM, Liu D, Zhang Y-G, Neander AI, Ji Q. 2017. New

1212 evidence for mammaliaform ear evolution and feeding adaptation in a Jurassic ecosystem.

$1213 \quad$ Nature 548: 326-329.

1214

1215 Lyckegaard A., Johnson G., Tafforeau P. 2011. Correction of ring artifacts in X-ray

1216 tomographic images. International Journal of Tomography and Statistics 18: 1-9.

1217

1218 Martin T. 2005. Postcranial anatomy of Haldanodon exspectatus (Mammalia, Docodonta) from

1219 the Late Jurassic (Kimmeridgian) of Portugal and its bearing for mammalian evolution.

1220 Zoological Journal of the Linnean Society 145: 219-248.

1221

1222 Martin T. 2006. Early mammalian evolutionary experiments. Science 311: 1109-1110.

1223

1224 Martin T. 2008. Mesozoic mammals - early mammalian diversity and ecomorphological

1225 adaptations. In: Zachos FE, Asher AJ, eds. Handbook of Zoology, Mammalia, Mammalian

1226 Evolution, Diversity and Systematics. Berlin: De Gruyter, 199-299.

1227

1228 Martin T, Averianov AO, Pfretzschner H-U. 2010. Mammals from the Late Jurassic Qigu

1229 Formation in the Southern Junggar Basin, Xinjiang, Northwest China. Palaeobiodiversity and

1230 Palaeoenvironment 90: 295-319.

1231 
1232 Maschenko EN, Lopatin AV, Voronkevich AV. 2002. A new genus of the tegotheriid 1233 docodonts (Docodonta, Tegotheriidae) from the Early Cretaceous of West Siberia. Russian 1234 Journal of Theriology 1: 75-81.

1235

1236

Meng Q-J, Ji Q, Zhang Y-G, Liu D, Grossnickle DM, Luo Z-X. 2015. An arboreal docodont 1237 from the Jurassic and mammaliaform ecological diversification. Science 347: 764-768. 1238

Mirone A, Brun E, Gouillart E, Tafforeau P, Kieffer J. 2014. The PyHST2 hybrid distributed 1240 code for high speed tomographic reconstruction with iterative reconstruction and a priori 1241 knowledge capabilities. Nuclear Instruments and Methods in Physics Research Section B: Beam Interactions with Materials and Atoms 324: 41-48.

Morton N, Hudson JD. 1995. Field guide to the Jurassic of the Isles of Raasay and Skye, Inner 1245 Hebrides, NW Scotland. In: Taylor PD, ed. Field Geology of the British Jurassic. London: Geological Society, 209-280.

Paganin D., Mayo S., Gureyev T.E., Miller P.R.\& Wilkins S.W. 2002. Simultaneous phase 1249 and amplitude extraction from a single defocused image of a homogeneous object. Journal of 1250 Microscopy 206: 33-40.

1251

1252 Panciroli E, Benson RBJ, Walsh S. 2017a. The dentary of Wareolestes rex

1253 (Megazostrodontidae): a new specimen from Scotland and implications for morganucodontan 1254 tooth replacement. Papers in Palaeontology 3: 373-386.

1256 Panciroli E, Walsh S, Fraser N, Brusatte SL, Corfe I. 2017b. A reassessment of the 1257 postcanine dentition and systematics of the tritylodontid Stereognathus (Cynodontia, 
1258 Tritylodontidae, Mammaliamorpha), from the Middle Jurassic of the UK. Journal of Vertebrate 1259 Paleontology 37: 373-386.

1260

1261 Panciroli E, Schultz JA, Luo Z-X. 2018a. Morphology of the petrosal and stapes of 1262 Borealestes (Mammaliaformes, Docodonta) from the Middle Jurassic of Skye, Scotland. Papers 1263 in Palaeontology 5: 139-156.

1264

1265

Panciroli E, Benson RBJ, Butler RJ. 2018b. New partial dentaries of Palaeoxonodon ooliticus

1266

(Mammalia, Amphitheriidae) from Scotland, and posterior dentary morphology in stem

1267 cladotherians. Acta Palaeontologica Polonica 63: 197-206.

1268

1269

Panciroli E, Benson RBJ, Luo Z-X. 2019. The mandible and dentition of Borealestes

1270

serendipitus (Docodonta) from the Middle Jurassic of Skye, Scotland. Journal of Vertebrate

1271

Paleontology 39: p.e1621884.

1272

1273

Panciroli E, Benson RBJ, Walsh S, Butler RJ, Castro TA, Jones MEH, Evans SE. 2020.

1274

Diverse vertebrate assemblage of the Kilmaluag Formation (Bathonian, Middle Jurassic) of

1275 Skye, Scotland. Earth and Environmental Science Transactions of the Royal Society of

1276 Edinburgh (accepted).

1277

1278 Rees J, Underwood CJ. 2005. Hybodont sharks from the Middle Jurassic of the Inner

1279 Hebrides, Scotland. Earth and Environmental Science Transactions of the Royal Society of

1280 Edinburgh 96: 351-363.

1281

1282 Rougier GW, Sheth AS, Carpenter K, Appella-Guisafre L, Davis BM. 2015. A new species of

1283 Docodon (Mammaliaformes, Docodonta) from the Upper Jurassic Morrison Formation and a 
1284 reassessment of selected craniodental characters in basal mammaliaforms. Journal of 1285 Mammalian Evolution 22: 1-16.

1286

1287 Rowe T. 1988. Definition, diagnosis and origin of Mammalia. Journal of Vertebrate Paleontology 1288 8: $241-264$.

1289 Rowe TB, Macrini TE, Luo Z-X. 2011. Fossil evidence on origin of the mammalian brain. 1290 Science. 332: 955-957.

1291

1292

Ruf I, Luo Z-X, Martin T. 2013. Reinvestigation of the basicranium of Haldanodon exspectatus 1293 (Mammaliaformes, Docodonta). Journal of Vertebrate Paleontology 33: 382-400.

Schultz JA, Bhullar BAS, Luo Z-X. 2017. Re-examination of the Jurassic mammaliaform

Docodon victor by computed tomography and occlusal functional analysis. Journal of 1297 Mammalian Evolution 26: 9-38.

1298

1299

Sigogneau-Russell D. 2003. Docodonts from the British Mesozoic. Acta Palaeontologica 1300 Polonica 48: 357-374.

1301

Sigogneau-Russell D, Hahn R. 1995. Reassessment of the Late Triassic symmetrodont 1303 mammal Woutersia. Acta Palaeontologica Polonica 40: 245-260.

Simpson GG. 1929. American Mesozoic Mammalia. Memoirs of the Peabody Museum of Yale 1306 University 3: 1-235.

1308 Sues HD, Jenkins Jr FA. 2006. The postcranial skeleton of Kayentatherium wellesi from the 1309 Lower Jurassic Kayenta Formation of Arizona and the phylogenetic significance of postcranial 
1310 features in tritylodontid cynodonts. In: Carrano MT, ed. Amniote Paleobiology: Perspectives on 1311 the Evolution of Mammals, Birds, and Reptiles. Chicago: University of Chicago Press, 114-152.

1313 Swofford, D.L. 2003. PAUP*. Phylogenetic Analysis Using Parsimony ( ${ }^{*}$ and Other Methods).

1314 Version 4. Sinauer Associates, Sunderland, Massachusetts.

1315

1316 Wakefield MI. 1995. Ostracod biostratinomy at lagoonal shorelines: examples from the Great

1317 Estuarine Group, Middle Jurassic, Scotland. Proceedings of the Geologists' Association 106:

$1318 \quad 211-218$.

1319

1320

Waldman M, Evans SE. 1994. Lepidosauromorph reptiles from the Middle Jurassic of Skye.

1321 Zoological Journal of the Linnean Society 112: 135-150.

1322

1323 Waldman M, Savage RJG. 1972. The first Jurassic mammal from Scotland. Journal of the 1324 Geological Society of London 128: 119-125.

1325

1326

Wible JR, Hopson JA. 1993. Basicranial evidence for early mammal phylogeny. In: Szalay FS,

1327 Novacek MJ, McKenna MC, eds. Mammal phylogeny: Mesozoic differentiation,

1328 multituberculates, monotremes, early therians and marsupials. New York: Springer, 45-62.

1329

1330 Wible JR, Burrows AM. 2016. Does the Jurassic Agilodocodon (Mammaliaformes, Docodonta)

1331 have any exudativorous dental features? Palaeontologia Polonica 67: 289-299.

1332

1333 Wills S, Barrett PM, Walker A. 2014. New dinosaur and crocodylomorph material from the 1334 Middle Jurassic (Bathonian) Kilmaluag Formation, Skye, Scotland. Scottish Journal of Geology 1335 50: 183-190. 
1337 Zhou CF, Wu S, Martin T, Luo Z-X. 2013. A Jurassic mammaliaform and the earliest 1338 mammalian evolutionary adaptations. Nature 500: 163-167.

Zhou C-F, Bhullar, B-AS, Neander Al, Martin T. Luo Z-X. 2019. New Jurassic mammaliaform sheds light on early evolution of mammal-like hyoid bones. Science 365: 276-279.

FIGURE LEGENDS

1344 Figure 1: The stratigraphy of the Great Estuarine Group, and location of type locality of 1345 Borealestes serendipitus NMS G.1992.141.1 and Borealestes cuillinensis sp. nov. NMS 1346 G.2020.4.1.1, Cladach a'Ghlinne near Elgol.

1347 Figure 2: Borealestes serendipitus cranial elements (NMS G.1992.47.121.1) Visualisation from 1348 synchrotron $\mu$ CT data. A, NMS G.1992.47.121.1, showing location of cranial elements; $B$, digital 1349 rendering of surface of NMS G.1992.47.121.1; C, digital rendering of surface of NMS 1350 G.1992.47.121.1 with matrix semitransparent, showing skeletal elements within the block. Scale 1351 bar equals $10 \mathrm{~mm}$.

1352 Figure 3: Borealestes cuillinensis sp. nov. cranial elements (NMS G.2020.4.1.1 parts AA and 1353 BB) visualisation from $\mu C T$ data. $A$, digital rendering of surface of NMS G.2020.4.1.1; $B$, digital 1354 rendering of NMS G.2020.4.1.1 with matrix semitransparent, showing cranial skeletal elements 1355 within the block. Scale bar equals $10 \mathrm{~mm}$.

1356 Figure 4: Phylogeny of Docodonta based on updated phylogenetic analysis. Strict consensus of 1357 six trees of 131 steps resulting from parsimony analysis of data matrix for docodontans and 1358 outgroups as in Panciroli et al. (2019), with the addition of Borealestes cuillinensis and revision 
1359 of Dobunnodon (='Borealestes' mussettae). First-to-last appearances represented by black bars 1360 (see Supplementary). Nodes uniting taxa do not imply divergence times.

1362 Figure 5: Diagnostic dental features of Borealestes species, and Dobunnodon gen. nov. A, 1363 Borealestes serendipitus: A1, NMS G.1992.47.121.1 left M3 (mirrored) in occlusal view 1364 alongside diagrammatic illustration; A2, holotype BRSUG 20570 right m2 (mirrored) in occlusal 1365 view, cusps only, alongside diagrammatic illustration; and A3, BRSUG 20570 right m2 1366 (mirrored) crests only; A4 BRSUG 20570 right m2 (mirrored) in lingual view alongside 1367 diagrammatic illustration. B, Borealestes cuillinensis: B1, NMS G.2020.4.1.1 right M3 in occlusal 1368 view alongside diagrammatic illustration; B2, NHMUK PV M46871 left upper molar in occlusal 1369 view (mirrored) with cusps marked; B3, NMS G.2020.4.1.1 m2 in occlusal view; and B4 NMS 1370 G.2020.4.1.1 m2 in lingual view with cusps alongside diagrammatic illustration. C, Dobunnodon 1371 mussettae gen. nov.: C1, holotype NHMUK PV M46495 lower right molar in occlusal view with 1372 crests and diagrammatic illustration below; C2, holotype NHMUK PV M46495 mirrored for 1373 comparison and diagrammatic illustration below, C3, holotype NHMUK PV M46495 lingual view 1374 with crests and diagrammatic illustration below; C4, holotype NHMUK PV M46495 mirrored for 1375 comparison. A and C adapted from Panciroli et al. (2019). Darker grey areas indicate broken 1376 surfaces. Scale bars equal $1 \mathrm{~mm}$.

1377 Figure 6: Dentition of Borealestes serendipitus and Borealestes cuillinensis for comparison. A 1378 and C. Borealestes serendipitus upper dentition of NMS G.1992.47.121.1 and lower dentition of 1379 NMS G.1992.47.121.3 (C mirrored for comparison). B and D Borealestes cuillinensis NMS 1380 G.2020.4.1.1. Scale bars equal $1 \mathrm{~mm}$.

1381 Figure 7: Diagnostic mandibular features of Borealestes species. A1 and A2 dentaries belong to 1382 Borealestes serendipitus, showing diagnostic features of Meckel's sulcus and mandibular 
1383 symphysis. Bottom dentary B, belongs to Borealestes cuillinensis. Shows diagnostic features of 1384 Meckel's sulcus and mandibular symphysis. Scale bar equals $1 \mathrm{~mm}$, scale same throughout.

1385 Figure 8: Skull reconstruction of Borealestes serendipitus in lateral (top) dorsal (middle) and 1386 ventral (bottom) views. Green shaded areas represented in specimen NMS G.1992.47.121.1 1387 and associated material. Dotted lines indicate unrepresented areas where boundaries unknown. 13881 Premaxilla; 2 anterior nasal foramina; 3 maxilla; 4 infraorbital foramen; 5 posterior nasal 1389 foramen; 6 lacrimal; 7 nasal; 8 lacrimal foramen; 9 zygomatic process of lacrimal; 10 jugal (not 1390 known); 11 infraorbital foramen; 12 frontal; 13 parietal; 14 interparietal suture; 15 sagittal crest; 139116 squamosal; 17 dorsal flange of squamosal; 18 postparietal; 19 occipital condyles; 20 midline 1392 ridge of postparietal; 21 postparietal foramina; 22 septomaxilla; 23 anterior projection of nasal; 139324 internarial bar; 25 anterior premaxillary foramen; 26 incisive foramen; 27 palatal posterior 1394 salient of premaxilla; 28 greater palatine foramen; 29 palatal process (not known); 30 glenoid 1395 fossa; 31 external auditory meatus; 32 fenestra vestibuli; 33 pars cochlearis; 34 orbital area (not 1396 known); 35 basicranium (not known); 36 pterygoid and basicranium (not known); 37 primary 1397 palate (not known); 38 I3 foramen; 39 posterior projection of premaxilla into incisive foramen; 40 1398 coronoid process; 41 nuchal crest; 42 angular process of dentary; 43 masseteric foramen; 44 1399 dentary; 45 mental foramen; 46 anterior premaxillary foramen. Scale bar equals $5 \mathrm{~mm}$.

1400 Figure 9: Skull reconstruction of Borealestes cuillinensis in lateral (top) dorsal (middle) and 1401 ventral (bottom) views. Blue shaded areas represented in specimen NMS G.2020.4.1.1. Dotted 1402 lines indicate unrepresented areas where boundaries unknown. 1 Premaxilla; 2 anterior nasal 1403 foramina; 3 maxilla; 4 infraorbital foramen; 5 posterior nasal foramen (not known); 6 lacrimal; 7 1404 nasal; 8 lacrimal foramen; 9 zygomatic process of lacrimal; 10 jugal (not known); 11 infraorbital 1405 foramen (not known); 12 frontal (not known); 13 parietal (not known); 14 interparietal suture; 15 1406 sagittal crest (not known); 16 squamosal; 17 dorsal flange of squamosal; 18 postparietal (not 1407 known); 19 occipital condyles; 20 midline ridge of postparietal; 21 postparietal foramina; 22 
1408 septomaxilla; 23 anterior projection of nasal; 24 internarial bar; 25 anterior premaxillary foramen 1409 (not known); 26 incisive foramen; 27 palatal posterior salient of premaxilla (not known); 28 1410 greater palatine foramen; 29 palatal process (not known); 30 glenoid fossa; 31 external auditory 1411 meatus; 32 fenestra vestibuli; 33 pars cochlearis; 34 orbital area (not known); 35 basicranium 1412 known); 36 pterygoid and basicranium (not known); 37 primary palate (not known); 38 I3 1413 foramen (not known); 39 posterior projection of premaxilla into incisive foramen (not known); 40 1414 coronoid process; 41 nuchal crest (not known); 42 angular process of dentary; 43 masseteric 1415 foramen; 44 dentary; 45 mental foramen; 46 anterior premaxillary foramen. Scale bar equals 5 $1416 \mathrm{~mm}$.

1417 Figure 10: Borealestes cuillinensis sp. nov. (holotype, NMS G.2020.4.1.1) left mandible, A, 1418 occlusal view; B, lateral view; C, lingual view. Arrows indicate anterior direction. The triangle 1419 indicates the alignment of the ultimate molar to the coronoid process. Angular process broken 1420 during preparation and replaced digitally, broken lines indicate missing piece of process. Scale 1421 bar equals $1 \mathrm{~mm}$, scale same throughout.

1422 Figure 11: Borealestes cuillinensis (holotype, NMS G.2020.4.1.1) anterior part of right dentary 1423 and right premaxilla. $A$, right dentary: $A 1$, right lateral view; $A 2$, lingual view; $A 3$, occlusal view. $1424 \mathrm{~B}$, fragment of right premaxilla: B1, right lateral view; B2, occlusal view. Arrows indicate anterior 1425 direction. Scale bar equals $1 \mathrm{~mm}$, scale same throughout.

1426 Figure 12: Borealestes serendipitus skull elements. Premaxillae with incisors and anterior nasal 1427 part (NMS G.1992.47.121.4), with diagrammatic illustrations; A1, left lateral view; A2, right 1428 lateral view; A3, anterior view; A4, dorsal view; A5, ventral view; A6, semitransparent digital 1429 rendering of reconstructed premaxillae and incisors, showing path of premaxillary canal. B, 1430 Nasal anterior part: B1 ventral view; B2, medial view; B3, dorsal view; B4, left lateral view. 1431 Arrows indicate anterior direction. Dark grey areas on diagrammatic illustrations indicate broken 1432 surfaces. Scale bar equals $1 \mathrm{~mm}$, scale same throughout. 
1433 Figure 13: Borealestes serendipitus (NMS G.1992.47.121.1) palatal portion of cranium and right 1434 lacrimal. A, ventral view; A2, right lateral view with diagrammatic illustration below; $B$, right 1435 lacrimal (see also Fig. 13); B1, right posterolateral view; B2, dorsal view; B3, medial view; B4 1436 right lateral view. Arrows indicate anterior direction. Dark grey areas on diagrammatic 1437 illustrations indicate broken surfaces. Scale bar equals $1 \mathrm{~mm}$, scale same throughout.

1438 Figure 14: Borealestes serendipitus (NMS G.1992.47.121.1) palatal portion of cranium and left 1439 lacrimal. A, virtual slice from synchrotron $\mu \mathrm{CT}$ showing cross-section of palate; $\mathrm{B}$, dorsal view 1440 with diagrammatic illustration below; C, left lacrimal: C1, dorsal view; C2, left lateral view; C3 1441 medial view; C4, ventral view. Arrows indicate anterior direction. Dark grey areas on 1442 diagrammatic illustrations indicate broken surfaces. Scale bar equals $1 \mathrm{~mm}$, scale same 1443 throughout.

1444 Figure 15: Borealestes cuillinensis (holotype, NMS G.2020.4.1.1) left maxilla. A, left maxilla with 1445 diagrammatic illustrations: A1, left lateral view; A2, occlusal view; A3, dorsal/endocranial view. 1446 Arrows indicate anterior direction. Dark grey areas on diagrammatic illustrations indicate broken 1447 surfaces. Scale bar equals $1 \mathrm{~mm}$, scale same throughout.

1448 Figure 16: Borealestes cuillinensis (holotype NMS G.2020.4.1.1) right maxilla and palatal 1449 process. A, posterior portion of right maxilla: A1, right lateral view; A2, occlusal view; A3, 1450 dorsal/endocranial view. B, palatal process of right maxilla: B1, dorsal/endocranial view; B2, 1451 ventral/palatal view; B3, medial view. Arrows indicate anterior direction. Scale bar equals $1 \mathrm{~mm}$, 1452 scale same throughout.

1453 Figure 17: Borealestes cuillinensis (holotype, NMS G.2020.4.1.1) nasals and ?lacrimal. A, right 1454 nasals: A, ventral/endocranial view; A2, dorsal view; A3, medial view. B, right ?nasal: B1, dorsal 1455 view; B2, lateral view; B3, medial/endocranial view. Arrows indicate anterior direction. Scale bar 1456 equals $1 \mathrm{~mm}$, scale same throughout. 
1457 Figure 18: Borealestes cuillinensis (holotype, NMS G.2020.4.1.1) right lacrimal and 1458 diagrammatic illustrations: A1, right lateral view; C2, endocranial view; C3, dorsal view. Arrows 1459 indicate anterior direction. Dark grey areas on diagrammatic illustrations indicate broken 1460 surfaces. Scale bar equals $1 \mathrm{~mm}$, scale same throughout.

1461 Figure 19: Borealestes serendipitus (NMS G.1992.47.121.1) elements of cranium. A, left frontal:

1462 A1, synchrotron $\mu$ CT slice showing cross section through left frontal; A2, ventral view; A3, 1463 dorsal view; A4, medial view; A5, left lateral view. B the left squamosal, reconstructed (originally 1464 in two misaligned pieces): B1, ventral view; B2, dorsal view; C, the occipital condyles. D, 1465 postparietal: D1, posterodorsal view; D2, virtual slice from synchrotron $\mu C T$ showing cross 1466 section through postparietal; D3, anterior/endocranial view; D4, anteroventral view. Arrows 1467 indicate anterior direction. Scale bar equals $1 \mathrm{~mm}$, scale same throughout.

1468 Figure 20: Borealestes serendipitus (NMS G.1992.47.121.1) left parietal. A, endocranial/ventral 1469 view; B, dorsal view; C, medial view; D, left lateral view. Arrows indicate anterior direction. Scale 1470 bar equals $1 \mathrm{~mm}$, scale same throughout.

1471 Figure 21: Borealestes cuillinensis (holotype, NMS G.2020.4.1.1) squamosal and occipitals. A, 1472 the right squamosal: $A 1$, ventral view; $A 2$, dorsal view; $A 3$, medioventral view; $A 4$, laterodorsal 1473 view; A5, right lateral view. B, the anterior tip of the left squamosal of (zygomatic process): B1, 1474 dorsal view; B2, ventral view; B3, lateral view. C, the occipital condyles: C1, condyles as 1475 preserved in specimen; C2, condyles reconstructed. Arrows indicate anterior direction. Scale 1476 bar equals $1 \mathrm{~mm}$, scale same throughout. 
1479 Table 1: List of parameters used for XCT acquisition of the specimens. N. of Proj = number of 1480 projections; fr. av. = frame averaging; UoB = University of Bristol; UoE = University of 1481 Edinburgh. Asterisk indicated data is missing.

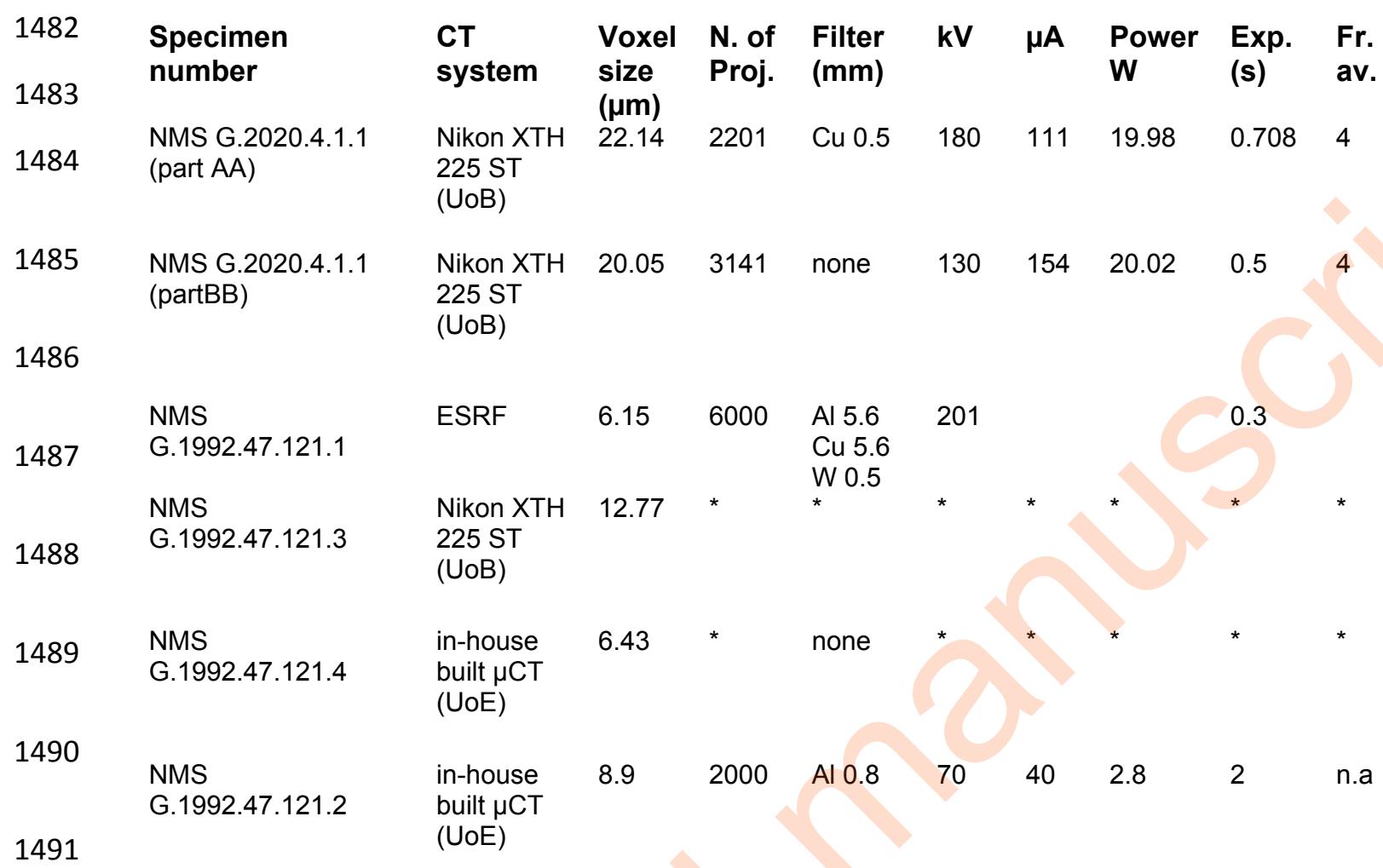


Table 2: Measurements of the dentition of Borealestes and Dobunnodon. All measurements in mm. Methodology as for Panciroli et al. (2019)

\begin{tabular}{|c|c|c|c|c|c|c|c|c|c|c|c|c|c|}
\hline & $(\mathrm{mm})$ & & $\begin{array}{l}\mathrm{cl} \\
\mathrm{C}\end{array}$ & $\begin{array}{l}\mathrm{pm} 1 / \\
\mathrm{PM} 1\end{array}$ & $\begin{array}{l}\text { pm2/ } \\
\text { PM2 }\end{array}$ & $\begin{array}{l}\text { pm3/ } \\
\text { PM3 }\end{array}$ & $\begin{array}{l}\text { pm4/ } \\
\text { PM4 }\end{array}$ & $\begin{array}{l}\text { pm5/ } \\
\text { PM5 }\end{array}$ & $\begin{array}{l}\mathrm{m} 1 / \\
\mathrm{M} 1\end{array}$ & $\begin{array}{l}\mathrm{m} 2 / \mathrm{M} \\
2\end{array}$ & $\begin{array}{l}\text { m3/ } \\
\text { M3 }\end{array}$ & $\begin{array}{l}\mathrm{m} 4 / \\
\mathrm{M} 4\end{array}$ & $\begin{array}{l}\text { m5/ } \\
\text { M5 }\end{array}$ \\
\hline \multicolumn{14}{|l|}{ Lower tooth row } \\
\hline \multirow{4}{*}{ NMS G.1992.47.121.3 } & \multirow{2}{*}{ Length } & $d$ to $b$ & - & - & 0.84 & 1.04 & 1.15 & 1.25 & 1.38 & 1.47 & 1.5 & 1.33 & 0.93 \\
\hline & & df to $e$ & - & - & - & - & - & - & 1.35 & 1.41 & 1.49 & 1.31 & 0.85 \\
\hline & \multirow{2}{*}{ Width } & cross $\mathrm{C}$ & - & 0.36 & 0.39 & 0.42 & 0.46 & 0.48 & 0.79 & 0.89 & 0.97 & 0.78 & 0.43 \\
\hline & & cross $\mathrm{g}$ & - & - & - & - & - & - & 0.69 & 0.83 & 0.92 & 0.83 & 0.57 \\
\hline \multirow{4}{*}{$\begin{array}{l}\text { NMS G.2020.4.1.1 (B. } \\
\text { cuillinensis) (ant right } \\
\text { dentary) }\end{array}$} & \multirow{3}{*}{ Length } & $d$ to $b$ & 0.73 & 0.63 & 0.74 & 0.95 & 1.10 & 1.1 & 1.32 & 1.42 & - & - & - \\
\hline & & df to $e$ & - & - & - & - & - & - & 1.4 & 1.33 & - & - & - \\
\hline & & cross $\mathrm{C}$ & 0.43 & 0.34 & 0.34 & 0.32 & 0.47 & 0.48 & 0.56 & 0.64 & - & - & - \\
\hline & Width & cross $\mathrm{g}$ & - & - & - & - & - & - & 0.71 & 0.68 & - & - & - \\
\hline \multirow{4}{*}{$\begin{array}{l}\text { NMS G.2020.4.1.1 (B. } \\
\text { cuillinensis) (post left } \\
\text { dentary) }\end{array}$} & \multirow[t]{2}{*}{ Length } & $d$ to $b$ & - & - & - & - & 1.05 & 1.11 & 1.3 & 1.36 & 1.2 & 1.04 & 0.7 \\
\hline & & df to $e$ & - & - & & 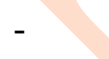 & 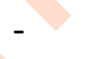 & - & 1.3 & 1.36 & 1.25 & 1.07 & 0.63 \\
\hline & \multirow[t]{2}{*}{ Width } & cross $\mathrm{C}$ & & & & & 0.44 & 0.43 & 0.83 & 0.86 & 0.90 & 0.62 & 0.42 \\
\hline & & cross $\mathrm{g}$ & & & & D & - & - & 0.71 & 0.83 & 0.84 & 0.7 & 0.48 \\
\hline \multirow{4}{*}{$\begin{array}{l}\text { NHMUK PV M46495 } \\
\text { (Dobunnodon. } \\
\text { mussettae) }\end{array}$} & \multirow{2}{*}{ Length } & $d$ to $b$ & - & 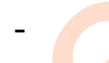 & - & - & - & - & 1.51 & - & - & - & - \\
\hline & & $d f$ to $e$ & - & 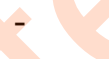 & - & - & - & - & 1.57 & - & - & - & - \\
\hline & \multirow{2}{*}{ Width } & rean & - & & - & - & - & - & 0.67 & - & - & - & - \\
\hline & & cross $g$ & 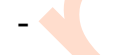 & - & - & - & - & - & 0.58 & - & - & - & - \\
\hline \multicolumn{14}{|l|}{ Upper tooth row } \\
\hline \multirow{4}{*}{$\begin{array}{l}\text { NMS G.1992.47.121.1 } \\
\text { (B. cuillinensis) }\end{array}$} & \multirow{3}{*}{$\begin{array}{l}\text { Right tooth } \\
\text { row }\end{array}$} & \multirow{3}{*}{ Length } & buccal & - & - & - & - & - & - & - & 1.6 & 1.17 & - \\
\hline & & & lingual & - & - & - & - & - & 0.81 & 0.98 & 0.95 & 0.7 & - \\
\hline & & & & - & - & - & - & - & 1.4 & 1.6 & 1.67 & 1.41 & - \\
\hline & Left tooth row & Length & buccal & - & - & - & - & - & - & - & 1.42 & 1.18 & - \\
\hline
\end{tabular}




\begin{tabular}{|c|c|c|c|c|c|c|c|c|c|c|c|c|}
\hline & & & lingual & - & - & - & - & - & 0.77 & 0.9 & 0.93 & 0.7 \\
\hline & & Width & & - & - & - & - & - & 1.77 & 1.63 & 1.39 & 1.77 \\
\hline \multirow[t]{6}{*}{$\begin{array}{l}\text { NMS G.2020.4.1.1 } \\
\text { (B. cuillinensis) }\end{array}$} & $\begin{array}{l}\text { Right tooth } \\
\text { row }\end{array}$ & Length & buccal & - & - & - & 0.99 & 1.02 & 1.5 & 1.38 & 1.2 & 0.9 \\
\hline & & & lingual & - & - & - & - & - & 0.74 & 0.84 & 0.71 & 0.63 \\
\hline & & Width & & - & - & - & 0.58 & 0.75 & 1.51 & 1.66 & 1.58 & 1.1 \\
\hline & Left tooth row & Length & buccal & - & - & 1.09 & 1.01 & - & - & 1.28 & 1.46 & 0.97 \\
\hline & & & lingual & - & - & - & - & - & & 0.9 & 0.83 & 0.8 \\
\hline & & Width & & - & - & - & - & - & & 1.58 & 1.58 & 1.06 \\
\hline
\end{tabular}


Table 3: Measurements of dentaries and maxillae of Borealestes.

$\begin{array}{llll}\text { Specimen number } & \text { Element } & \text { Length (mm) } & \text { Width (mm) } \\ \text { NMS G.1992.47.121.1 } & \text { Right dentary } & 22.98 & 0.97 \text { (ventral to m3) } \\ & \text { Left maxilla (partial) } & 4.15 & - \\ & \text { Right maxilla (partial) } & 4.67 & - \\ \text { NMS G.2020.4.1.1 } & \text { Right dentary (partial) } & 9.01 & 1.01 \text { (ventral to m2) } \\ & \text { Left dentary (partial) } & 16.4 & 0.98 \text { (ventral to m3) } \\ & \text { Left maxilla (partial) } & 7.91 & -\end{array}$




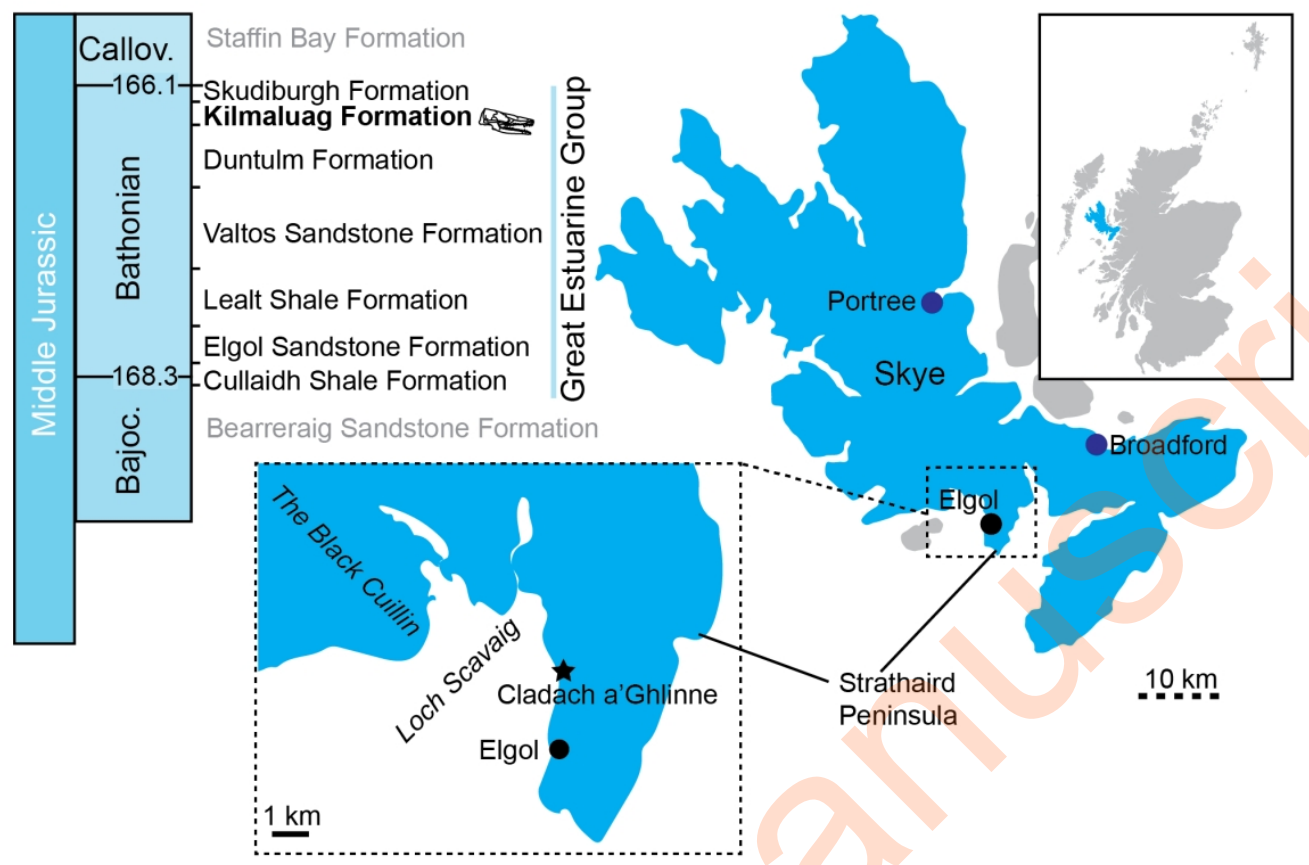

Figure 1: The stratigraphy of the Great Estuarine Group, and location of type locality of Borealestes serendipitus NMS G.1992.141.1 and Borealestes cuillinensis sp. nov. NMS G.2020.4.1.1, Cladach a'Ghlinne near Elgol. 


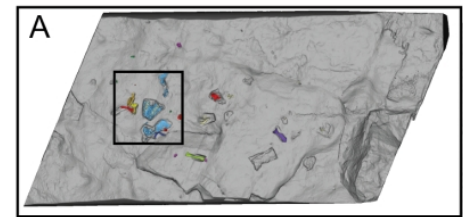

B
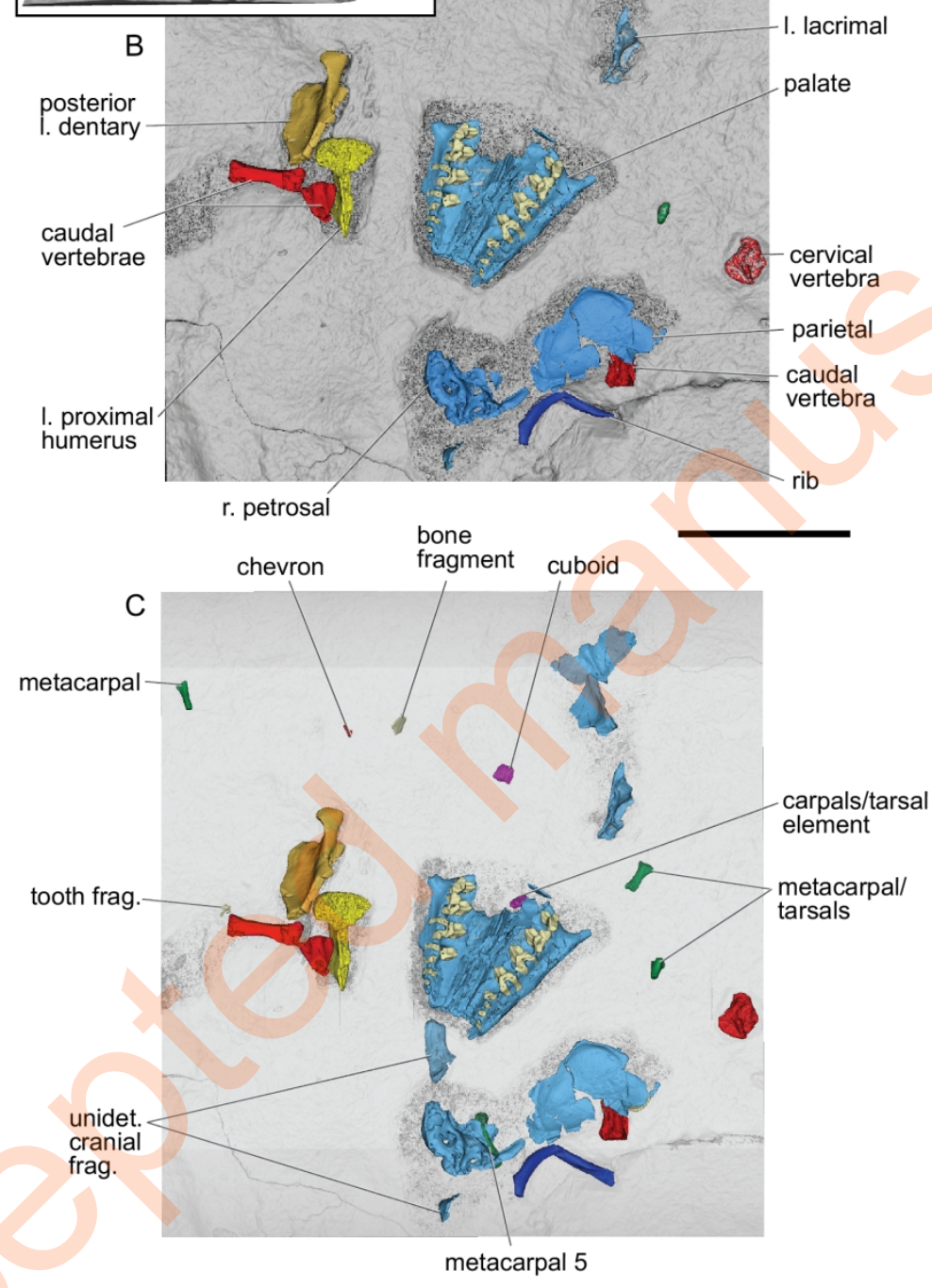

Figure 2: Borealestes serendipitus cranial elements (NMS G.1992.47.121.1) Visualisation from synchrotron $\mu C T$ data. A, NMS G.1992.47.121.1, showing location of cranial elements; B, digital rendering of surface of NMS G.1992.47.121.1; C, digital rendering of surface of NMS G.1992.47.121.1 with matrix semitransparent, showing skeletal elements within the block. Scale bar equals $10 \mathrm{~mm}$. 

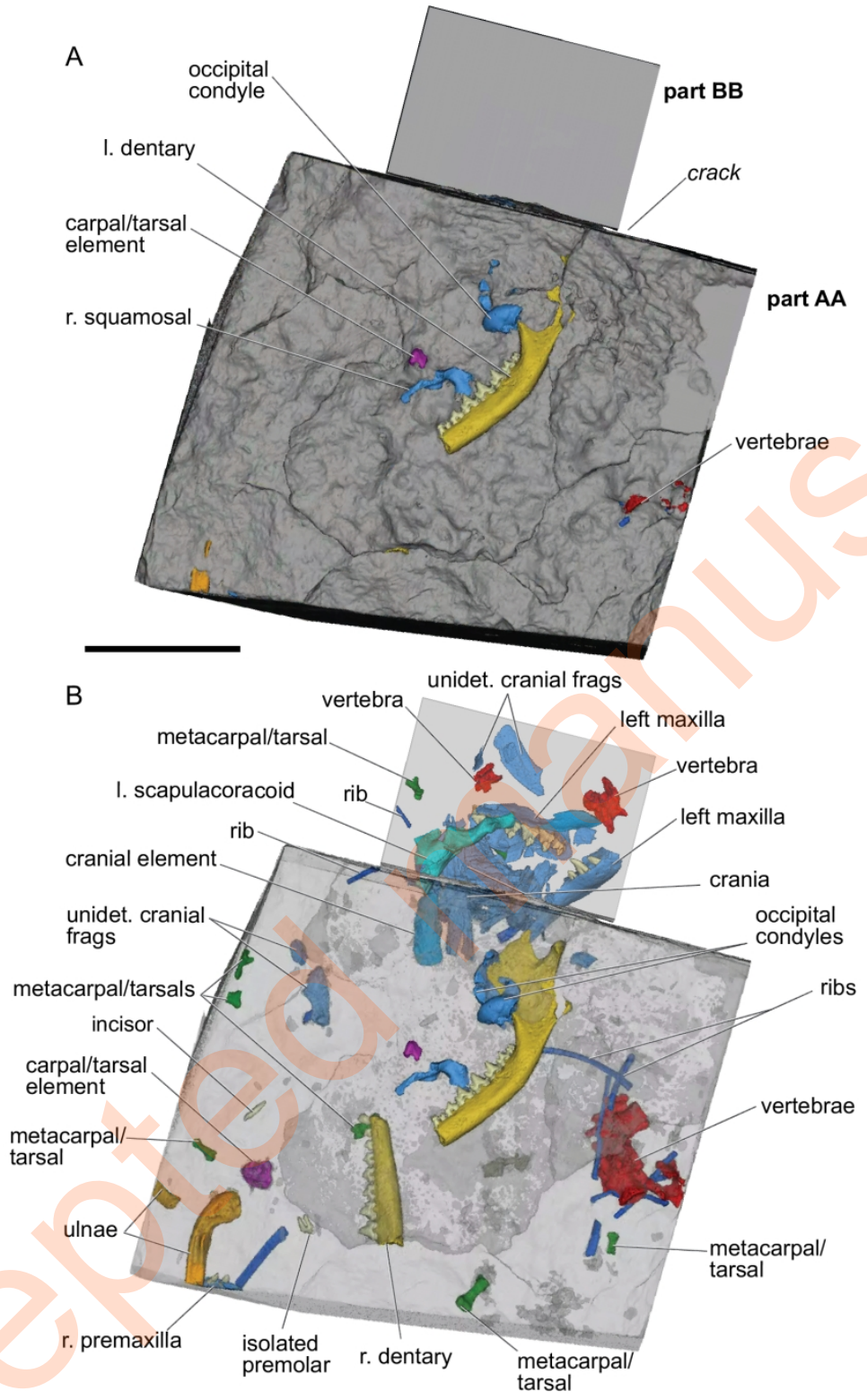

Figure 3: Borealestes cuillinensis sp. nov. cranial elements (NMS G.2020.4.1.1 parts AA and BB) visualisation from $\mu C T$ data. A, digital rendering of surface of NMS G.2020.4.1.1; B, digital rendering of NMS G.2020.4.1.1 with matrix semitransparent, showing cranial skeletal elements within the block. Scale bar equals $10 \mathrm{~mm}$. 


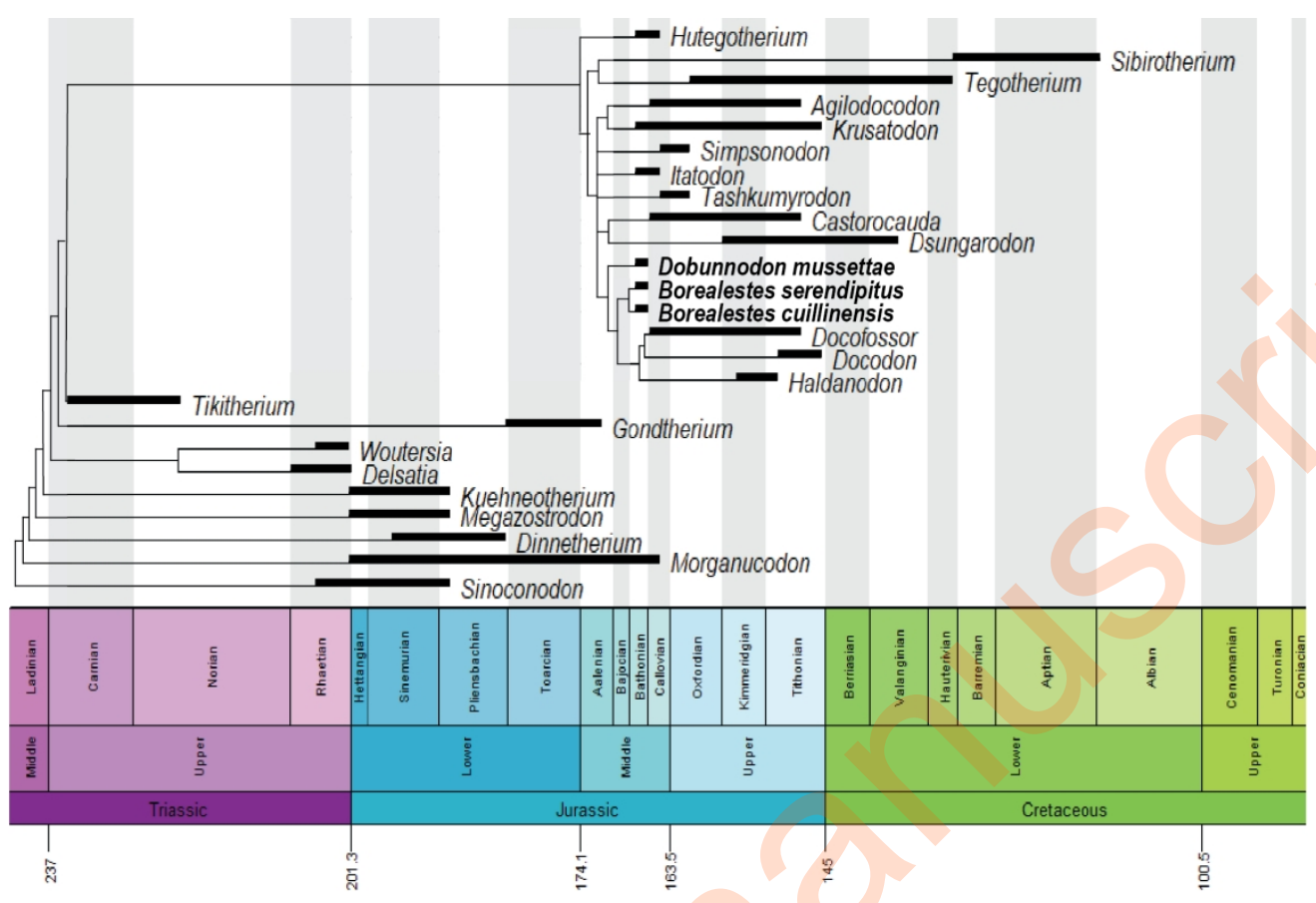

Figure 4: Phylogeny of Docodonta based on updated phylogenetic analysis. Strict consensus of six trees of 131 steps resulting from parsimony analysis of data matrix for docodontans and outgroups as in Panciroli et al. (2019), with the addition of Borealestes cuillinensis and revision of Dobunnodon (='Borealestes' mussettae). First-to-last appearances represented by black bars (see Supplementary). Nodes uniting taxa do not imply divergence times. 
Figure 5: Diagnostic dental features of Borealestes species, and Dobunnodon gen. nov. A, Borealestes serendipitus: A1, NMS G.1992.47.121.1 left M3 (mirrored) in occlusal view alongside diagrammatic illustration; A2, holotype BRSUG 20570 right $\mathrm{m} 2$ (mirrored) in occlusal view, cusps only, alongside diagrammatic illustration; and A3, BRSUG 20570 right m2 (mirrored) crests only; A4 BRSUG 20570 right m2 (mirrored) in lingual view alongside diagrammatic illustration. B, Borealestes cuillinensis: B1, NMS G.2020.4.1.1 right M3 in occlusal view alongside diagrammatic illustration; B2, NHMUK PV M46871 left upper molar in occlusal view (mirrored) with cusps marked; B3, NMS G.2020.4.1.1 m2 in occlusal view; and B4 NMS G.2020.4.1.1 m2 in lingual view with cusps alongside diagrammatic illustration. C, Dobunnodon mussettae gen. nov.: C1, holotype NHMUK PV M46495 lower right molar in occlusal view with crests and diagrammatic illustration below; C2, holotype NHMUK PV M46495 mirrored for comparison and diagrammatic illustration below, C3, holotype NHMUK PV M46495 lingual view with crests and diagrammatic illustration below; C4, holotype NHMUK PV M46495 mirrored for comparison. A and C adapted from Panciroli et al. (2019). Darker grey areas indicate broken surfaces. Scale bars equal $1 \mathrm{~mm}$. 
Figure 6: Dentition of Borealestes serendipitus and Borealestes cuillinensis for comparison. A and C. Borealestes serendipitus upper dentition of NMS G.1992.47.121.1 and lower dentition of NMS G.1992.47.121.3 (C mirrored for comparison). B and D Borealestes cuillinensis NMS G.2020.4.1.1. Scale bars equal $1 \mathrm{~mm}$.

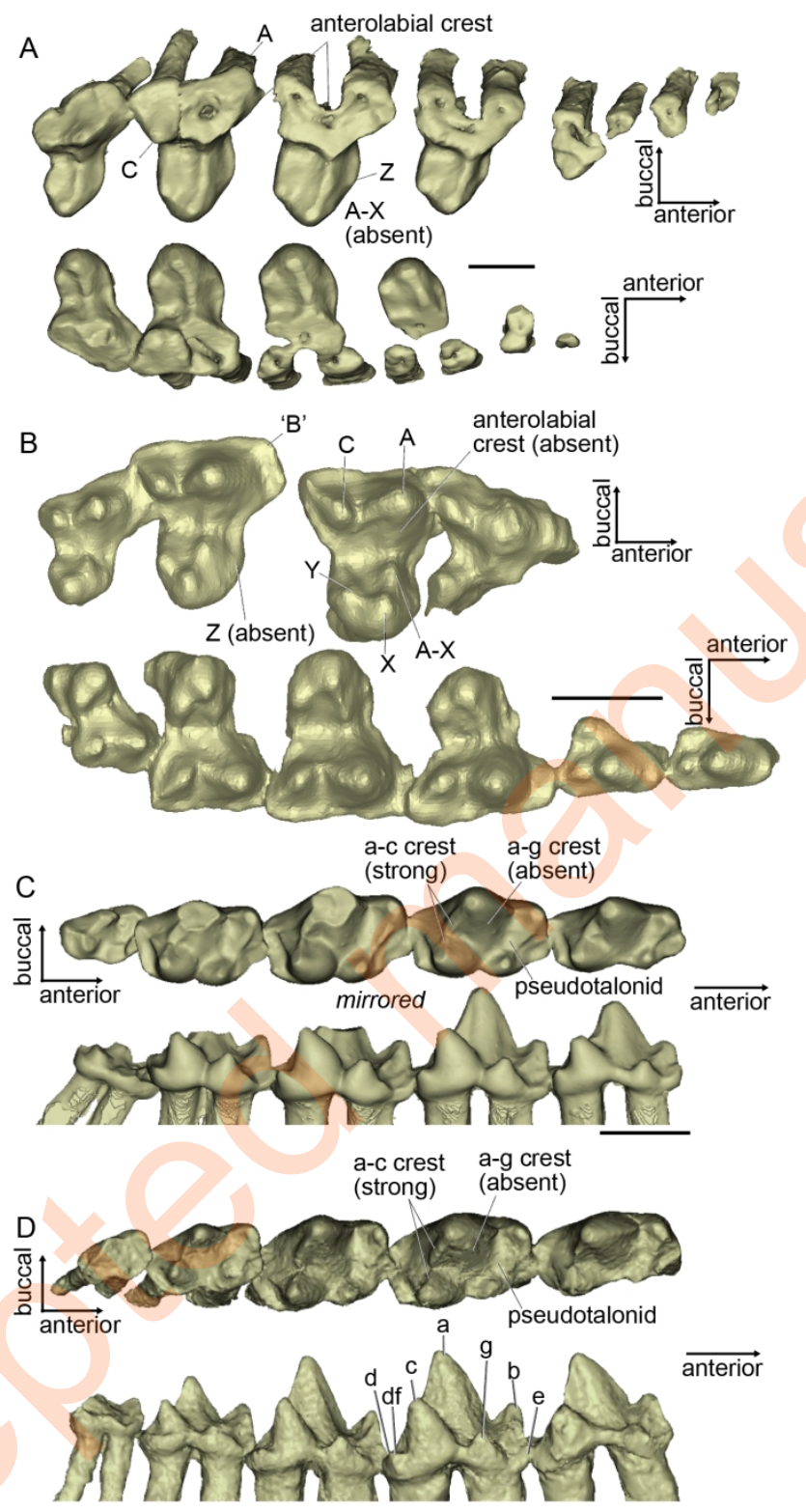




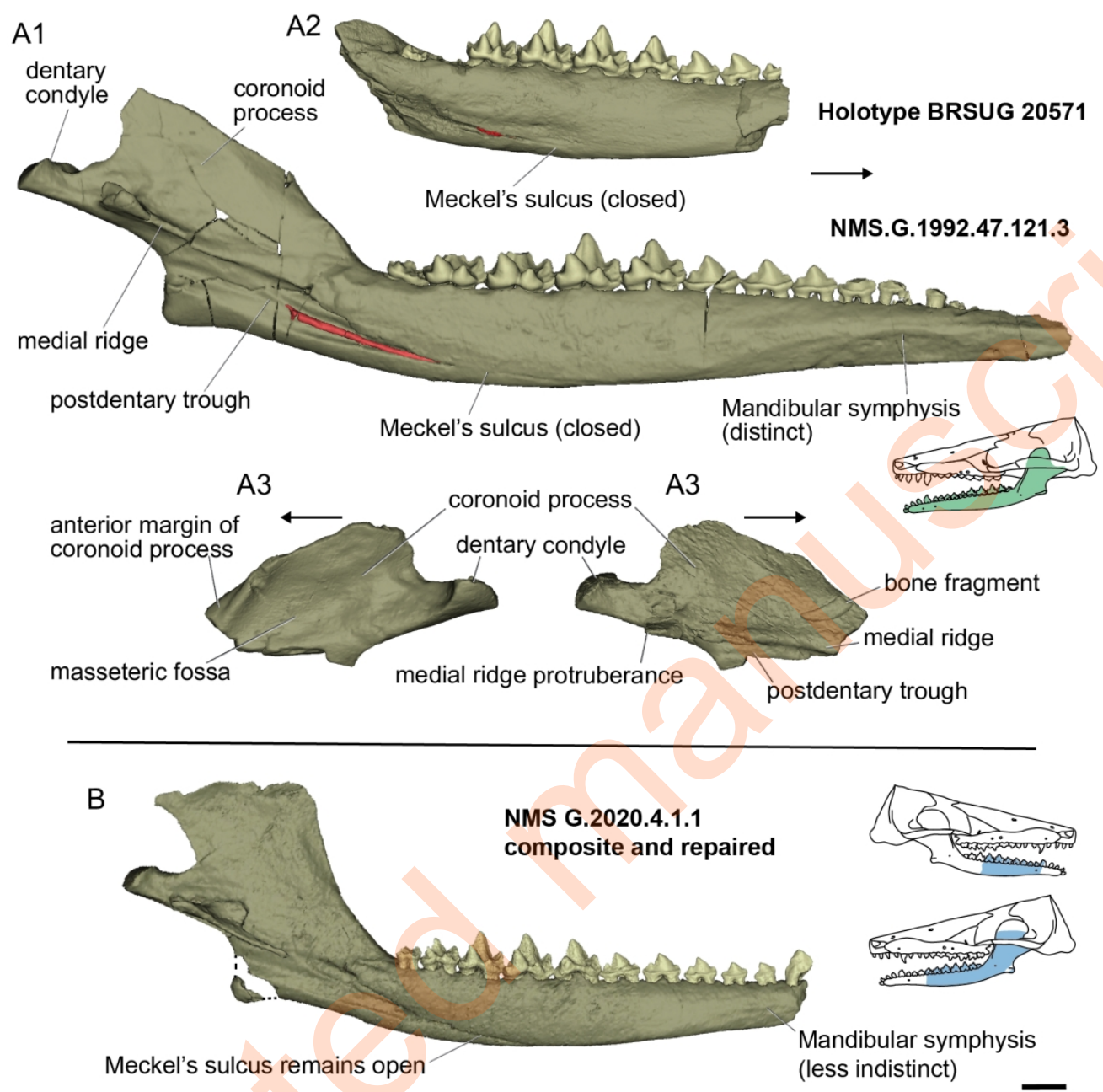

Figure 7: Diagnostic mandibular features of Borealestes species. A1 and A2 dentaries belong to Borealestes serendipitus, showing diagnostic features of Meckel's sulcus and mandibular symphysis. Bottom dentary B, belongs to Borealestes cuillinensis. Shows diagnostic features of Meckel's sulcus and mandibular symphysis. Scale bar equals $1 \mathrm{~mm}$, scale same throughout. 
Figure 8: Skull reconstruction of Borealestes serendipitus in lateral (top) dorsal (middle) and ventral (bottom) views. Green shaded areas represented in specimen NMS G.1992.47.121.1 and associated material. Dotted lines indicate unrepresented areas where boundaries unknown. 1 Premaxilla; 2 anterior nasal foramina; 3 maxilla; 4 infraorbital foramen; 5 posterior nasal foramen; 6 lacrimal; 7 nasal; 8 lacrimal foramen; 9 zygomatic process of lacrimal; 10 jugal (not known); 11 infraorbital foramen; 12 frontal; 13 parietal; 14 interparietal suture; 15 sagittal crest; 16 squamosal; 17 dorsal flange of squamosal; 18 postparietal; 19 occipital condyles; 20 midline ridge of postparietal; 21 postparietal foramina; 22 septomaxilla; 23 anterior projection of nasal; 24 internarial bar; 25 anterior premaxillary foramen; 26 incisive foramen; 27 palatal posterior salient of premaxilla; 28 greater palatine foramen; 29 palatal process (not known); 30 glenoid fossa; 31 external auditory meatus; 32 fenestra vestibuli; 33 pars cochlearis; 34 orbital area (not known); 35 basicranium (not known); 36 pterygoid and basicranium (not known); 37 primary palate (not known); 38 I3 foramen; 39 posterior projection of premaxilla into incisive foramen; 40 coronoid process; 41 nuchal crest; 42 angular process of dentary; 43 masseteric foramen; 44 dentary; 45 mental foramen; 46 anterior premaxillary foramen. Scale bar equals $5 \mathrm{~mm}$. 
Figure 9: Skull reconstruction of Borealestes cuillinensis in lateral (top) dorsal (middle) and ventral (bottom) views. Blue shaded areas represented in specimen NMS G.2020.4.1.1. Dotted lines indicate unrepresented areas where boundaries unknown. 1 Premaxilla; 2 anterior nasal foramina; 3 maxilla; 4 infraorbital foramen; 5 posterior nasal foramen (not known); 6 lacrimal; 7 nasal; 8 lacrimal foramen; 9 zygomatic process of lacrimal; 10 jugal (not known); 11 infraorbital foramen (not known); 12 frontal (not known); 13 parietal (not known); 14 interparietal suture; 15 sagittal crest (not known); 16 squamosal; 17 dorsal flange of squamosal; 18 postparietal (not known); 19 occipital condyles; 20 midline ridge of postparietal; 21 postparietal foramina; 22 septomaxilla; 23 anterior projection of nasal; 24 internarial bar; 25 anterior premaxillary foramen (not known); 26 incisive foramen; 27 palatal posterior salient of premaxilla (not known); 28 greater palatine foramen; 29 palatal process (not known); 30 glenoid fossa; 31 external auditory meatus; 32 fenestra vestibuli; 33 pars cochlearis; 34 orbital area (not known); 35 basicranium known); 36 pterygoid and basicranium (not known); 37 primary palate (not known); 38 I3 foramen (not known); 39 posterior projection of premaxilla into incisive foramen (not known); 40 coronoid process; 41 nuchal crest (not known); 42 angular process of dentary; 43 masseteric foramen; 44 dentary; 45 mental 
foramen; 46 anterior premaxillary foramen. Scale bar equals $5 \mathrm{~mm}$. 
Figure 10: Borealestes cuillinensis sp. nov. (holotype, NMS G.2020.4.1.1) left mandible, A, occlusal view; B, lateral view; $\mathrm{C}$, lingual view. Arrows indicate anterior direction. The triangle indicates the alignment of the ultimate molar to the coronoid process. Angular process broken during preparation and replaced digitally, broken lines indicate missing piece of process. Scale bar equals $1 \mathrm{~mm}$, scale same throughout.

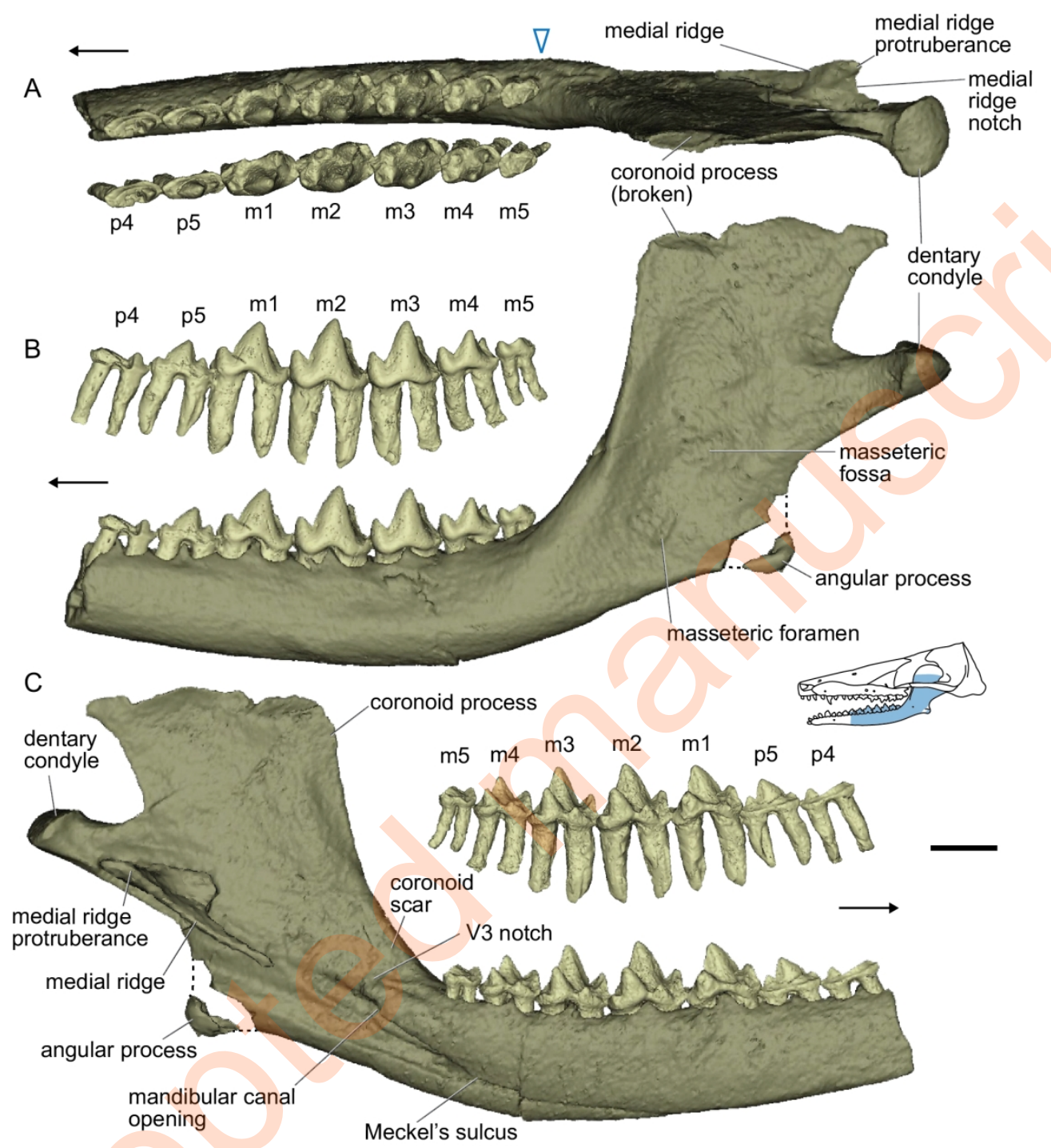



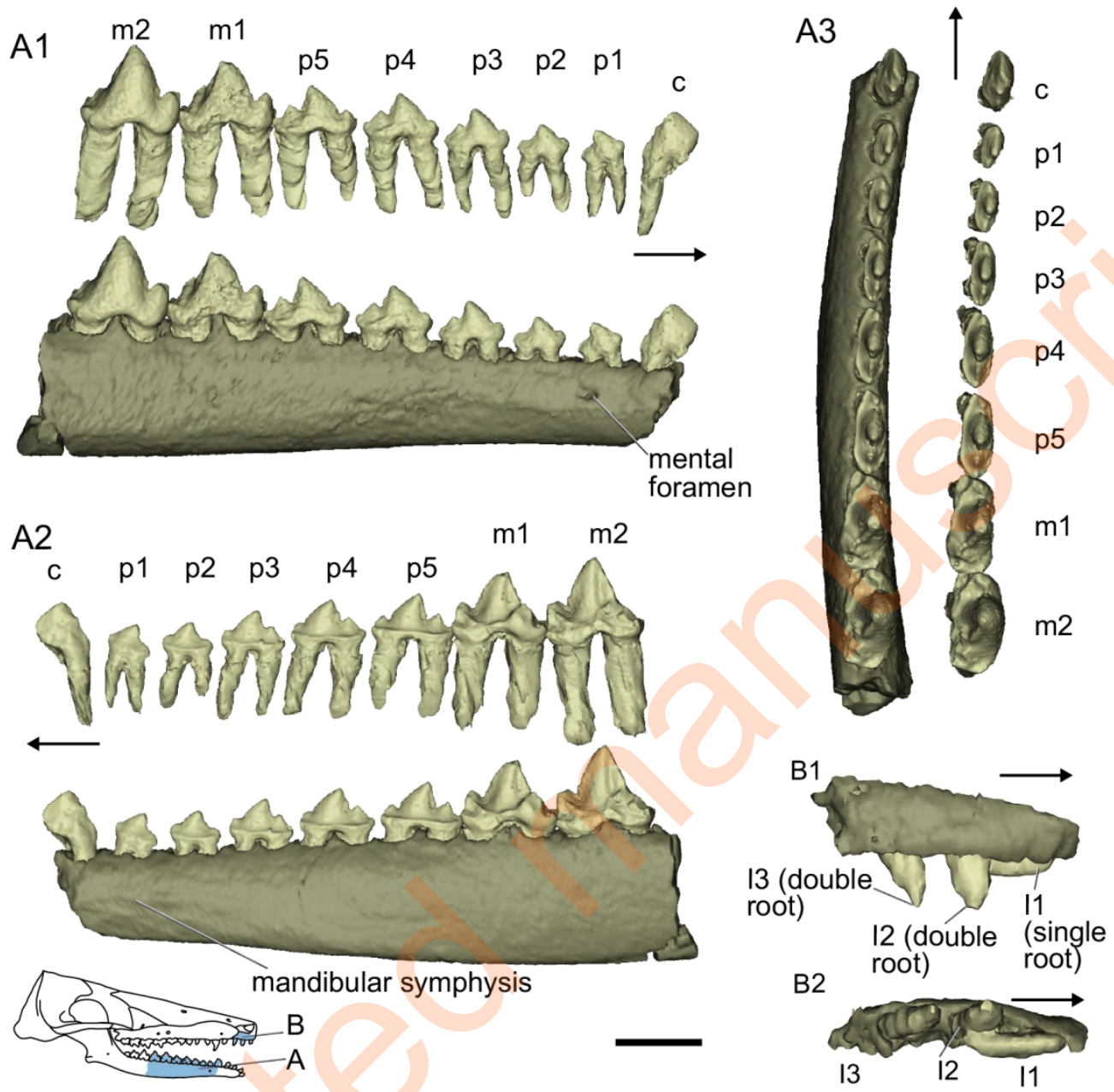

Figure 11: Borealestes cuillinensis (holotype, NMS G.2020.4.1.1) anterior part of right dentary and right premaxilla. A, right dentary: A1, right lateral view; A2, lingual view; A3, occlusal view. B, fragment of right premaxilla: B1, right lateral view; B2, occlusal view. Arrows indicate anterior direction. Scale bar equals 1 $\mathrm{mm}$, scale same throughout. 

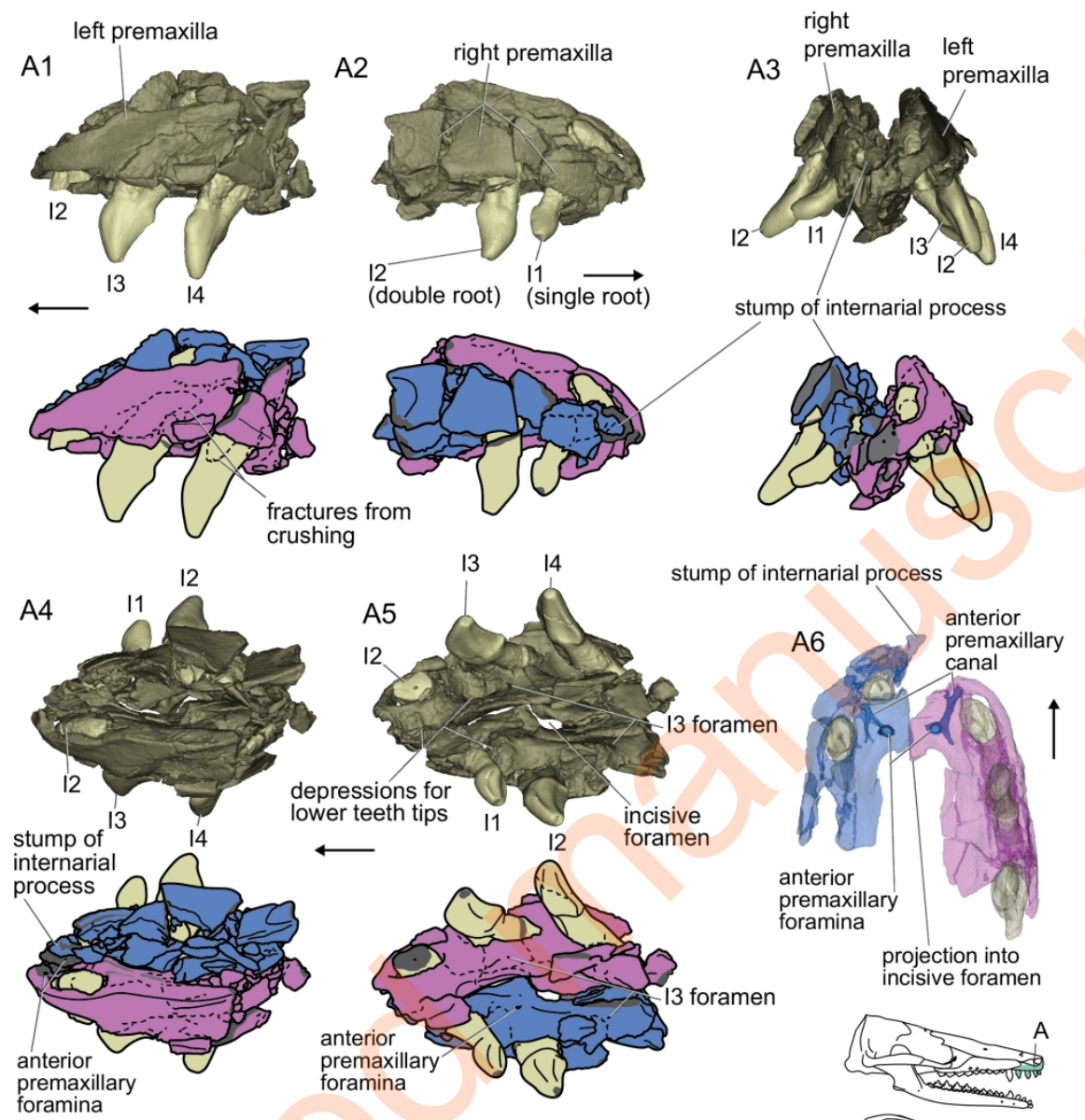

tump of internarial process

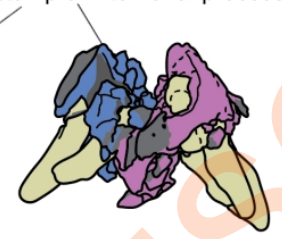

A4

stump of

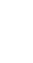

(2)
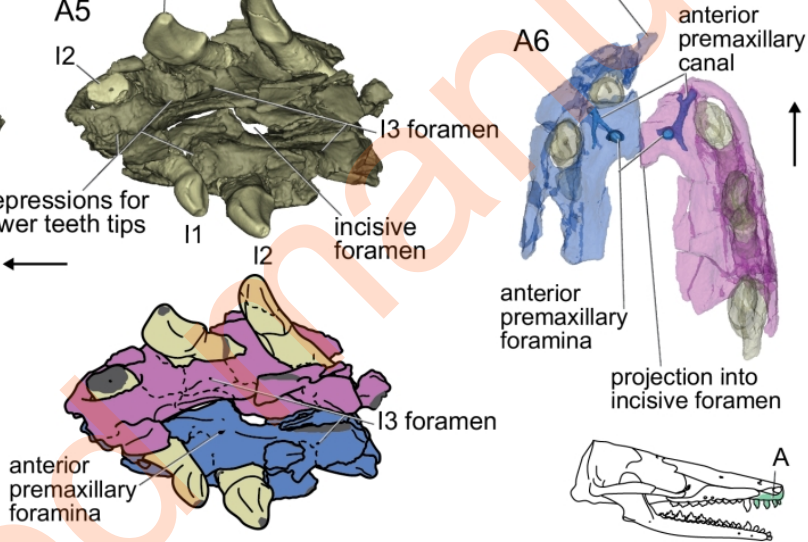

rim of nasal notch

B1

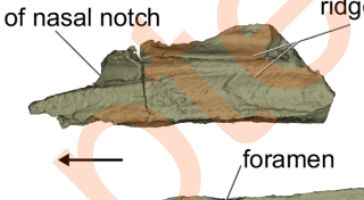

ridges of nasoturbinates

deep midline suture
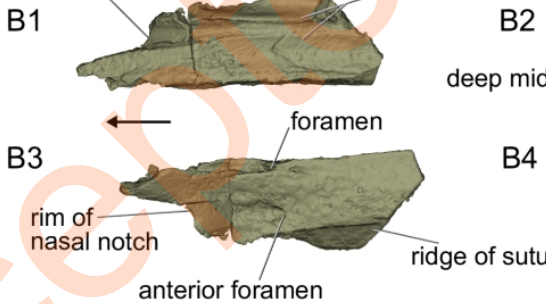

B2
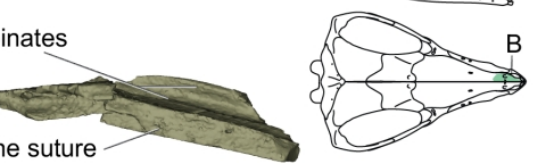

B4

anterior foramen

ridge of suture with maxilla

Figure 12: Borealestes serendipitus skull elements. Premaxillae with incisors and anterior nasal part (NMS G.1992.47.121.4), with diagrammatic illustrations; A1, left lateral view; A2, right lateral view; A3, anterior view; A4, dorsal view; A5, ventral view; A6, semitransparent digital rendering of reconstructed premaxillae and incisors, showing path of premaxillary canal. B, Nasal anterior part: B1 ventral view; B2, medial view; B3, dorsal view; B4, left lateral view. Arrows indicate anterior direction. Dark grey areas on diagrammatic illustrations indicate broken surfaces. Scale bar equals $1 \mathrm{~mm}$, scale same throughout. 


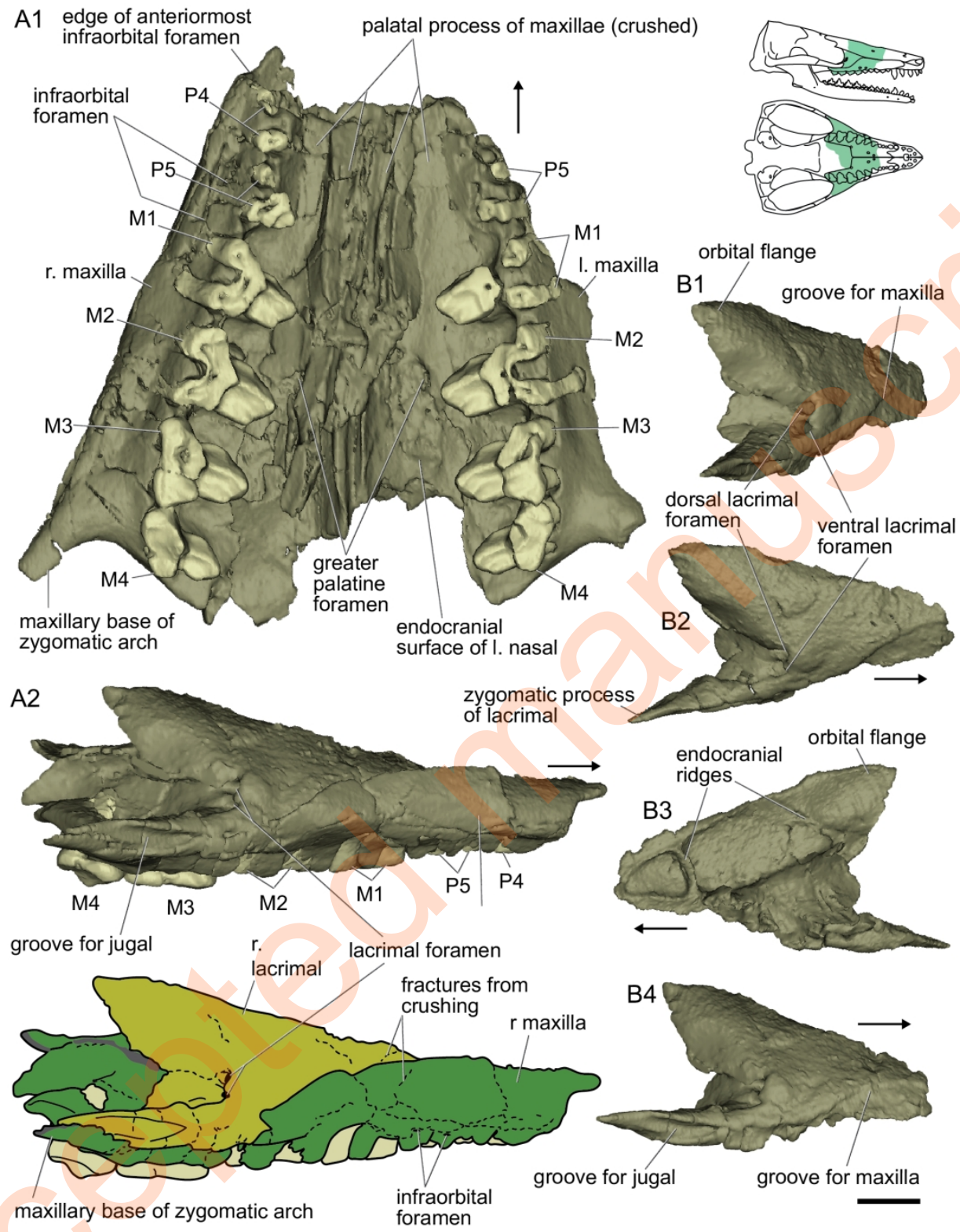

Figure 13: Borealestes serendipitus (NMS G.1992.47.121.1) palatal portion of cranium and right lacrimal. A, ventral view; A2, right lateral view with diagrammatic illustration below; B, right lacrimal (see also Fig. 13);

B1, right posterolateral view; B2, dorsal view; B3, medial view; B4 right lateral view. Arrows indicate anterior direction. Dark grey areas on diagrammatic illustrations indicate broken surfaces. Scale bar equals 1 $\mathrm{mm}$, scale same throughout. 
Figure 14: Borealestes serendipitus (NMS G.1992.47.121.1) palatal portion of cranium and left lacrimal. A, virtual slice from synchrotron $\mu C T$ showing cross-section of palate; $B$, dorsal view with diagrammatic illustration below; C, left lacrimal: C1, dorsal view; C2, left lateral view; C3 medial view; C4, ventral view. Arrows indicate anterior direction. Dark grey areas on diagrammatic illustrations indicate broken surfaces. Scale bar equals $1 \mathrm{~mm}$, scale same throughout. 

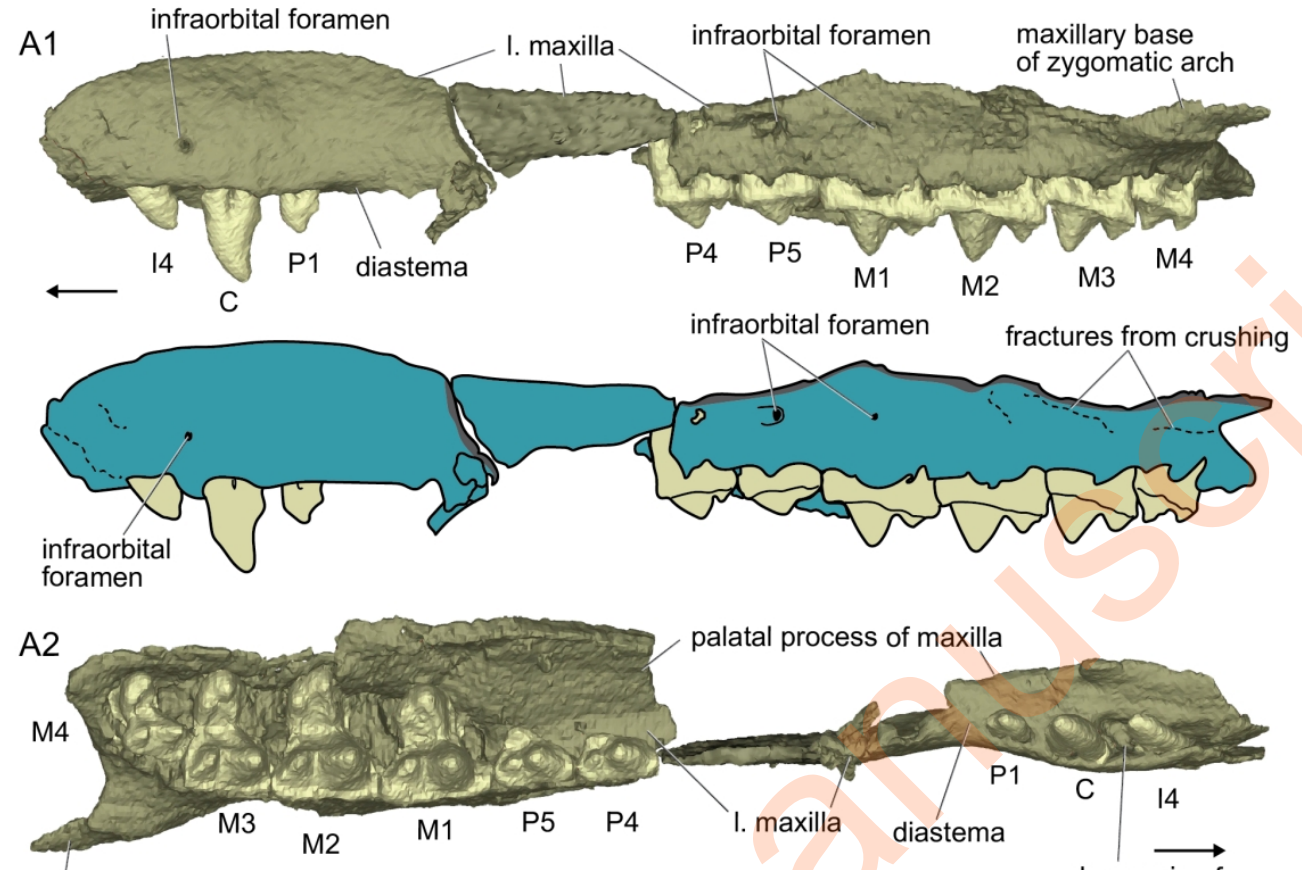

maxillary base of zygomatic arch
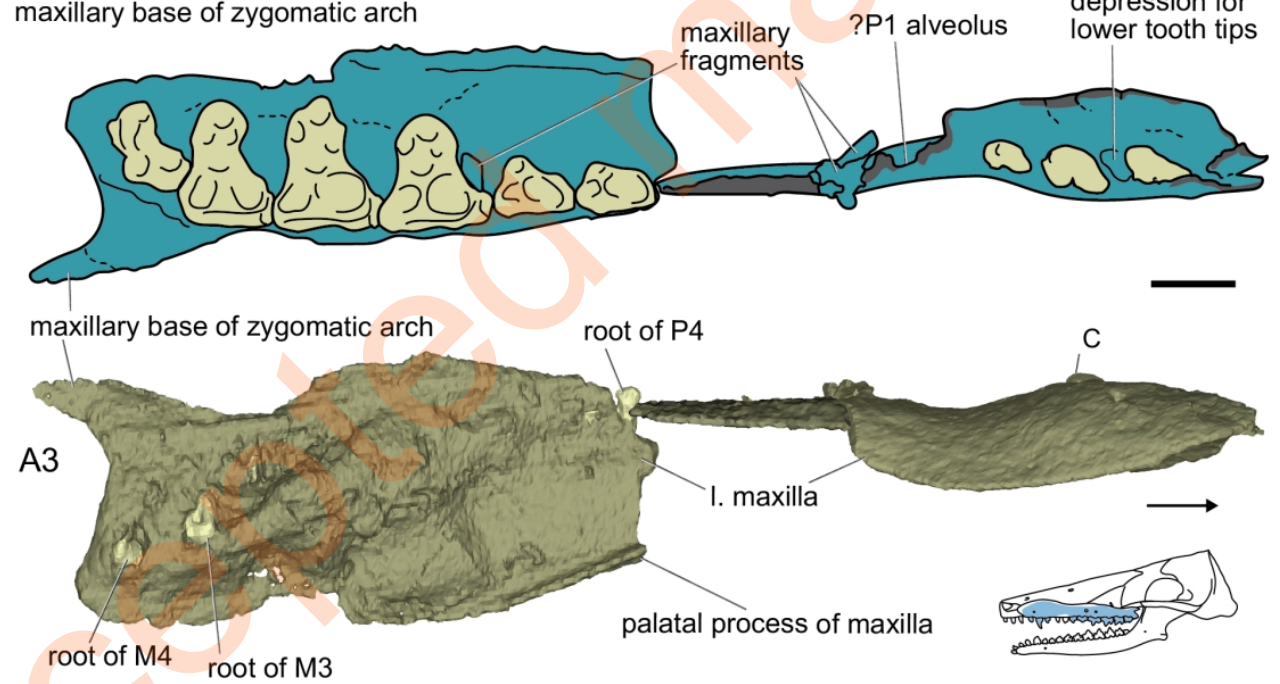

Figure 15: Borealestes cuillinensis (holotype, NMS G.2020.4.1.1) left maxilla. A, left maxilla with diagrammatic illustrations: A1, left lateral view; A2, occlusal view; A3, dorsal/endocranial view. Arrows indicate anterior direction. Dark grey areas on diagrammatic illustrations indicate broken surfaces. Scale bar equals $1 \mathrm{~mm}$, scale same throughout. 
Figure 16: Borealestes cuillinensis (holotype NMS G.2020.4.1.1) right maxilla and palatal process. A, posterior portion of right maxilla: A1, right lateral view; $A 2$, occlusal view; $A 3$, dorsal/endocranial view. $B$, palatal process of right maxilla: B1, dorsal/endocranial view; B2, ventral/palatal view; B3, medial view. Arrows indicate anterior direction. Scale bar equals $1 \mathrm{~mm}$, scale same throughout.

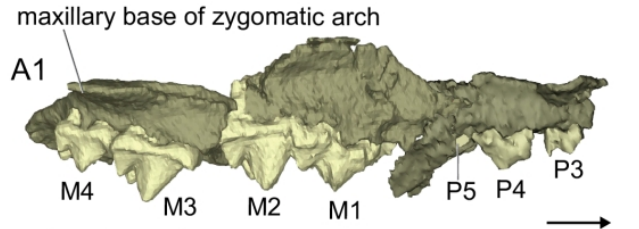

maxillary base of zygomatic arch
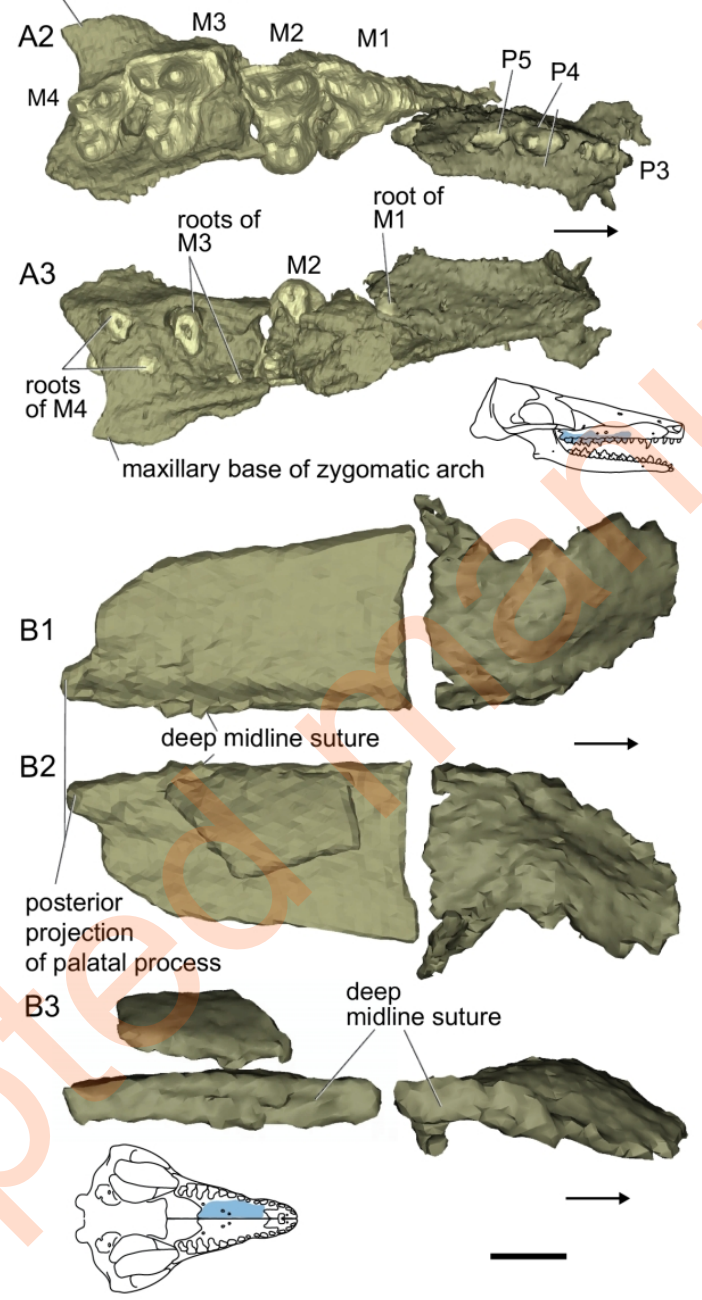
Figure 17: Borealestes cuillinensis (holotype, NMS G.2020.4.1.1) nasals and ?lacrimal. A, right nasals: A, ventral/endocranial view; A2, dorsal view; A3, medial view. B, right ?nasal: B1, dorsal view; B2, lateral view; B3, medial/endocranial view. Arrows indicate anterior direction. Scale bar equals $1 \mathrm{~mm}$, scale same throughout.
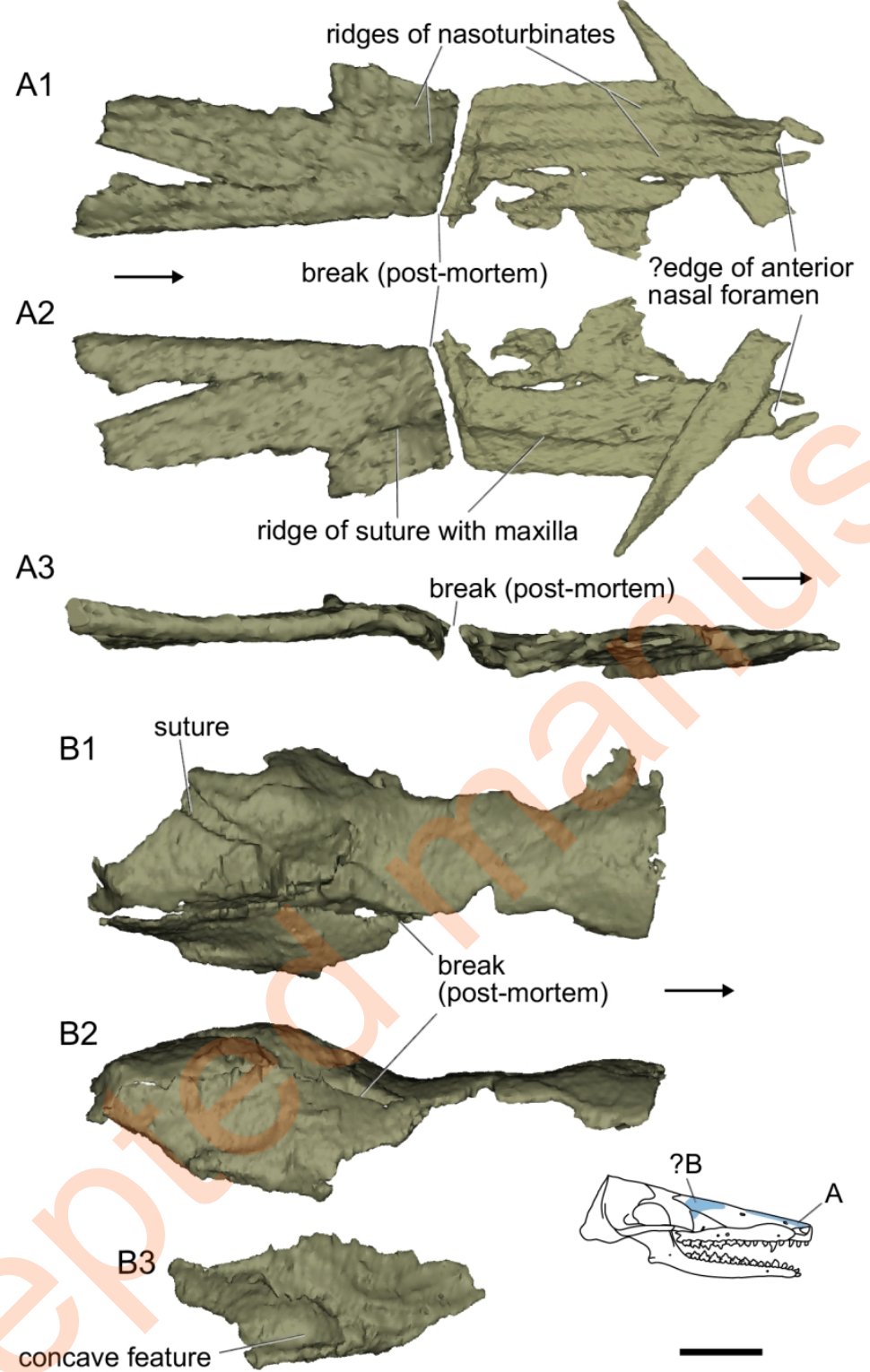


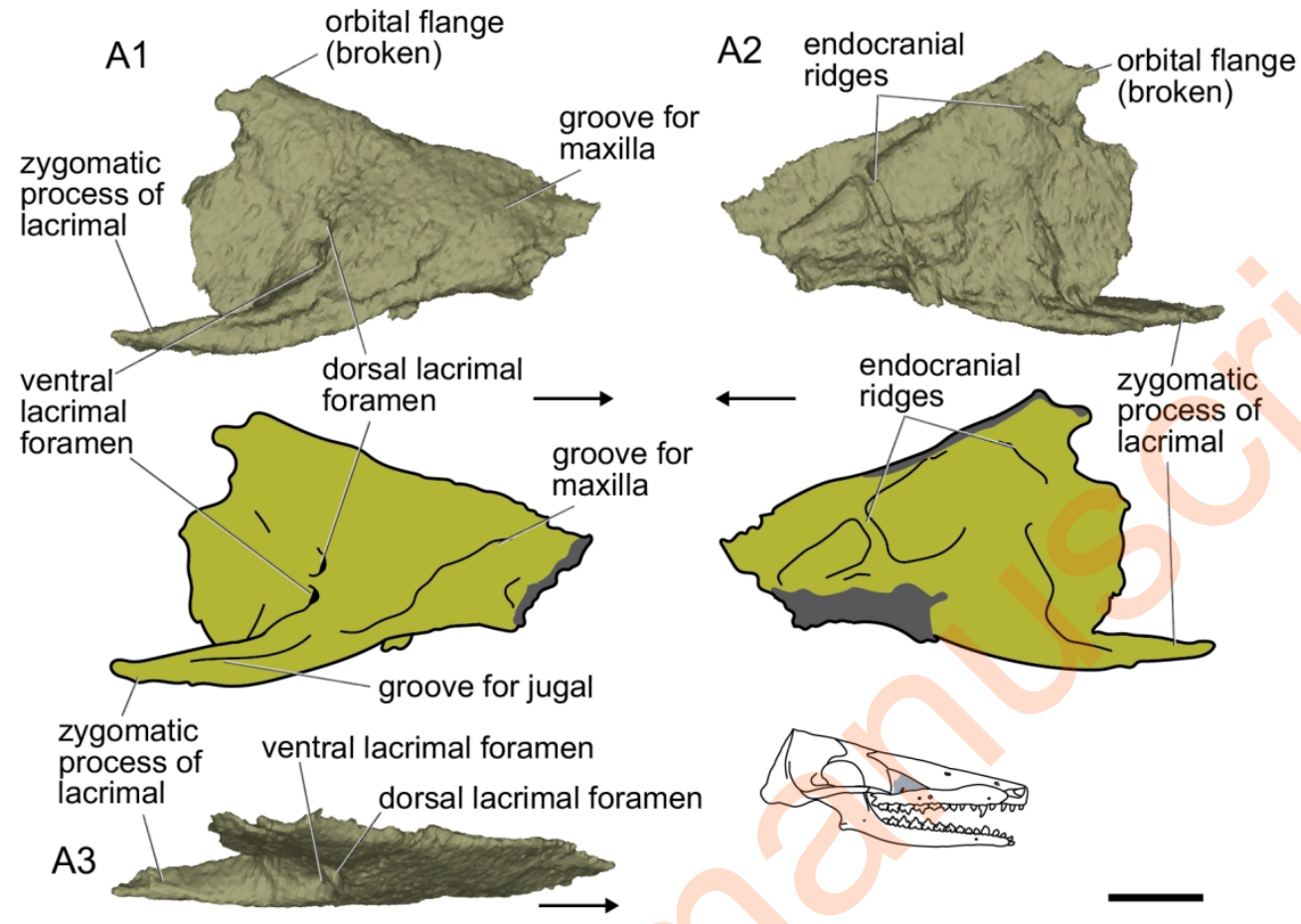

Figure 18: Borealestes cuillinensis (holotype, NMS G.2020.4.1.1) right lacrimal and diagrammatic illustrations: A1, right lateral view; C2, endocranial view; C3, dorsal view. Arrows indicate anterior direction. Dark grey areas on diagrammatic illustrations indicate broken surfaces. Scale bar equals $1 \mathrm{~mm}$, scale same throughout. 


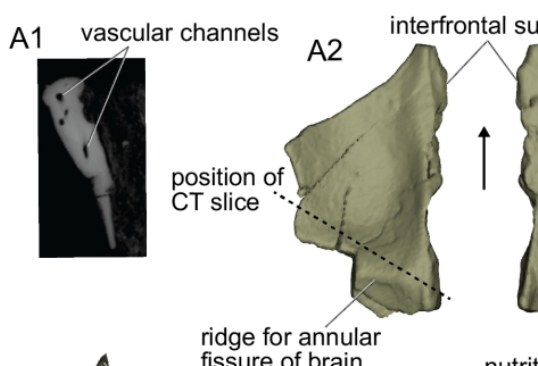

A3

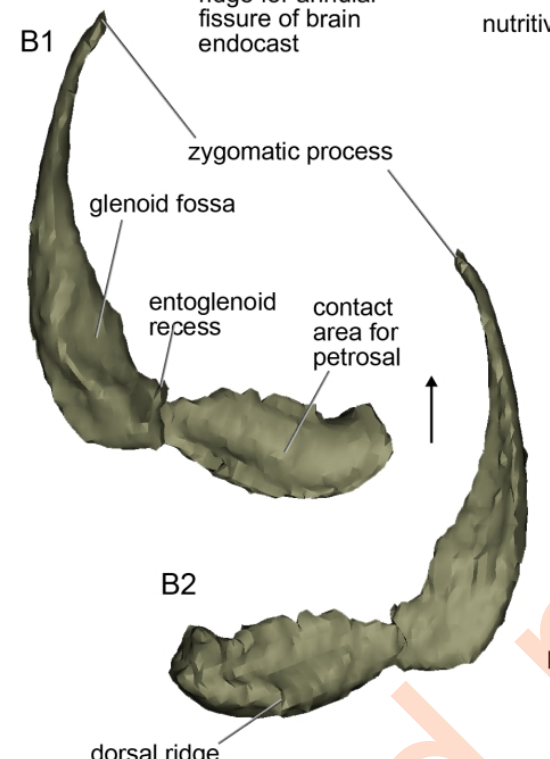

tritive foramen

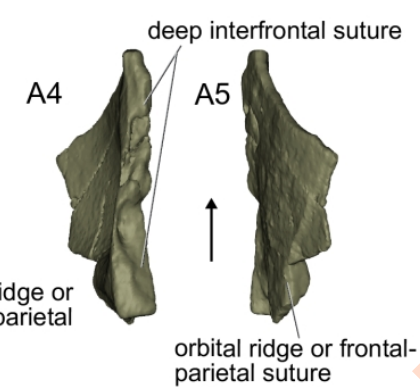
parietal suture

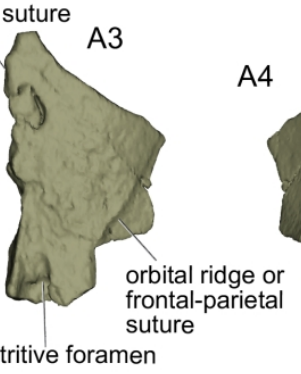

eep interfrontal suture

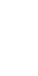

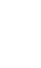

.

.

.

.
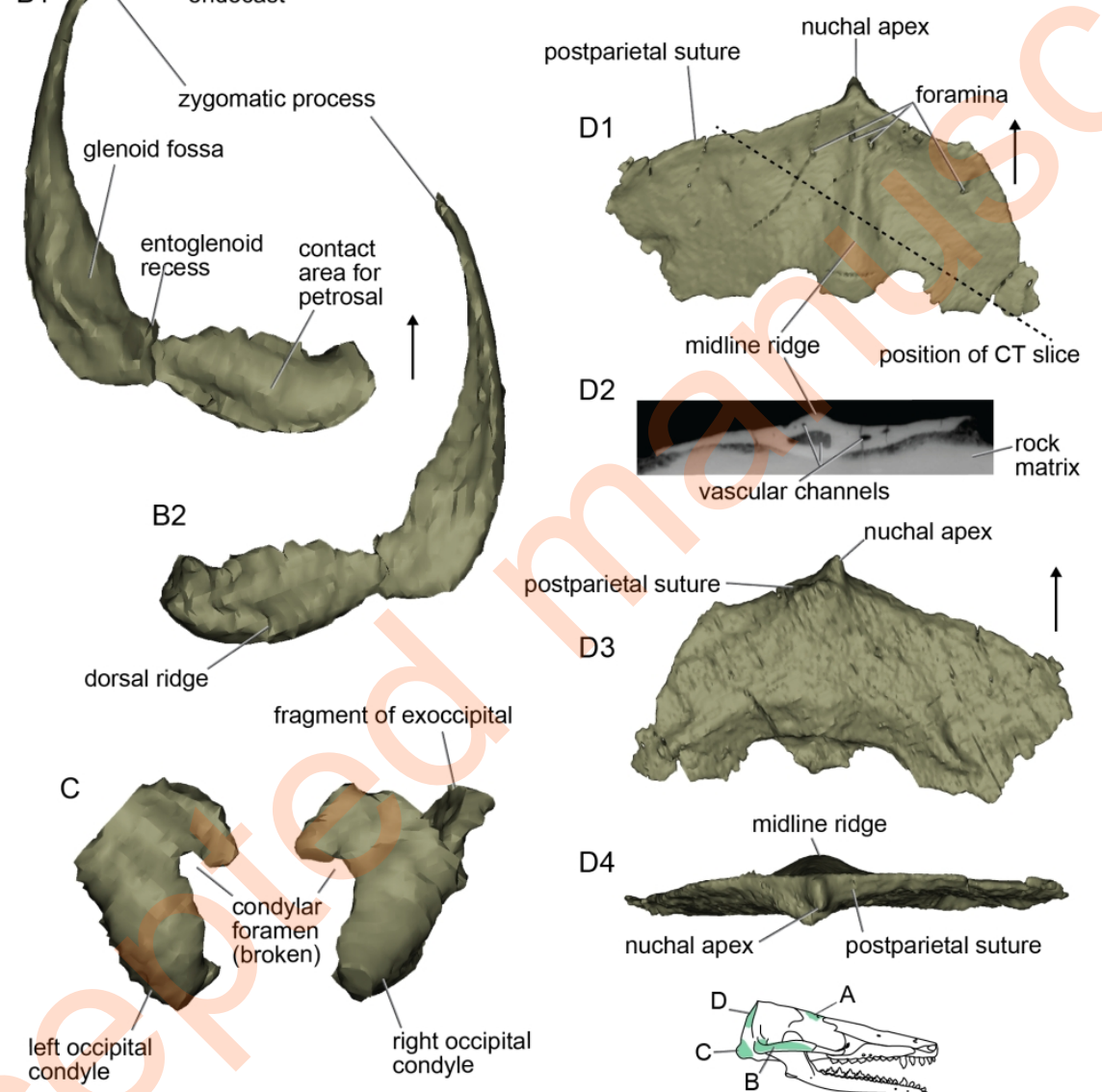

left occipita condyle

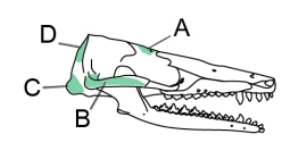

Figure 19: Borealestes serendipitus (NMS G.1992.47.121.1) elements of cranium. A, left frontal: A1, synchrotron $\mu C T$ slice showing cross section through left frontal; A2, ventral view; A3, dorsal view; A4, medial view; A5, left lateral view. B the left squamosal, reconstructed (originally in two misaligned pieces): B1, ventral view; B2, dorsal view; C, the occipital condyles. D, postparietal: D1, posterodorsal view; D2, virtual slice from synchrotron $\mu \mathrm{CT}$ showing cross section through postparietal; D3, anterior/endocranial view; D4, anteroventral view. Arrows indicate anterior direction. Scale bar equals $1 \mathrm{~mm}$, scale same throughout. 


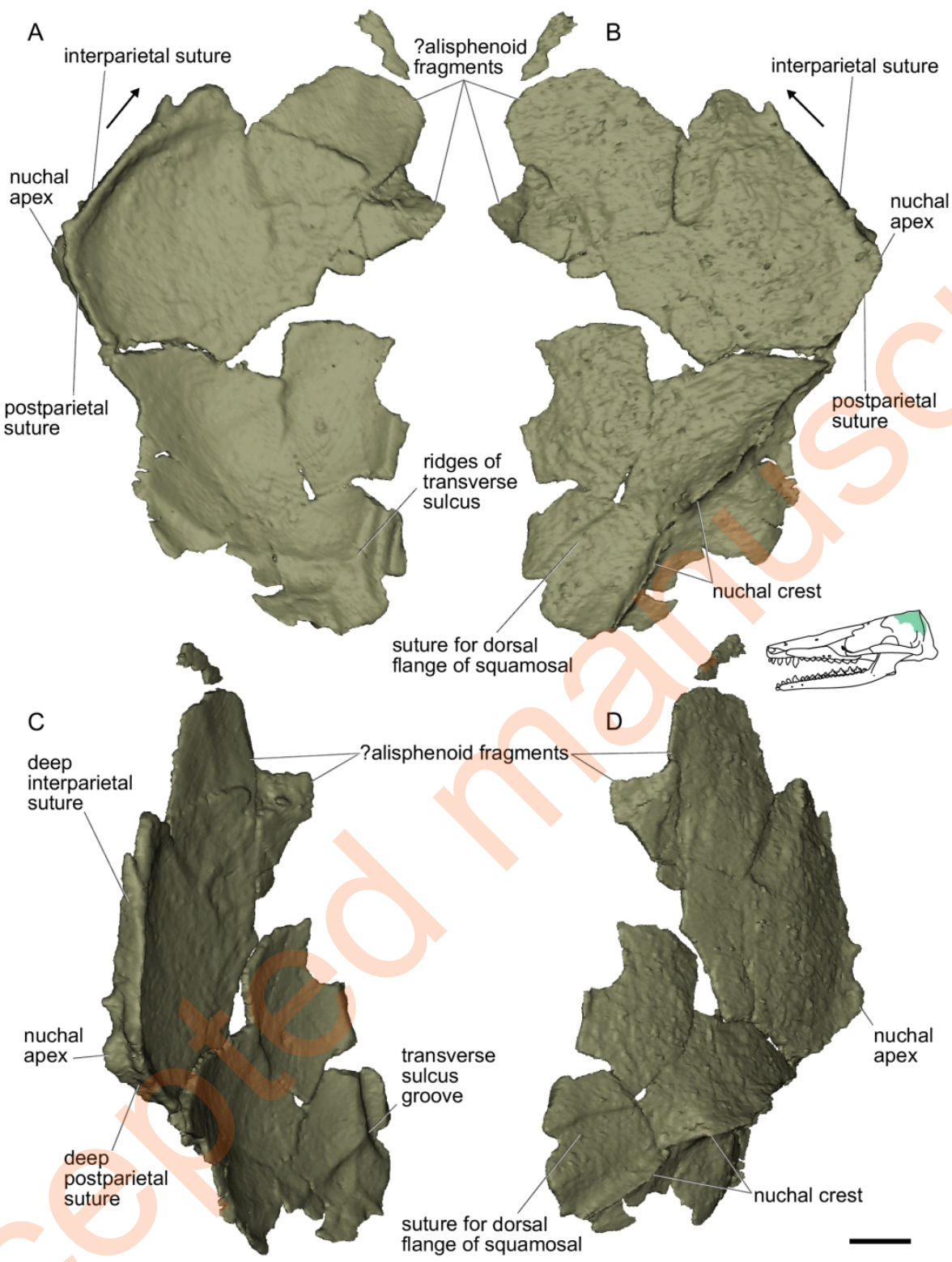

Figure 20: Borealestes serendipitus (NMS G.1992.47.121.1) left parietal. A, endocranial/ventral view; B, dorsal view; C, medial view; D, left lateral view. Arrows indicate anterior direction. Scale bar equals $1 \mathrm{~mm}$, scale same throughout. 


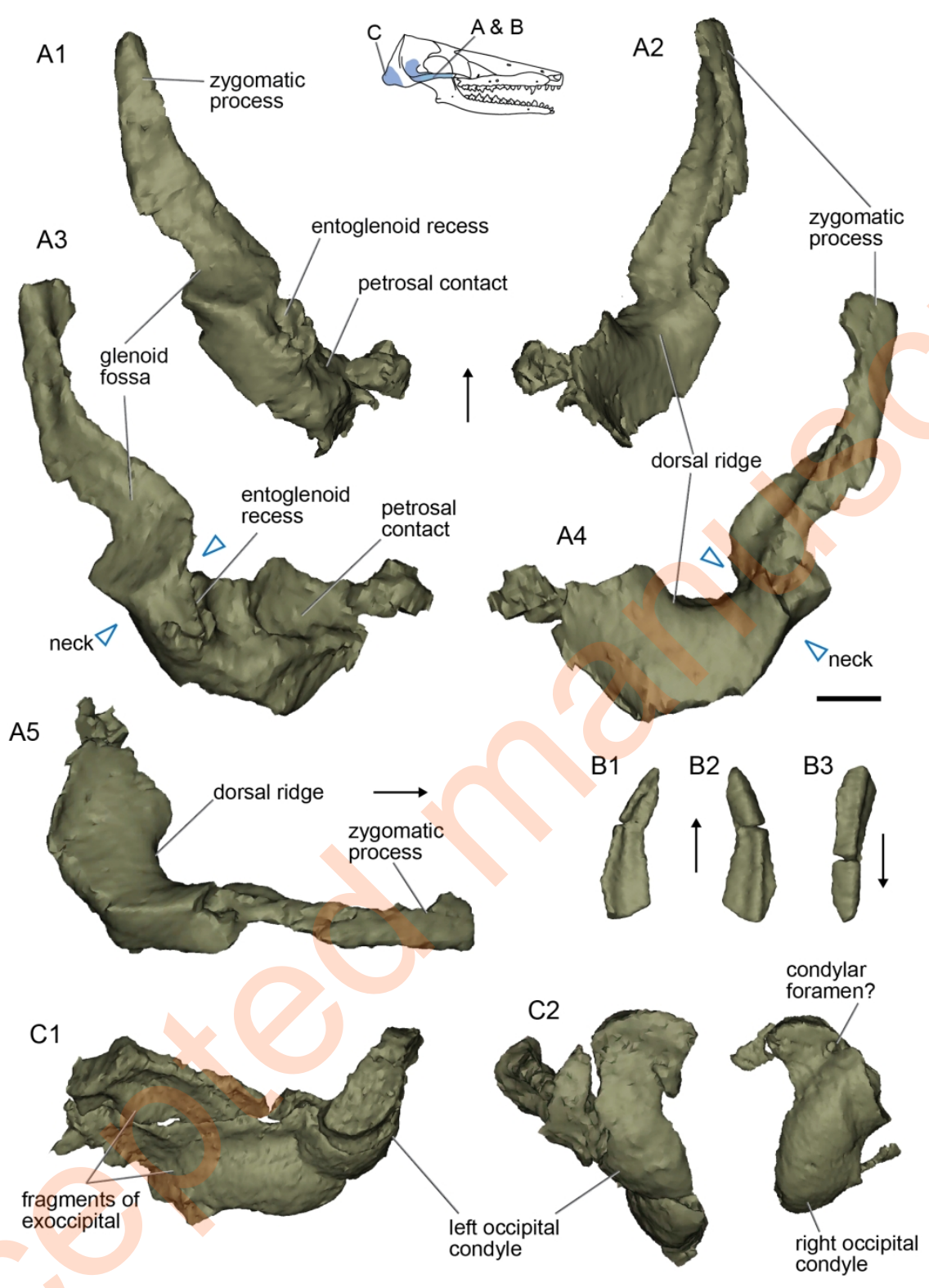

Figure 21: Borealestes cuillinensis (holotype, NMS G.2020.4.1.1) squamosal and occipitals. A, the right squamosal: $A 1$, ventral view; $A 2$, dorsal view; $A 3$, medioventral view; $A 4$, laterodorsal view; $A 5$, right lateral view. B, the anterior tip of the left squamosal of (zygomatic process): B1, dorsal view; B2, ventral view; B3, lateral view. C, the occipital condyles: C1, condyles as preserved in specimen; C2, condyles reconstructed. Arrows indicate anterior direction. Scale bar equals $1 \mathrm{~mm}$, scale same throughout. 